\title{
The Value of Names - Civil Society, Information, and Governing Multinationals on the Global Periphery*
}

\author{
David Kreitmeir, Nathan Lane, Paul A. Raschky
}

09 July 2022 [First Draft: December 2020]

\begin{abstract}
Civil society plays a critical role in governance where laws and authority are weak. We study how a key strategy of international civil society-disseminating information about human rights abuse-impacts multinationals. We consider trends at the center of international campaigns: the assassination of activists, and collect 20 years of data related to murders tied to the global mining sector. Using event study methodology, we estimate the impact of the human rights spotlight on the stock price of firms connected to events. We find that the effect of the human rights spotlight is substantial. Firms named in assassination coverage have large, negative abnormal returns following assassinations. Our estimates imply a median loss in market capitalization of 100 million USD. Meanwhile, these events do not impact the social responsibility (ESG) scores of firms. We show that the media plays a crucial role in these effects: the negative impact of assassinations is strongest when they coincide with calm news cycles versus peak news cycles, when news may be crowded out by large, international stories. In addition, we argue our results are driven by events where companies are explicitly named in the reporting. Last, we show that assassinations are positively related to the royalties paid by mining projects to domestic governments. JEL: O16, O17, D74, G3, G14, L82
\end{abstract}

\section{Introduction}

Multinational corporations are political institutions-and powerful ones at that. By revenue alone, the largest multinationals rival the size of states. In 2018, 69 of the top 100 largest economic entities in the world were global corporations (Global Justice Now, 2018). ${ }^{1}$ The activities of multinationals span the world without a single authority. Many operate under uncertain legal obligations and in weakly-governed territories. This complex setting poses a classic problem

${ }^{*}$ We benefited greatly from conversations with Daron Acemoglu, Sam Bazzi, Sascha O. Becker, Roland Hodler, Eliana La Ferrara, Weijia Li, Nicola Limodio, Martin Schmalz, David Strömberg, and Christopher Woodruff. We benefited from participants of the Applied Young Economist Webinar (AYEW), Bocconi, CSAE-Oxford, NEUDC, PACDEV, Royal Economic Society, Stanford GSB, and the U. Rosario Applied Micro Seminar. We would like to thank Satya Borgohain, Rony Rodrigo Maximiliano Rodríguez Ramírez, Lucy Valentine, and Natasha Watkins for their outstanding research assistance.

${ }^{\dagger}$ Department of Economics and SoDa Labs, Monash University. See davidkreitmeir.netlify.app and david.kreitmeir@mo nash.edu

‡University of Oxford, Department of Economics and Merton College, Oxford; and SoDa Labs. See nathanlane.info and nathaniel.lane@economics.ox.ac.uk

$\S$ Department of Economics and SoDa Labs, Monash University. See praschky.github.io and paul.raschky@monash.edu

${ }^{1}$ Scholars have long juxtaposed the footprint of multinationals and states (Greene, 1983). These comparisons include market capitalization and revenue (Zingales, 2017). 
of global governance (Fukuyama, 2016; Ruggie, 2018). Given the lack of formal authority, can the behavior of multinationals be governed? Human rights scholars and political economists suggest civil society plays potent roles in holding powerful actors accountable (Scholte, 2002; Acemoglu and Robinson, 2020), a role that has only grown in importance through the era of globalization (McGrew and Held, 2002; Sending and Neumann, 2006). For us civil society refers to a political space where voluntary-neither market nor state-associations shape the rules that govern social life. This definition follows seminal work by Scholte (2002). Yet without formal power, how does civil society influence the activities of multinational firms? An influential scholarship argues that information is a key weapon used by international activists to confront governments (Brysk, 1993; Keck and Sikkink, 1998, 1999; Khagram et al., 2002). However, to what extent can these tools impact multinationals?

The tension between civil society and multinationals is exemplified by the natural resource sector (Ruggie, 2013). Home to some of the largest international firms, the sector is a flashpoint across the developing world. Since the onset of the COVID19 pandemic, attacks against business-focused human rights activists have occurred at a rate of one per day, with mining activity linked to a third of all attacks. $^{2}$ Since 2002, more global environmental activists have been killed than Australian and U.K. soldiers in war zones (Butt et al., 2019). Figure 2 shows this growing trend, from 1998 to 2019, in the assassination of activists involved in mining campaigns. These deaths in Figure 2 -both the names of the victims and firms involved-are the focus of global publicity campaigns by human rights groups. While a vibrant empirical scholarship has begun to evaluate the impact of these strategies on political actors (e.g. nations or political leaders) (Meernik et al., 2012; Hill Jr et al., 2013; Murdie and Peksen, 2014), we know little about their impact on market actors. Can human rights activists, and their informational politics, impact multinationals?

We study the power of publicity and its impact on global firms. We focus on how informational strategies employed by civil society (e.g. "naming-and-shaming" in media) impact multinationals. To answer this question, we turn to salient, well-publicized events at the heart of current advocacy: the assassination of environmental activists. We zoom into the sector at the center of this conflict, the global mining sector.

We focus on the assassinations of activists, a rising phenomenon in the developing world (Butt et al., 2019). These events are discrete, noteworthy, and-importantly, for this study-well-reported in the media. ${ }^{3}$ The names of these individuals and circumstances around their death are often the focal point of human rights reporting and journalism (Ramos et al., 2007; Hafner-Burton, 2008; Peksen et al., 2014). Thus, rather than conflict writ large, we focus on these salient events and their repercussions.

We estimate how publicity surrounding activist assassinations impacts the stock price of multinationals "associated" with these events. To do so, we collect and code 20 years of data on activist assassinations across the globe. Combing hundreds of assassination incidents, we identify the mining projects associated with - that is, named in news coverage of-violence, and hand-match them to publicly-listed parent companies. Using the precise dates of assassinations allows us to study how markets respond to the news surrounding these events.

\footnotetext{
${ }^{2}$ See Hearon et al. (2020), and the Human Right's NGO Business and Human Rights Resource Centre report, Business and Human Rights Resource Centre (2021)

${ }^{3}$ By definition, these are notable individuals in the community. We largely follow international press norms in defining these individuals. See Section 2.1 for case selection.
} 
To estimate these effects we use event study methodology. With rich data, our research design allows us to identify how publicity around human rights events is incorporated into the stock price of firms. More precisely, we use two related event study estimation strategies. Each method uses a different variation from our data. First 1), we consider only firms tied to assassinations, and use traditional event study methods to estimate the abnormal returns for these firms-before and after the assassination event.

Next, 2) we use an intuitive regression strategy to estimate the impact of assassinations, comparing the abnormal returns for "associated" firms versus the abnormal returns of control firms. These control firms operate in the same sector, event country, and event period, but are not otherwise identified in the reporting. Furthermore, we use the dimensionality of our data-e.g. firm-level, event-country, and time variation - to show our estimates are robust to the inclusion of an array of fixed effects. Together, both (1) traditional event study and (2) regression estimates tell a consistent, robust story for those firms caught in human rights scandals.

Our results show that news of human rights abuse has substantial negative effects on multinationals. Following assassinations, we estimate significant negative abnormal returns for firms associated with these events. Negative effects appear on the (trading) day after an assassination occurs. These negative effects are amplified for the ten days after the event-and beyond. We do not observe reversion to the mean or market corrections. Moreover, we show these effects were unanticipated; for days leading up to assassinations, abnormal returns are zero. Both event study methods yield similar results, and our results are robust to alternative test statistics-for standard event study estimates—and across alternative OLS specifications.

We interpret our findings as evidence that disclosure of information on human rights violations impacts markets-and these impacts are meaningful. For companies named in assassination news, the median 10-day cumulative loss in market capitalization is over 100 million USD. In other words, the informational tools of civil society impact the bottom line of multinationals connected to the killing of activists. Even where the legal and formal costs of these events are exceedingly rare (Christensen and Hausman, 2016).

In addition to the core effects above, we explain the mechanisms driving these results-in particular the importance of the media and institutional investors. We highlight the importance of the media and the salience of events in two ways. First, we examine this channel by considering the likelihood that news of human rights events reaches financial decision-makers. More precisely, we ask how the impact of human rights events varies over the news cycle? We use daily "news pressure" data (Eisensee and Strömberg, 2007), and compare market reactions during periods with many newsworthy events to those with fewer newsworthy events. We find that the penalty of human rights news disappears when they coincide with more active news cycles. On the other hand, the penalty survives when events occur during less eventful news periods-when news is less likely to be crowded out.

While the salience of reporting matters, we show the visibility of the multinationals in this coverage - that is, the firm names-also matter. We compare abnormal returns for companies named in connection to assassinations versus merely operating closely (geographically proximate) to events. We find that firms operating in the vicinity of events-though not named in media 
coverage-do not experience significant penalties, relative companies explicitly named in the media. The human rights tactics of "naming-and-shaming" may thus carry currency.

We show that informationally sensitive, institutional investors may play important roles in our effects. Following assassinations, we examine differential responses across institutional investors. We find institutional investors that follow event-based trading strategies—such as hedge-funds—divest in mining companies after assassination events. These results dovetail with work on the role institutional investors play in promoting social responsibility (Dyck et al., 2019), especially in emerging markets with weak institutions (Dyck et al., 2008).

If violence against activists is costly to publicly traded owners, why do these events occur? To help understand these events, we turn to the political economy the mining projects. First, to the extent that multinationals have prior knowledge of these events, we do not find evidence that insiders trade off of prior knowledge of these events. On the other hand, we show a relationship between domestic mining activity and the structure of local public finance. Assembling international data on mining royalties, we show that assassinations correspond significantly with the importance of mining royalties paid to domestic governments. Multinationals may not have full control over costly actions of local affiliates, especially where local operations collude with governments and paramilitary forces.

Thus, although we find the association with egregious human rights violations may be costly, there may be a multitude of reasons why these events continue. For example, formal liability and reputational costs may be insufficient to constrain firms from engaging in socially deleterious behavioror "rational wrongdoing" (Shapira and Zingales, 2017). In the case of human rights abuse, parentcompany liability is likely also incredibly limited (Ruggie, 2013), and cases against the firms in our study are exceedingly rare (Christensen and Hausman, 2016).

This study is a new empirical attempt to show the impact of global human rights violations on multinationals. Although firms in our setting are unlikely to face formal sanction, our findings complement work on the impact of publicity from legally-binding violations of human rights norms in developed economies (e.g. discrimination) (Au et al., 2019; Borelli-Kjaer et al., 2021). ${ }^{4}$ BorelliKjaer et al. (2021) show firms embroiled in high-profile sexual misconduct scandals face swift, long-run drops in value (250 million loss in value per firm during the period of 60 trading days after a scandal breaks). Our results also comport with early work by Kappel et al. (2009)—one of the few studies on the subject-who explore the impact of a multitude of human rights violations (e.g. labor misconduct, sexual harassment, and discrimination) on OECD firms. Kappel et al. (2009) find UK and US investors "punish" firms accused of human rights violations: the median US-listed firm loses 47.31 million USD in value within 11 days following an event.

With this in mind, our results dovetail with studies on the impact of civil society action on notable and consumer-facing brands. Although firms in our study tend to be relatively low-profile, upstream commodity producers, our results align with work on more salient brands. Notable work by Harrison and Scorse (2010) shows that anti-sweatshop campaigns reduced investment and profitability for firms subject to anti-sweatshop campaigns. Likewise, Borelli-Kjaer et al. (2021) find a strong effect for consumer- and public-facing brands. Using trade-flow data, Klymak

\footnotetext{
${ }^{4}$ In our setting, firms may not be directly complicit; and if so, they are unlikely to face formal sanction. Ruggie (2013) covers the complex reasons why punitive actions against multinationals are rare. Work on discrimination by Huber et al. (2021) examines that the dismissal of Jewish managers in Nazi Germany led to a decline in firm stock market value.
} 
(2020) shows that more formal "naming and shaming" campaigns from the US government have material consequences on the trade performance for more consumer-facing products versus upstream intermediate goods. Important work by Couttenier and Hatte (2016) show that NGOs can materially impact high-profile sponsors (e.g. Adidas and Coca Cola) of global sporting events (e.g. FIFA World Cup). They find critical reports from NGOs, released during sporting events, reduced returns by 2 percent for targeted firms.

Additionally, we contribute to the literature on market reactions to firm misconduct. Earlier work has shown evidence that investors react negatively to convictions of corporate wrongdoing, such as fraud (Miller, 2006; Dyck et al., 2010), and new law constraining unethical behavior (Zeume, 2017; Cousins et al., 2020). ${ }^{5}$ Our results parallel these findings, and show market reactions for those firms operating in developing markets and where formal penalties are rarer. Recent papers by Krüger (2015), Capelle-Blancard and Petit (2019) and Cui and Docherty (2020) also show that stock markets react negatively to negative news about environmental, social, and governance (ESG) events. Though this literature has focused on self-governance, and the response to malfeasance in high-income economies, our results broaden the context of these key findings. ${ }^{6}$

We also join work emphasizing the role of media in holding firms accountable. ${ }^{7}$ Our results comport with those by Miller (2006) and Dyck et al. (2010), who stress the importance of media in uncovering corporate misconduct and promoting corporate accountability. ${ }^{8}$ We emphasize the interaction between institutional investors (hedge funds) and the media in holding firms accountable in murky legal environments (Dyck et al., 2008). Our results show that the penalty associated with the human rights spotlight varies over the news cycles. These results are supported by work showing that the impact of scandals on stock performance is, in part, driven by the salience of media coverage (Palomino et al., 2009; Borelli-Kjaer et al., 2021). Couttenier and Hatte (2016) show that campaigns are most impactful for large NGOs, when targeted firms are sponsors of prominent, global sporting events. ${ }^{9}$

More broadly, our results contribute to the rich empirical literature on the role of information in promoting accountability, in particular the role of media and political governance (Prat and Strömberg, 2013). Ferraz and Finan (2008) and Larreguy et al. (2020) highlight the impact of local media and audits, respectively, in monitoring politicians. ${ }^{10}$ For China, Qin et al. (2017) discuss the tacit approval of central authorities of controversial media as means of overseeing local-level corruption. Related work by Enikolopov et al. (2018) shows the impact of activist blog disclosures on the stock prices and governance outcomes in Russian state-owned firms. We build on this body

\footnotetext{
${ }^{5}$ Dai et al. (2015) show that media reports on past insider trading curb the profits of future insider transactions.

${ }^{6}$ While our subject matter touches on ESG and corporate governance, throughout this study, our use of governance is conceptually different from that of the corporate finance literature and follows the broader, public finance conception of the term.

${ }^{7}$ These include Fang and Peress (2009), Bushee et al. (2010), Griffin et al. (2011), and Birz and Lott Jr (2011) on the media influence on financial markets as an information intermediary.

${ }^{8}$ The media's role as a monitor is further illustrated by the effect of public scrutiny and negative sentiment on managerial compensation (Kuhnen and Niessen, 2012) as well as capital decisions in the form of acquisition abandonment (Liu and McConnell, 2013). Using newspaper strikes as information shocks, Peress (2014) find strike days are accompanied by drops in trading volume, dispersion, and intra-day return volatility.

${ }^{9}$ Importantly, high profile sporting events crowd-out coverage for non-sponsoring firms, like those in our sample.

${ }^{10}$ Also see seminal work in Indonesia by Olken (2009). For the US, Snyder and Strömberg (2010) show how media coverage disciplines congressional behavior. Gao et al. (2020), similarly, shows consequential impacts of media on local public finance, Campa (2018) shows that newspaper media markets also reduce emissions and promotes environmental compliance for local industry. Also see recent work by Do et al. (2020) also highlighting the importance of the media in France's historic "Dreyfus Affair."
} 
of work by showing how media can potentially constrain the behavior of formal state actors and influence how multinationals operate in weakly governed domains. Likewise, Couttenier and Hatte (2016) shows that critical NGO reports can materially impact the value of consumer-facing sponsors of sporting events.

Last, we contribute to the literature on the global financial consequences of political events. In particular, empirical work using asset price movements to understand political phenomena (Chaney, 2008; DellaVigna and La Ferrara, 2010; Guidolin and La Ferrara, 2010; Dube et al., 2011; Girardi, 2020). ${ }^{11}$ Girardi (2020) uses a large sample of international election events to study how internal asset prices respond to formal political shocks across democracies. Using the sample of CIA-authorized coups, Dube et al. (2011) explore how the market responded favorably to multinationals who stood to benefit from US coup authorizations.

In our setting, we study how the market values a firm's association with micro-level societal conflict. We build on forensic analysis of how firm assets respond to conflict, using asset prices where outcomes may be sparse (e.g. Chaney, 2008; Guidolin and La Ferrara, 2007). For Egypt's Arab Spring protests, Acemoglu et al. (2017) find returns fall for companies tied to the incumbent government, as investors adjust their expectations about the potential of future rents. ${ }^{12}$ For example, Guidolin and La Ferrara (2010) document positive stock market reactions to the onset of conflict. Guidolin and La Ferrara (2007) show international diamond firms reacted negatively to de-escalation of conflict in Angola. DellaVigna and La Ferrara (2010) use similar methods to detect illegal weapons trade for countries under arms embargo. Their results suggest companies headquartered in corrupt countries may profit from increased conflict intensity. Our firms caught amid human rights abuse in low-intensity conflict fare much worse, for reasons we speak to in the following analysis.

The remainder of the paper is organized as follows. Section 2 details our data and our coding process. Section 3 describes our empirical methodology and presents the results. Section 4 presents the analysis of the media channels. Section 5 provides explanations for the occurrence of the assassinations. We conclude with a brief discussion of our results in Section 6.

\section{Data, Definitions and Context}

We use event study methodology to study the impact of salient, well-reported human rights violations: assassinations. To do so, we collect 20 years of data on the assassination of activists connected to mining activity. The following sections describe the context of the violent events we study and how we code these events. We do so in three steps. First, we describe the definition and assassination events used in our analysis, as well as the rationale for mining sector case selection. Second, we describe the coding human rights reporting and matching publicly listed firms to these events. Last, we describe the financial, mining, and geographic data used in our analysis.

\footnotetext{
${ }^{11} \mathrm{~A}$ number of rich event studies explore how firm and sectors respond to formal political transitions. Including important examples in the UK (Herron, 2000) and US (Knight, 2006; Wagner et al., 2018).

${ }^{12}$ This follows a large literature on political connections, including Fisman (2001).
} 


\subsection{Assassination Events}

Defining Assassinations and Sectoral Scope. Figure 2 shows the global trend in activist killings since 2008. Data come from our data on global activist assassinations. These events-including the victims and associated actors-embody the protagonists in international human rights campaigns.

Our focus on assassinations is purposeful. Since the early 2000s, the global human rights community has drawn attention to a rising trend in violence toward environmental activists (Butt et al., 2019; Hale, 2020). Specifically, the killing of activists connected to campaigns around extractive activity. This strategy of "informational politics" of international human rights tends to coalesce around the names of victims and the naming of targeted (states and firms) associated with these events (Keck and Sikkink, 1998; MCENTIRE et al., 2015).

By assassinations, we mean the intentional killing of prominent members of society. Our definition is not idiosyncratic. Our usage largely tracks the journalistic standards (e.g. Associated Press and US National Public media standards) and those human rights scholarship (see: DeMeritt, 2012). By definition, assassinated persons are notable. In our data, many individuals are likewise notable in their communities - as advocates or key players - and we refer to their slayings as assassinations. These people include indigenous and tribal leaders; environmental and labor activists; members of the clergy; and more. Throughout the paper, we use the terms assassination and extra-judicial killing interchangeably.

By construction, the assassinations we study are relatively well-publicized. That is, these episodes are those that draw human rights and media attention. We follow scholarship on "naming-andshaming" campaigns, and focus on the publicity of these events (Ramos et al., 2007; Hafner-Burton, 2008; Peksen et al., 2014). ${ }^{13}$ Since we study the impact of news of these events, unpublicized killings are not the scope of our study.

The empirical advantage of focusing on assassinations, as opposed to other human rights violations, are numerous. In general, these events are less ambiguous than other forms of human rights abuse. As noted above, these events are salient, well-publicized events. Importantly, we focus on the most unambiguous human rights violations-and the most egregious. By far the most numerous human rights violations related to business activity encompass labor disputes and sexual harassment (Ruggie, 2013). For these events, there is great institutional capacity to arbitrate these disputes, thus their coverage in human rights databases is idiosyncratic. ${ }^{14}$ Last, for the purpose of an event study, having a concrete timeline is important. Unlike other norm violations, we often deal with events that have clear timelines. Thus, the gap between an assassination event and news in the media is minimal.

Our focus is on assassinations surrounding mining activity. We focus on mining activity for four reasons. First, for human rights scholars and legal practitioners, the sector has exemplified the weakness of current institutions in constraining human rights violations of multinationals (Ruggie, 2013). Second, as such, it is one of the deadliest sectors for activists (Business and Human Rights Resource Centre, 2021; Butt et al., 2019). Third, it is a capital-intensive sector and one where equity financing is common. As such, it is a sector where we can connect publicly traded firms to human

\footnotetext{
${ }^{13}$ Scholarship in this area emphasized both individual dissemination of information from the NGOs themselves, the media reporting, and the UN.

${ }^{14}$ Noted by Ruggie (2013)'s UN fact finding assessments.
} 
rights events. Fourth, we limit our attention to relatively homogeneous, upstream product markets. By doing so, we attempt to limit the extent to which these products may face consumer boycotts in response to human rights reporting.

In sum, a study of multinationals and human rights must focus on mining and extractive activity. Of the recent-and rare-human rights cases brought against multinationals, Hearon et al. (2020) show nearly half involve the extractive industry. For US based firms, this is the sector where the Alien Tort Statute has been notably deployed (unsuccessfully) against firms accused of human rights abuse (Christensen and Hausman, 2016).

Event Collection. Our data covers 354 assassinations (496 victims) over 20 years. Table 1 provides an overview of this data. Our first observation is recorded in 1998, and the sample expands to cover events across 31 countries. Peru and the Philippines are the most dangerous countries for mining activists. The geographic distribution of events are reported in Figure 4.

The data collection process for the events in Table 1 can be summarized, broadly, in four steps. First, we consider killings that are publicly reported in media or human rights campaigns. Second, we consider events where reporting connects a victim (or victims) to local mining and mineral extraction activity. Third, we then code the location (e.g. the ADMIN1 unit) where the death occurred. Fourth, we code those mining companies or projects (if any) named in relation to the event. We detail this process below, and more technical details are described in Appendix B.1.

Thus, activist assassinations are collected using both algorithmic and human searches of international full-text media archives. These include databases of the International Herald Tribune; the Associated Press wire archive; popular news APIs (e.g. the Guardian); and, importantly, global news databases (e.g. LexisNexis). ${ }^{15}$ Coding is done by research assistants and cross-validated by principal investigators.

Of our event data, assassinations are mapped to 15 of the 26 members of the International Council on Mining and Metals (ICMM) — an industry network dedicated to Corporate Social Responsibility (CSR) in the mining industry. That is, over half of these firms have at least one assassination associated with them. But what exactly do we mean by "associated"? We turn to this now.

\subsection{Associated Multinationals}

Defining Company Association. Table 1 shows publicly traded firms that have been matched to-or "associated" with—at least one assassination event in our sample. We use the following section to explain how we operationalize this definition and code these relationships.

Throughout this study, association means that a company or their project is named in reporting surrounding an assassination event. In our setting, a publicly traded company may be an indirect owner of a project where violence occurs. The association between a firm's operations and violence is coded directly from source material-all of which is sourced from publicly available human rights journalism or human rights reports.

\footnotetext{
${ }^{15}$ We perform multilingual searches, for example, Spanish. However, core media databases provide translations of international news coverage, such as LexisNexis.
} 
A firm is connected to an event insofar as it-or its operations-are mentioned in the reporting of an event. Importantly, we do not take a stance on the relationship between a firm and an event, beyond their operations being named in human rights reporting. That is, an "associated" company may not play any role in organizing or participating in violence. As shown later, in the aggregate it may be unlikely that multinationals themselves play active roles in these events.

Figure 3 breaks down the global distribution of assassinations and the headquarters of companies associated with assassinations. Colored panels (left) correspond to an event country. Their height represents the total number of assassination events in that country. Gray panels (right) correspond to the headquarter country for publicly traded firms. Their height represents the total number of events connected to firms headquartered in a given country.

Figure 3 shows that most assassinations in our data are matched to firms headquartered in Canada, the United Kingdom, and the United States. Though these are advanced liberal, democracies, suits against multinationals for human rights abuses are exceedingly rare (Schrempf-Stirling and Wettstein, 2017).

Coding Associated Companies. We hand-match the "nearest" publicly traded firm associated with each assassination. Matching public firms is done in three steps.

First, we determine whether a company named in human rights reporting is publicly traded. ${ }^{16}$ For consistency, we consider the most direct, publicly traded companies-except when the international, corporate owner is specifically tied to the event in reporting.

Second, when a company named in human rights reporting is not publicly listed, we manually search for its parent company. To do so, we examine whether a named company is a subsidiary or joint venture of publicly traded companies (when the event occurred). We then verify this information using sources such as, but not limited to: official firm websites, corporate reports, SEC filings, public business registers. In many cases this process is non-trivial.

Third, human rights reporting may refer to a mining project instead of the company responsible for the project. Rather than using firm names per se, it is common practice for geographic or administrative unit names to demarcate mining operations. For example, a report may refer to Rapu-Rapu Polymetallic Project (Philippines), as opposed to the ultimate firm, Lafayette Mining. In these cases, we attribute ownership of the project to the publicly traded company using the process described in step 2.

Figure 5 illustrates our coding process. The figure shows an excerpt from the Guardian newspaper for an assassination event in our sample; color highlights indicate key information which we code for our data set. ${ }^{17}$. The piece identifies a victim, Ecuadorian indigenous leader José Isidro Tendetza Antún-shown in green-and establishes they were an activist working in opposition to mining activity. The latter is highlighted in purple. Importantly, the piece in Figure 5 describes the victim's violent death, which is highlighted in yellow.

\footnotetext{
${ }^{16} \mathrm{~A}$ special case arises if another public mining company holds shares of the company at the time of the event: i.e. the named company is not the ultimate owner.

${ }^{17}$ The source article is available at https: / / www.theguardian.com/world/2014/dec/06/ecuador-indigenous-leaderfound-dead-lima-climate-talks.
} 
Critically, the example in Figure 5 describes a specific mining project, rather than the firms. In this example, the death involved "Mirador copper and gold mine" (blue), owned by Corriente Resources Inc. through a subsidiary EcuaCorriente S.A. Our process codes the ultimate owner using a public records search. For the case in Fig. 5, public data shows Corriente Resources Inc. was acquired in 2010; at the time of the event, it was owned by two publicly traded companies: China Railway Construction Corporation and TongLing Nonferrous Metals Group Holdings. ${ }^{18}$ Here, both publicly listed companies (China Railway and TongLing) are coded as being "associated" with the event in our data.

Sometimes, specific projects or companies may not be named in reporting. In these cases, an assassination is then not associated with a company. Once again, consider the example in Figure 5. In this example if no identifying data (shown in blue) were available, then the assassination is not matched to a specific firm. For a detailed example, refer to Appendix Figure C.1 where an assassination related to mining opposition occurred but reports failed to name the project related to the event.

Figure 5 also provides an important example of how we consider ambiguity around event dates. For the example in Fig. 5, although a date (highlighted in pink) of the crime occurred on November 28,2014 , an event may make the news only after discovery of the body, etc. In this case, financial markets are likely to react only days after the de facto event date. We consider these issues in detail in our estimation process below.

\subsection{Financial Outcomes and Geo-Location}

We collect daily stock return data for mining companies associated with an event (see: Section 2.1 above), as well as returns for other companies operating within the same country, during the year the event took place. Daily return data for 1998-2019, and additional firm-level data, come from the Datastream database. ${ }^{19}$

For mining projects in our data, location and company ownership data comes from the SNL Minings \& Metals database, which we matched to our assassination data. ${ }^{20}$ This database also allows us to identify a robust set of control companies for each event-year because we can identify other mining companies with operations in the geographic vicinity of the event mine. Project ownership information is available at the annual level allowing us to track (treated and control mining) companies operating in an event-country over time.

For example, if we observe an assassination in Colombia for 2013, the control company set for this event comprises all publicly traded companies that own mining projects in Colombia in 2013 but are not directly associated with the assassination in media or NGO reports. Figure C.2 Panel A in the Appendix provides a graphical illustration of this example case.

\footnotetext{
${ }^{18}$ See for instance http://www.corriente.com/news/news.php and https://www.banktrack.org/project/el_mirador_cop per_mine for more information.

${ }^{19}$ Market holidays are removed from the closing price time series. We use financial variables in a common USD denomination to account for currency fluctuations.

${ }^{20}$ See: https://www.spglobal.com/marketintelligence/en/campaigns/metals-mining. Other recent studies using the SNL Minings \& Metals database comprise Berman et al. (2017) and Knutsen et al. (2017), who explore the impact of local mining operations on conflict and corruption.
} 
Table 2 shows summary statistics for our financial data. We construct market returns using the Morgan Stanley Capital International (MSCI) stock indices. We match each mining company security to the MSCI country index where they are listed.

For completeness, we require that companies are traded at least 200 days out of the 250 trading days in the estimation window, which we turn to in the next section. We deal with ambiguities in our data in standard ways. For example, if an assassination event falls on a non-trading day, the event date is assigned to the first trading day after the actual event date. Finally, we exclude thinly traded mining company securities from our sample.

The financial data in Table 2 forms the basis of our event study analysis, which we turn to now.

\section{Estimating the Impact of Activist Assassinations and Stock Re- turns}

How do assassinations impact firms caught in the human rights spotlight? We use event study methodology to estimate how the stock price for these companies change in the days surrounding assassinations. We study the abnormal returns in the days before, during, and after the assassination. In this section we estimate the impact in two steps, employing event study methodology to estimate these impacts from different variation in our data. First, in section 3.1, we use classic event study methodology to estimate the cumulative abnormal returns only for firms (operations) associated with assassinations. Here, the counterfactual is the firm's own returns in the absence of the event, which we estimate using a standard market model. Second, in section 3.4, we estimate the impact of the human rights events and avail of our full panel of firms. Specifically, we use OLS to estimate the differences in CARs for associated (i.e. treated) firms versus control firms.

\subsection{Traditional Event Study and Inference}

We now turn to the traditional event study setup in the context of our assassination events, and discuss our preferred approach to statistical inference. ${ }^{21}$ Consider the security of a company associated with an assassination event. Figure 1 presents the timeline around such an event: an assassination $e$ occurs at date $\tau=0$, where $\tau$ denotes the time relative to the date of the assassination. Time is broken into three windows around this event, an estimation window, an event window, and a post-event window. Each are shown in Figure 1.

\begin{tabular}{cccccc}
\multicolumn{2}{c}{ (estimation window $]$} & (event window] & (post-event window] & \\
\hline$T_{0}$ & $T_{1}$ & 0 & $T_{2}$ & $T_{3} \tau$
\end{tabular}

Figure 1: Event Study Time Line

Traditional Estimation. The Abnormal Return (AR) is the difference between a firm's observed return and their expected return-absent an assassination. Around an assassination event $e$, we calculate the AR for company $i$ at time $\tau$ as

\footnotetext{
${ }^{21}$ This setup follows the standard event study methodology literature (MacKinlay, 1997).
} 


$$
A R_{i e \tau}=R_{i e \tau}-E\left(R_{i e \tau} \mid X_{\tau}\right)
$$

where expectations about "normal" returns are conditional on a set of information, $X_{\tau}$.

We estimate the normal returns for firm $i$ over an estimation window $\left(\tau=T_{0}+1, \ldots, T_{1}\right)$, using the following linear market model:

$$
R_{i e \tau}=\alpha_{i e}+\beta_{i e} R_{i e \tau}^{M}+\epsilon_{i e \tau}
$$

where $R_{i e \tau}$ is the daily return observed for firm $i$, and $R_{i e \tau}^{M}$ is the return for overall market index where they are listed. We estimate (2) using an estimation window of 250 trading days, ending 30 days before the event ( $\mathrm{Li}$ and Lie, 2006; Acemoglu et al., 2016). We require securities to be traded at least 200 out of the 250 trading days, and 8 out of the 11 trading days during an event window ( $\tau_{1}$ and $\tau_{2}$ ).

Using the estimates from (2), we then compute the daily abnormal returns for the event window:

$$
\widehat{A R}_{i e \tau}=R_{i e \tau}-\hat{\alpha}_{i e}-\hat{\beta}_{i e} R_{i e \tau}^{M}
$$

We then calculate the cumulative abnormal returns (CARs) by aggregating the daily abnormal returns (3) over the event window $\left(\tau_{1}\right.$ and $\left.\tau_{2}\right)$ for each firm and each event:

$$
\widehat{C A R}_{i e}\left(\tau_{1}, \tau_{2}\right)=\sum_{\tau=\tau_{1}}^{\tau_{2}} A R_{i e \tau}
$$

This study considers the average impact of assassinations, thus we aggregate cumulative abnormal returns across $N$ company-event pairs in our data. The average CAR and its variance are equal to the following,

$$
\begin{aligned}
\overline{C A R}\left(\tau_{1}, \tau_{2}\right) & =\frac{1}{N} \sum_{j=1}^{N} \widehat{C A R}_{i e}\left(\tau_{1}, \tau_{2}\right) \\
\sigma^{2}\left(\overline{C A R}\left(\tau_{1}, \tau_{2}\right)\right) & =\frac{1}{N^{2}} \sum_{j=1}^{N} \sigma^{2}\left(\widehat{C A R}_{i e}\left(\tau_{1}, \tau_{2}\right)\right) .
\end{aligned}
$$

Inference and Preferred Tests. We present multiple test statistics for inference. Assuming normally distributed security returns, absent clustering (overlapping event-windows), $\overline{C A R}\left(\tau_{1}, \tau_{2}\right)$ follows a normal distribution with mean zero and variance $\sigma^{2}\left(\overline{C A R}\left(\tau_{1}, \tau_{2}\right)\right) .{ }^{22}$ We refer to this test as the "Normality" test, which is simply a baseline.

\footnotetext{
${ }^{22}$ Following MacKinlay (1997), the normality assumption requires the absence of clustering in order to set the covariance terms in (6) to zero.
} 
We go beyond standard tests in three ways, following the literature in event study methodology and inference (Boehmer et al., 1991; MacKinlay, 1997). Our preferred method is Kolari and Pynnönen (2011)'s non-parametric generalized rank t-statistic, or GRANK, which is particularly fitting for our setting. We provide technical details for the following discussion in Appendix A.1. The three tests are the following.

First, we use a parametric test suggested by Boehmer et al. (1991) (BMP), which scales abnormal returns and adjusts for differences in the variance of pre-event residuals. ${ }^{23}$ Intuitively, more volatile securities are down-weighted to prevent them from biasing estimates toward detecting average effects. Second, we use a refinement of BMP, adjusted BMP (ADJ-BMP), a parametric test which further accounts for event clustering (Kolari and Pynnönen, 2010). Though we suspect clustering is not an issue in our setting, we account for its potential role in bias. ${ }^{24}$

Third, our preferred approach relaxes parametric assumptions and introduces refinements that are suited to our setting (see recent applications by Barrot and Sauvagnat, 2016, and Luechinger and Moser (2014)). We implement the non-parametric generalized rank $t$-statistic, or GRANK, proposed by Kolari and Pynnönen (2011). Kolari and Pynnönen (2011) show their generalized rank statistic outperforms both parametric and other non-parametric tests in studies where a) the exact event day may be unknown and b) long event windows are used. Both circumstances are useful for our environment, where sensitive information may percolate slowly into the market, and the precise day of the pricing - in contrast to the assassination date-is uncertain. Additionally, the GRANK statistic is robust to event-induced volatility, serial correlation and event-day clustering.

For completeness, we show results using the three test-statistics, plus conventional parametric tests. We turn to these estimates now.

\subsection{Anecdotal Evidence - The Case of Bear Creek Mining Corp and the Santa Ana Mining Project.}

Before presenting the full analysis, we illustrate the dynamics behind our event study analysis with useful case study evidence. Specifically, we explore the case of Canadian based Bear Creek Mining Corp. ${ }^{25}$ which, in 2011, faced local opposition against the company's planned Santa Ana silver mining project in the Puno region of Peru. After a week-long stand-off, local Aymara Indian activists resumed protests against the planned mining operation and blocked a major highway. The mine was projected to have reserves of 63.2 million ounces of silver, and on 1 June the government put the concession process on hold for a year.

Consider the days before the violent event. The CARs, aggregated backwards over the 10 trading days before the event (10-23 June), show that the stock of Bear Creek Mining Corp. stabilized after the hold, and even outperformed the market for most days over the period.

However, on 24 June hundreds of protesters-according to reports, mostly indigenous activiststook to the airport, blocking the runway to demonstrate against feared environmental impacts of

\footnotetext{
${ }^{23}$ The BMP test builds on and goes beyond Patell (1976), by accounting for changes in event-induced volatility.

${ }^{24}$ In our study, at most four public firms are associated with any given event. The correction might, however, be warranted as our market model extracts less correlation from regression residuals than the alternative Fama-French model.

${ }^{25}$ The majority of examples in our data set are more conventional assassinations, this illustrates the pattern more broadly for a protest event.
} 
the mining projects. The police crack-down resulted in the death of 5 demonstrators. On the day of the event, the CAR dropped by 15.6 percentage points and a total drop in the CAR of 43.6 percentage points over the two days following the event. Bear Creek Mining Corp.'s price stabilized over the next days at the new low-news about a legal challenge by the company did not have an effect on the outlook of market participants.

\subsection{Traditional Event Study Results}

Table 3 shows our core results. Overall, we find assassination events lead to negative abnormal returns for firms associated with violence. Table 3 shows that negative effects start soon after the date of the assassination, and these effects grow through time. Both in a) magnitude and b) significance. Importantly, the effects are significant across tests.

The steady pattern in Table 3 is consistent with sensitive information gradually diffusing through the market. On the day of an assassination, we see little market reaction, followed the next day by a (borderline) significant effect of around -0.7 percentage points. This initial reaction is followed by a stable decline over the next four days, and a steep—and robustly significant—decline from Day 5 through to Day 10 after the event. This cascade suggests that market participants may first gather additional information surrounding an event, before pricing the expected reputational and legal costs for an "associated" mining company.

The average cumulative abnormal return is -2.0 percentage points 10 days following the event. These estimates are significant: at the 1 percent level using our preferred GRANK statistic (Column 6), and at the 5 percent level with the "BMP" (4) and adjusted BMP statistics (5). Furthermore, by considering multiple test statistics, our findings in Table 3 suggest differences in volatility across securities could bias inference if not accounted for: comparing our adjusted test and non-parametric statistics to the "normal" test in Column (3). Meanwhile, the clustering issues in our setting seem negligible - the differences between the BMP and adjusted BMP tests are small (Column 4 versus Column 5).

All tests account for non-trading days of securities, adjusting for the length of the estimation and event window. However, our results are robust to more conservative trading day criteria. Appendix Table D.1 shows results are unchanged when we require companies to be traded each day within an event window, and 225 out of 250 days during the estimation window. This adjustment drops seven company-event pairs, leading to a slight decline in the magnitude of our CARs to -1.5 percentage points ten days after an event. Nevertheless, these results are still highly significant and robust across tests. The difference in point estimates may be driven by a trading halt for highly affected securities. On the other hand, the securities of small mining companies are also less frequently traded; we may expect these firms are more vulnerable to disruption following an event. Thus, stricter requirements on trading frequency might disguise the true effect of assassination events and we default to our original cut-off criteria.

Next, we turn to the days leading to the event. By considering the days before an assassination, we test whether market participants traded on foreknowledge events. Furthermore, where events are planned, the "authorization" date of assassinations is unknown to us. A reasonable assumption is that-if private information exists-it should be priced close to the actual event date, when the likelihood of execution can be best assessed by insiders. 
We test this "prior knowledge" hypothesis—and for pre-treatment movements more broadly-by aggregating abnormal returns backwards starting on the day before the event (see Dube et al., 2011). Appendix Table D.2 reports these results. The average abnormal return on the day before the event is positive, while the cumulative abnormal return over the ten days before an event is close to 0 slightly negative-and insignificant across test statistics.

Thus, the results in Appendix Table D.2 indicate two findings. First, the market did not price prior knowledge of assassinations. Second, and importantly, our core event study results are not merely picking up a downward pre-trend in the asset prices for those companies associated with violence.

\subsection{OLS Event Study Using Treatment and Control Firms}

We now build on the traditional event study design above and use the full variation of our event data. Relative to many smaller-N event studies, our event data (over 160 companies-event pairs) introduces rich panel and cross-sectional variation to further explore reactions to assassinations. This section introduces an intuitive OLS estimation strategy that makes full use of this data.

Our regression framework examines the relationship between the publicity around assassinations and stock returns of companies differentially exposed to violence. Intuitively, we compare the cumulative abnormal returns for companies whose projects are directly associated (named) with these events versus companies operating in the same sector, country, and period of the assassination. The regression model we consider can be written as

$$
C A R_{i e}\left(\tau_{1}, \tau_{2}\right)=\alpha+\delta D_{i e}+\boldsymbol{X}_{i e}^{\prime} \phi+\gamma_{e}+\epsilon_{i e}
$$

where $C A R_{i e}\left(\tau_{1}, \tau_{2}\right)$ is the cumulative abnormal returns for company $i$. For each event $e$, we estimate CARs for a window between periods $\tau_{1}$ and $\tau_{2}$. The indicator $D_{i e}$ denotes treatment, and is equal to one if a company is associated with an event and zero otherwise.

The coefficient of interest $\delta$ captures the average difference in CARs between "treated" firms versus control firms. More precisely, control firms are companies with operations in the same country and in the same sector over the event period. Our empirical strategy is valid if, absent association with violence over the event period (being named in publicity), we would not observe systematic differences in the returns of treated ("associated") versus the control firms.

Our set of control companies has a number of advantages. First, we account for exposure to political risk events common to mining companies operating in a given location at the time of the event. This allows us to account, among other things, for incidents where violence against activists changes the national sentiment against the mining industry. Second, we follow the rationale established by Guidolin and La Ferrara (2007); we wish to compare treated companies to those with a similar "comparative advantage" for operating in political risk environments (p.1987). Last, by limiting the control group geographically, we control for commodity price fluctuations similarly impacting mining companies operating in similar commodity markets and the same domestic market. ${ }^{26}$

\footnotetext{
${ }^{26}$ For example, commodities mined in Columbia from 2013-2017 comprise coal, nickel, gold, emerald and iron according to EITI records, with about $70 \%$ of the companies active during those years mining coal.
} 
Our preferred specification (7) includes event-specific effects, $\gamma_{e}$. Including event-specific effects controls for common market reactions around dramatic events, such as shifts in market sentiment toward the event country, or increased excess volatility.

Alongside (7), we present a specification which includes company fixed effects $\left(\gamma_{i}\right)$. Depending if a company was merely active in the country during an event-period or directly tied to an assassination, the company can be part of both the control and treatment group for different assassination events.

The baseline specifications include a set of time-variant, firm-level controls, $\boldsymbol{X}_{i e}$. These are firm size, total assets, and leverage (total debt to capital). Small or highly-leveraged firms may be more dependent on specific mining projects, and thus differentially impacted by events in our study. Disruptions of projects may be more punitive for smaller (more leveraged) firms. To address issues of "bad controls" we use lagged values for controls. Standard errors are robust to heteroscedasticity and clustered at the event level.

\subsubsection{OLS Event Study Results}

Figure 6 reports the core results. The top panel presents regression coefficients $(\hat{\delta})$ for our baseline specification with event fixed effects, the bottom panel presents estimates for company fixed effects. In total, 42 individual regression estimates are displayed with the vertical axis showing the $(\tau)$ days after (before) the event. We present 95 percent confidence error bands.

Figure 6 shows a clear pattern. In the days preceding the event, CARs are not significantly different between exposed and non-exposed firms. Returns for associated firms are, if anything, slightly positive.

Following an assassination, we find a consistent negative decline in abnormal returns for treated versus control companies. We see no market reaction on the event day. Soon after, markets start responding to the assassination reporting. Two days following an assassination, CARs amount to $-1,0$, respectively -1.4 percentage points and are statistically significant . Thereafter, CARs remain negative, gradually dropping five days after the event. By day ten, the abnormal returns for exposed mining companies are between -2.2 to -2.4 percentage points. These findings reinforce our interpretation of our classic event study results. Financial markets take time to absorb the publicity and assess risk for mining companies tied to the assassination event.In fact, the pattern in Figure 6 and the estimated magnitude of effects closely resembles that found in our traditional event study results, providing further support for our interpretation that the estimated effect is capturing the associated corporation being put under the put under a magnifying glass, rather than gains by unnamed competitors in the aftermath of the event.

The results are particularly strong for our specification using firm fixed effects (Figure 6, Row 2 ). When we use only within-firm variation and a company implicitly serves as its own "control group", the significant difference in CARs is strong evidence that the (actual or expected) disclosure of a company's association with the assassination event is behind the estimated effect. We investigate this mechanism further in Section 4.

Furthermore, Appendix Figure C.3 shows that our baseline results are robust to accounting for potential non-linear effects of covariates when including cubics in size, leverage and additionally 
profitability (return on equity) (Column 2). ${ }^{27}$ Moreover, the core pattern remains qualitatively and quantitatively unchanged for specifications with different fixed effects. These include less conservative sets of fixed-effects, like year $\left(\gamma_{y}\right)$ and headquarter country $\left(\gamma_{h}\right)$ effects (Rows 2 and $3)^{28}$

We quantify our results in Figure 7 and show they are economically meaningful. Figure 7 shows the estimated loss in market capitalization for the median treated company. Results are shown for each day. Dots correspond to baseline estimates. Error bars correspond to the minimum and maximum loss across specifications. Figure 7 shows the median treated company is estimated to loose between 100 and 150 million USD in market capitalization over the ten days following the event. ${ }^{29}$

\subsubsection{Robustness of OLS Results}

We show the OLS event study results above are not driven by an individual nation or company, nor are they sensitive to specific events or window size. The following section presents robustness results by considering robustness of our OLS results across these dimensions.

Figure 8 presents a "leave-one-out" analysis of our OLS results, and shows that estimates are not driven by single countries or firms. Our baseline regression results are shown in bold, and permutations are shown in light gray. In Figure 8 Panel A, we re-estimate our baseline specification, but sequentially drop individual event-countries from our sample. Visually, the negative effects are similar across sample permutations. Panel A shows a clear and gradual decrease in abnormal returns over the 10 days following the event. As well, abnormal returns in the days leading up to the event remain slightly positive, though close to zero. Importantly, the core pattern of our baseline results is robust to excluding the two deadliest countries for mining activists: Peru and the Philippines (shown in dashed red).

Figure 8 Panel B repeats the same exercise, now sequentially dropping firms. Here too our baseline results are qualitatively similar after sequentially dropping individual firms. The homogeneity across these light gray bands indicate that our findings are not driven by particular "bad actors". This suggests our results are applicable to publicly traded mining multinationals, broadly.

Our OLS results are also robust across different types of assassinations and similar events. Table D.4 shows that post-event assassination estimates are qualitatively unchanged when we exclude unsuccessful assassinations (Columns 1 to 5) —or, assassination attempts. Similarly, when we exclude activist killings during protests (Columns 6 to 10). Although the point estimates here follow a similar pattern to our baseline results, we exclude a substantial number of events. Excluding 42 observations, as in the previous case, reduces the power and significance of the results.

Our baseline results are not driven by outliers. Table D.4 shows dropping CARs larger than the 99th percentile or smaller than the 1st percentile (Columns 11 to 15) does not alter the substance of our results. The assassination coefficients are similar in magnitude. In fact, they are more precisely estimated across specifications, with the exception of company fixed effects. This latter case may

\footnotetext{
${ }^{27} \mathrm{C}$. for instance Acemoglu et al. (2016).

${ }^{28}$ In total, Figure C.3 presents 210 individual regression estimates. Columns correspond to two types firm-level controls used across different specifications. Each row shows five types of fixed effects. Each panel (cell), thus, shows a set of estimates for one of ten specifications. Corresponding regression tables are reported in Appendix Table D.3.

${ }^{29}$ Figure C.4 in the Appendix presents the distribution of losses across companies for the baseline specification. Demonstrating large, and economically meaningful losses for companies associated—even loosely—with violence. For clarity, due to long-tails, we do not display losses above the 90th percentile.
} 
indicate that the association with an assassination event constitutes an extreme observation for several companies that have been tied to an event at least once. Broadly, this supports the idea that assassinations can have substantial effects on single firms.

Finally, we expand the event window to twenty days prior and post the event day to investigate the possibility of pre-trends more closely and to test for a potential reversal in the estimated effects after day 10.

Appendix Figure C.5 plots the assassination coefficient estimates and the 95 percent confidence intervals for our baseline specification from over 40 specifications. ${ }^{30}$ After the event date, we observe a monotonic decrease in returns until Day 13 that seems to be permanent. Before the event date, estimates are positive and insignificant. We conclude that the effect of publicized assassination events is persistent and cannot be explained by pre-existing trends in the stock price. $^{31}$

\section{Mechanisms}

This section sheds light on the underlying mechanisms that explain how civil society campaigns around activist assassinations have such an immediate and relatively large impact on the stock price of associated companies. Therefore, the main strategy of civil society groups is to name the mining companies linked to the event and use the global news media to heighten awareness of the human rights abuse within the general public and the financial markets. The likelihood of news about an activist assassination getting wider attention and reaching financial decision-makers, depends on the number and scale of newsworthy events released simultaneously. Investors whose strategy is more sensitive to (negative) news will quickly decrease their holdings in associated stocks to avoid short-term losses. This sudden reaction by institutional investors who follow an event-based strategy, leads to the short-term drop in share prices depicted in our main results.

\subsection{Vicinity vs Associations to Assassinations}

So far, our classic event study, and the regression results, present a consistent story: assassination events significantly-and negatively-impact the returns for companies associated with violence. In this section we further unpack what may be driving these results. Specifically, we ask whether our results are driven by disruptions surrounding the violence per se. Rather than the market pricing the impact of being named in connection with the killing of an activist, our results may be driven by other, physical disruptions surrounding the event or unobserved regional violence correlated with the assassination event.

In this section we address this concern by comparing the asset price responses of firms publicly exposed to the event to other companies operating within the same administrative unit in the event country. We use the regression framework from above to compare the CARs of treated firms to untreated firms operating in the same sector and same administrative unit as the treated firm.

\footnotetext{
${ }^{30}$ Note that we adjust the minimum trading days required for this analysis: for companies to be considered, they have to be traded on at least 15 of the 21 days post the event, respectively 15 of the 20 days prior to the event.

${ }^{31}$ Figure C.6 in the Appendix provides further support for the persistence of the publicity effect. Graphing the average CARs for associated companies in the 90 days following the event reveals that there is no reversal in the estimated effect even when considering very long-time horizons. Note that C.6 simply displays average CARs when underlying the market model (see Section 3.1), not OLS estimates.
} 
For this robustness check, we construct a new set of control companies. We do so by matching the geolocation of our assassination events to properties in the SNL Minings \& Metals database. Specifically, we connect assassination events to mining projects in the same Admin1 region (see Figure C.2 Panel B in the Appendix for a graphical illustration). ${ }^{32}$ For 92 events in our sample, we were able to match at least one publicly traded control company operating in the same region as a company "exposed" to a violent event. Figure 9 shows the results of our analysis. The post-event assassination coefficient estimates for our Admin1 subsample are presented in Panel B, and Panel A displays the estimates for our baseline sample.

While we lose observations through our geo-matching process, we nonetheless observe a gradual relative decrease in the CARs for treated firms. CARs are -1.4 percentage points lower, ten days after an event for our baseline specification. Appendix Table D.5 shows that our estimates are broadly negative across specifications and similar magnitude with the exception of Column 9. Column 1 shows where we use maximal variation of our data, excluding fixed effects. Here, the average CAR is -2.8 percentage points, significant at the 5 percent level. Our results indicate that the negative impact we observe is likely not driven by the proximity to violence and spatial disruptions from these events. This reinforces that our results are likely driven by firms being associated to violence via the media channel. Furthermore, our results suggest that traders may be well informed about circumstances surrounding events, which we investigate further in Panel C.

In Figure 9 Panel C, we use publicized assassination events of activists where no company was linked in the media reports. In other words, we consider assassinations where no firm has been publicly named in connection with the violence. ${ }^{33}$

With this in mind, we rerun our regression analysis however, we consider slightly different treatment and control groups for these "unattributed events." As we did before, we geolocate the "unattributed events" in our sample. Using this location information, we then consider all companies within the same Admin1 region (for most countries, roughly the provincial level) of the event as treated $(D=1)$. All other companies in the event-country are in the control group $(D=0)$.

The results show that market participants appear to have a delayed and subdued reaction. ${ }^{34}$ This behavior is consistent with a lengthier information gathering process for events that, ex post, have no direct company tie. Furthermore, these results suggest that financial markets might have access to information that is not publicly available.

\subsection{The Role of the Media}

We now turn our attention on the nexus between publicity of activist assassinations and the media. The role of the media in this context is twofold: First, journalists are often among the first to shed light on activist assassinations and media outlets communicate these stories to a broader audience.

\footnotetext{
${ }^{32}$ Given the geographic resolution of assassination events and projects in the database, there will be uncertainty in the precision of our "matches" within an Admin1 region. However, even with this uncertainty, we suspect these matches are nevertheless informative. Opposition to mining usually arises due to a local land conflict—such as conflict over indigenous property rights-and these conflicts are geo-spatially correlated.

${ }^{33}$ Note that we cannot rule out the possibility that reports establishing a link between an assassination and a mining company or project exist. However, we are confident that the information is—at least-not easily accessible given the extensive time that has been attributed to researching the events.

${ }^{34}$ The estimated coefficients across specifications are presented in Table D.6 in the Appendix.
} 
In most cases, media outlets are also the main source of information for investors about these types of market-relevant events. Second, increased media attention for an assassination event, leads to more negative publicity and a higher chance of public backlash against the resource company tied to the assassination. As such, media attention for an event can be one of the main mechanisms driving our baseline results.

A major empirical challenge analyzing the media channel is that proxies for media attention are likely to be endogenous. For example, simply counting the number of news reports about a particular assassination might be a good measure for media attention, but at the same time could be driven by negative stock market reactions to the assassination event.

Instead of relying on a direct, but endogenous, measure for media attention for assassination events, we use an exogenous variable which influences the likelihood that an assassination receives media attention. In particular, we use the daily news pressure index of Eisensee and Strömberg (2007). ${ }^{35}$ We expect the likelihood of an event getting reported on, or gaining attention, to be less if the event coincides with a "high news pressure day" - defined as an above median news pressure day for the period from 1998 to $2018 .^{36}$ Even if investors obtain information from private sources and not the media, news pressure should serve as an indicator for the information demand of financial markets on the event day. For instance, news about natural disasters or recession forecasts are likely to both dominate trading behavior and feature in the top news segments. In contrast, assassinations of mining activists are highly unlikely to be broadcasted in the top three news segments, making daily news pressure an arguably exogenous measure in our setting.

To estimate the heterogeneity of the assassination effect by the likelihood of media attention, we expand our baseline regression model and add an interaction term between the treatment indicator $D_{i e}$ and a dummy variable $N_{e}$ equaling one if the event falls on a high news pressure day, and zero otherwise:

$$
C A R_{i e}\left(\tau_{1}, \tau_{2}\right)=\alpha+\alpha^{N} N_{e}+\delta D_{i e}+\delta^{N} D_{i e} N_{e}+X_{i e}^{\prime} \phi+\gamma_{e}+\epsilon_{i e}
$$

Note that we allow for different intercepts of high and low news-pressure days to account for generic differences in trading behavior on high news pressure days.

Figure 10 shows the influence of news pressure on market reactions graphically for all three samples. The red line in the top panel corresponds to the cumulative abnormal return if the event day coincides with a high news pressure day $\left(\delta+\delta^{N}\right)$, whereas the black line captures the effect of being tied to an event if the assassination date falls on a below median news pressure day $(\delta)$. The bottom panel graphs the difference in estimated effects $\left(\delta^{N}\right)$. Each panel also reports $95 \%$ confidence intervals.

For the baseline sample, the results show a significant and continuous decline in abnormal returns for associated companies if the assassination event falls on a low news pressure day, whereas the coefficient is indistinguishable from zero if the event coincides with a high news pressure day. The bottom panel plots the gradual divergence in cumulative abnormal returns. By Day 10, the differ-

\footnotetext{
${ }^{35}$ Eisensee and Strömberg (2007) define daily news pressure as the median number of minutes a news broadcast devotes to the top three news segments in a day. For more details on the construction of the daily news pressure see Eisensee and Strömberg (2007) Section II.C and Appendix V.B.

${ }^{36}$ Recall that 1998 constitutes the first year in our assassination dataset and 2018 is the last year for which the news pressure is available.
} 
ence in cumulative abnormal returns is 3.9 percentage points and significant at the $5 \%$ level. An attenuated but similar divergence in effects is visible for the Admin 1 control subsample in Column 2 , while a noisily estimated inverse pattern emerges for the sample without explicit company ties (Column 3). The latter, however, should be interpreted with caution, as the absence of direct company associations suggests an inferior role of the media in the dissemination of information.

A potential concern with this identification strategy is that the integration of media markets over time increased the availability of breaking news stories. Figure C.7 in the Appendix shows that the results are virtually unchanged if we detrend the daily news pressure before applying the median split. ${ }^{37}$ Moreover, the estimates are qualitatively similar if high news pressure days are defined as a daily news pressure above the 75th percentile or if we consider the day after the event (Figure C.8 in the Appendix). In the latter case, we still find a visible but attenuated difference in effects, which is consistent with the notion that breaking news stories dominate the news for more than a day.

Overall, one plausible interpretation of the results is that financial markets price in the company's continuous risks and continuous costs of the initial public exposure of the company's association with human rights abuses.

Next, we turn to a related question. Can more transparency in the event country's mining industry support human rights organizations-in cooperation with media outlets-in their mission to hold corporations accountable for misconduct?

We address this question by interacting our assassination indicator with a dummy variable for event country membership in the Extractive Industries Transparency Initiative (EITI) at the time of the event. The EITI initiative commits member countries to fully disclose taxes and payments made by mining companies to the government and serves as an indicator for quality of governance (Fukuyama, 2016).$^{38}$ For instance, Berman et al. (2017) find that EITI membership reduces the likelihood of mining-related, localized conflicts in Africa. The results in Appendix Figure C.9 provide further support that transparency can amplify the publicity effect on associated multinationals' stock value. Published assassination events that occurred in a country which was an EITI member at the time of the event have a relatively stronger, negative effect on the associated mining company's market value compared to events that happened in non-EITI member countries.

\subsection{Who Reacts to Publicity?}

Our findings in the previous sections show that investors react negatively to assassination events. In the next step, we investigate if institutional investors-sophisticated, informationally sensitive "big players" (e.g. Puckett and Yan, 2011; Hendershott et al., 2015)—respond to reports of human rights violations for companies in their portfolio. For instance, Mccahery et al. (2016) report that socially "irresponsible" corporate behavior is considered a very important trigger for shareholder activism as evidenced by $72 \%$ of the surveyed 143 institutional investors. ${ }^{39}$ Large scale sovereign wealth and pension funds have been early adopters of ethical investment policies and are increas-

\footnotetext{
${ }^{37}$ Eisensee and Strömberg (2007) note a slight upward trend in the daily news pressure for the 1968-2003 period.

${ }^{38}$ Data on "join" and "leave" dates of member countries is retrieved from the EITI API version v2. For more details on EITI, see Section 5 and https://eiti.org/ .

${ }^{39}$ Other recent studies (e.g. Dyck et al., 2019; Chen et al., 2020) have also found evidence for a positive relationship between institutional ownership and corporate social responsibility scores.
} 
ingly divesting from stocks that do not meet certain ESG criteria. ${ }^{40}$ Therefore, certain types of institutional investors could be more responsive to activist assassinations and sell off their holdings in the companies tied to the event.

We examine the relation between news about company "ties" to assassination events by leaning on an event study specification applied by Cengiz et al. (2019) to account for multiple events per unit of observation in the panel. In particular, we estimate:

$$
I O_{i t}=\alpha+\sum_{\tau=-4}^{4} \delta_{\tau} D_{i t}^{\tau}+\boldsymbol{X}_{i t}^{\prime} \phi+\gamma_{i}+\lambda_{t}+\epsilon_{i t}
$$

where $I O_{i t}$ is the ratio (as percent of market capitalization) held by institutional owners for quarter $t$ of company $i$. The "treatment" dummy $D_{i t}^{\tau}$ equals one if company $i$ was associated with (at least) one assassination event $\tau$ quarters from quarter $t$. This definition implies that $\tau=0$ represents the quarter in which an event took place. Following Dyck et al. (2019), we control for a set of annual firm characteristics $\boldsymbol{X}_{i t}$-i.e. size, asset tangibility, leverage, Tobin's q, and profitability lagged by one year. Our benchmark specification also accounts for company and quarter fixed effects, $\gamma_{i}$ and $\lambda_{t}$. We cluster our standard errors by company.

We use the estimated parameter $\delta_{\tau}$ from Equation (9) to calculate the change in the holding position of institutional investors in response to the assassination event. The difference-in-differences estimate between event date -1 and $\tau$ can be calculated as $\delta_{\tau}-\delta_{-1}$.

Data on institutional ownership comes from the Factset Ownership database. Factset has been widely used in empirical finance (Aggarwal et al., 2011; Dyck et al., 2019) and reports institutional investors' equity holdings collected globally from fund reports, regulatory authorities (e.g. 13F reports in the United States), fund associations, and fund management companies. ${ }^{41}$

Importantly, Factset data spans 2000 to 2017, at quarterly frequency, and covers 83 out of the 87 traded mining companies associated with assassination events (153 event-company pairs) in our sample. For those companies in this data, the average probability of an assassination event in a given quarter is 3.6 percent. For our baseline estimates the set of control company includes all corporations for which data is available throughout the entire sample period. We show in the Appendix that our results are however robust to refined control group specifications, i.e. if we restrict the control group set to corporations active in the "extractive" sector (Figure C.13) or draw a random sample of companies not active in the "extractive" sector (Figure C.14). ${ }^{42}$

Figure 11 shows that the total institutional ownership share, on average, does not significantly change in response to assassination events in the quarter of the assassination event. However, the estimated coefficient decreases over time and becomes statistically significant three quarters after the event. A possible explanation is that average institutional investors with holdings in mining companies follow a more long-term strategy and are less responsive to short-term events.

\footnotetext{
${ }^{40}$ See for example "Norway prepares to dump up to \$3.7b in Aussie shares", Jun 13 2019, Australian Financial Review, or "Norwegian wealth fund blacklists G4S shares over human rights concerns", Nov 14 2019, The Guardian.

${ }^{41}$ In particular, we rely on "Institutional Ownership Summary Statistics by Firm" as developed by Ferreira and Matos (2008) and provided by WRDS. Data on annual firm characteristics are obtained from the Factset Fundamentals database.

${ }^{42}$ We define corporations as operating in the "extractive" sector if their TRBC Business Sector classification is "Energy - Fossil Fuels", "Uranium" or "Mineral Resources". These corporations are excluded prior to randomly drawing 1000 corporations for the second robustness control company set.
} 
Institutional investors differ in their objectives and investment strategies, which may lead to differences in the timing and magnitude of investor's reaction to assassination events. To analyze this heterogeneity, we disaggregate our data by type of institutional investor and separately re-estimate specification (9) for each. The results are presented in Figure 11. Overall, we find that hedge funds, investment companies and investment advisers, decrease their holdings in associated mining companies in the quarters following an assassination. The estimated coefficient is only statistically significant for hedge funds which decrease their average holding position over the first two quarters by about 12.1 percent compared to their holding position in the quarter before an event. ${ }^{43}$ These results are consistent with the literature on hedge fund strategy which shows that hedge funds have a shorter investment horizon (Cella et al., 2013), are more inclined to monitor corporate behavior and respond rapidly to costly information disclosure (Gargano et al., 2017), in particular, following revelatory news events (Huang et al., 2020). Relative to other types of institutional investors, investment companies and advisors are also more likely to apply an event-based trading strategy and are therefore more likely to react to singular corporate news events.

In contrast, institutional investor types with a long-term, strategic view of investment portfolios, such as pension funds or insurance companies, do not seem to systematically change their holdings for mining companies in the aftermath of an assassination event. Results are quantitatively unchanged if we account for overlapping event windows (Figure C.12). ${ }^{44}$

These results may appear surprising because among institutional investors, pension funds are often considered to engage companies on human rights issues and make public statements to divest from mining companies accused of environmental and human rights misconduct. There are a number of reasons, why our results differ from this public perception. First, although the sector has been acknowledging that it has responsibility to acknowledge human rights in their investment decisions, more credible public commitments have been a very recent development. ${ }^{45}$ Second, despite these written commitments, even investors who actively engage companies on human rights issues appear to be reluctant to set clear timelines for divestment even in cases where investee companies contributed to severe human rights abuses over an extended period of time (UN Working Group on Business and Human Rights, 2021). It is possible that the few cases where institutional investors divested from companies accused of human rights violations are exceptions, and divestment is a tool of last resort among a variety of strategies to engage with investee companies on human rights issues. ${ }^{46}$ Third, information costs and lack of internal

\footnotetext{
${ }^{43}$ Note that $\frac{0.0025}{0.0206} \times 100 \approx 12.1 \%$.

${ }^{44} \mathrm{To}$ account for overlapping event windows we include an indicator variable taking the value 1 for the 4 quarters after an event if company $i$ expires another event within that 4 quarter period-a strategy also applied by Dube et al. (2011) to control for the fact that the current investor reaction might partially capture the response to a previous event when the events are sufficiently close together.

${ }^{45}$ In 2019, the National Council in Switzerland voted to support a bill introducing a broad mandatory human rights due diligence regime that received backing from 27 institutional investors representing over US $\$ 808$ billion in assets under management. Investors representing over US $\$ 4$ trillion assets under management filed multiple statements in support of the Australian Modern Slavery Act in 2018. In 2018, more than 70 large Dutch pension funds with combined assets of almost $€ 1.2$ trillion signed a covenant committing to worldwide cooperation aimed at promoting sustainable investment based on respect for human and labor rights. In late 2018, investors representing over US\$5 trillion in assets under management called on the US Securities and Exchange Commission to mandate corporate disclosure of ESG, including human rights information (see "The Investor Case for Mandatory Human Rights Due Diligence.", April 21 2020, Investor Alliance for Human Rights, https://investorsforhumanrights.org/sites/default/files/attachments/2020-04/The\%20Investor\%20Case $\% 20 \mathrm{f}$ or $\% 20 \mathrm{mHRDD} \% 20-\% 20 \mathrm{FINAL} 3$.pdf).

${ }^{46}$ For example, in December 2019, the largest Danish pension fund, ATP, decided to divest from Grupo Mexico after eight months of failed attempts to engage with the mining company over the environmental and human rights risks associated with a new dam project. "ATP resorts to DKK13m divestment after Mexican mining giant fails to engage.", Jan 31 2020.
} 
capacity makes it often difficult for some institutional investors to obtain reliable information human rights violations and formulate a change in a funds long-term investment strategy based on individual incidents (Business and Human Rights Clinic, 2018). As a result, investment managers may also rely on external indicators about a company's corporate social responsibility.

\subsection{Assassinations Do Not Effect Corporate Social Responsibility Scores}

Do ESG scores react to the human rights events in our study? Investment managers and institutional funds may rely on external ESG indicators as a source of information about human rights violations of a company. We examine if the long-term reaction of institutional investors is itself a reaction to changes in environmental and social performance (E\&S) indicators. To do so, we obtain data on firms' E\&S performance from the Thomson Reuters ASSET4 ESG database. Information is acquired from stock exchange filings, CSRs, annual reports, non-government organization websites, and news sources for large, publicly traded companies at annual frequency for the period 2002-2019. The data covers 46 firms experiencing at least one event during this period, and in total 104 event-years.

Our baseline tests examine the relation between assassination events and E\&S performance using the specification:

$$
\log \left(\operatorname{Score}_{i t}\right)=\alpha+\delta D_{i}+\boldsymbol{X}_{i t-1}^{\prime} \phi+\gamma_{i}+\lambda_{t}+\epsilon_{i t}
$$

where $\log \left(\right.$ Score $\left._{i t}\right)$ is the $\log$ (plus one) of the environmental or social scores of company $i$ in year $t, D_{i t}^{\tau}$ is a dummy equaling 1 if company $i$ was associated with (at least) one assassination event in year $t, \boldsymbol{X}_{i t}$ is a set of firm-level controls in year $t-1$ (size, asset tangibility, leverage, Tobin's q, and profitability), and $\gamma_{i}$ and $\lambda_{t}$ are year and company fixed effects, respectively. ${ }^{47}$

We report the results in Table 4. Column 1 and 2 show that the assassination event has no impact on either the overall ESG performance score or the ESG score when controversies are particularly discarded (ESGC score) as provided by Thomson Reuter. In Columns 3 and 4 we focus on the ESG categories which should be most impacted by the events in our data: human rights and community scores. For either category, we do not find a significant impact of our events on the score. While Thomson Reuter use rank-based scores relative to all other companies for categories, Dyck et al. (2019) rely on indicator based scores. ${ }^{48}$ Columns 5 and 6 present the results when underlying their scoring method. No significant effect is detected but the negative sign of the estimated coefficients is in line with expectations. The results are qualitatively unchanged when we account for the potential impact of institutional investors on ESG scores (c. Dyck et al., 2019) by including the total institutional owner share at the end of year $t-1$ as an additional control variable (Table D.7).

Our results mirror survey responses by institutional investors about the human rights information in external ESG indicators by Business and Human Rights Clinic (2018). Such studies show a concern that ESG indicators often lack coverage of large companies operating in emerging markets. In some instances, responsible investment managers often have to work directly with NGOs to receive information about human rights violations. One interviewed investment manager even stated that

\footnotetext{
${ }^{47}$ Following Dyck et al. (2019), we use logs of E\&S scores to obtain better distributional properties and to reduce the impact of outliers. Our results are qualitatively unchanged when using raw scores instead.

${ }^{48}$ Details on the calculation of the category scores in the manner of Dyck et al. (2019) are presented in Section B.2 in the Appendix.
} 
civil society accounts of companies' activities are a "fundamental component of his organization's tools for ensuring that they invest responsibly" (Business and Human Rights Clinic, 2018, p. 10).

\subsection{Legal and Financial Implications of Associations to Assassinations}

We now turn to the analysis of potential mechanisms that make assassination events salient for investor decisions. Potential legal implications for companies associated with assassinations is the first mechanism. There are prominent examples where companies have faced large fines due to environmental or social misconduct in more developed countries resulting in a devaluation of their stock price. However, this has not been the case for potential human rights violations associated with operations in less developed countries. We were unable to find evidence that any of the events in our sample had resulted in convictions or legal fines of any substantial nature for the associated companies occurring during our sample period ${ }^{49}$.

We also conduct an empirical analysis to see if the effect of being associated with an activist's assassination varies by the likelihood of being indicted for the human rights violation and/or face legal consequences. We combine our event level data with data on the quality of the judicial system in a country ("Law and Order") from The International Country Risk Guide (ICRG) from The PRS Group. In particular, we access information about the quality of the judicial system both for the mining company's HQ country and the country in which the assassination took place. Intuitively, if investors expect that the association with an activist assassination will result in a legal indictment and subsequent financial losses due to fines, the effect of the event on the associated company's CAR should increase in the quality of the (HQ and event) country's judicial system.

Our empirical analysis applies a similar logic as specification (8) in section 4.2. To analyze if the effect of assassination varies by the HQ (event) country's quality of the judicial system, we include an interaction term between the treatment indicator $D_{i e}$ and a dummy variable that switches to one if the HQ (event) country's quality of the judicial system is high and zero otherwise.

The results using the quality of the judicial system in the HQ country are presented in Figure C.10 and for the event country in Figure C.11, respectively. In both cases, we do not find any evidence that the magnitude of the assassination effect differs by the likelihood of facing legal challenges and fines (as proxied by the quality of the country's judicial system). Taking into account the lack of evidence for legal indictments resulting in any substantial penalties for the associated mining companies, we tentatively conclude that investors' reactions are not driven by expectations about future legal indictments for human rights violations.

\footnotetext{
${ }^{49}$ Again, court cases against multinational mining companies to hold them legally responsible for human rights violations are only a very recent phenomena. In a landmark case in 2019, Canadian mining company Tahoe Resources Inc. admitted that it "infringed the human rights" of protesters when security guards opened fire to break them up on April 27, 2013, (The Conversation,15 August 2019) after the Supreme Court had declined to hear similar cases in the past (The Guardian, 28 February 2020). During 2019 the UK Supreme Court ruled that Vedanta Resources was (potentially) liable for misconduct of its Zambian subsidiary KMC, in particular if "there are serious obstacles to claimants obtaining justice in their domestic jurisdictions" (Morrison E Foerster, 8 June 2020). The Thai Appeal Court decision in 2020 to allow against Asia's largest sugar producer, Mitr Phol., moreover, paved the way for Asia's first transboundary class action on human rights abuses (Forum Asia, 31 July 2020). To speak of an international trend, however, is premature, as the hurdles to hold multinationals accountable for human rights violations remain high, as exemplified by the rejection of the case against UK based African Mine Ltd. for excessive force by Sierra Leonean police in relation to its iron ore mine in Tonkolil (Morrison $\mathcal{E}$ Foerster, 8 June 2020).
} 
In the absence of legal consequences, human rights violations and associated civil society and media activism can however induce governments in the event country to apply other forms of punishment that have severe financial implications for the associated mining companies. For example, in the case of Bear Creek Mining Corp.'s operations in southern Peru (Section 3.2) the public outcry over the killing of five demonstrators induced the Peruvian government to revoke the mining concession granted to Bear Creek. This became public knowledge and is most likely the reason for the 43.6 percentage point drop in the Bear Creek's stock in the days following the event.

\subsection{Assassinations and Local Opposition}

The killing of mining activists could ignite even further backlash from the local community and increase opposition against a mining project. Forms of both non-violent and violent protests against a company's operations can lead to temporary disruptions in resource extraction, interruptions in logistics, physical damages to assets or even a permanent shut-down of the operation.

As such, the negative CAR in the subsequent days and weeks might not only be a result by civil society's informational campaign, but other, local anti-mining activities that have direct costs for the associated company. To examine the role of this local opposition channel, we construct a new dataset at the ADM1 and day level for the period 1998 to 2019 for countries where we observe at least one assassination event in association with a publicly traded company over this period. The resulting data set is a balanced panel for each day $t$ and 486 ADM1 regions, $i$ from 21 countries, $c$. For this sample we have 161 event-ADM1-day pairs, which will be our treatments. We accessed data on local protests from the Mass Mobilization Data Project (Clark, David and Regan, Patrick, 2016). This dataset contains more reliable information about protests than other data sources and also has an almost global coverage. The dataset also differentiates the protests into various subcategories depending on the type and cause of the protest. Unfortunately, the location information only contains string variables of the name of the location in an unstructured form with entries varying between city, district and state, among others. We used the GeoNames $\mathrm{API}^{50}$ combined with manual matching to assign each protest to the ADM1 polygons used in our study.

$$
P_{i t}=\alpha+\sum_{\tau=-10}^{10} \delta_{\tau} D_{i t}^{\tau}+\phi_{c, m, y}+\gamma_{i}+\lambda_{t}+\epsilon_{i t}
$$

where $P_{i t}$ is one on Day $t$ when we observe at least one protest in the Admin 1 region $i$ of country $c$ and zero otherwise. Apart from protest incidences we also investigate the probability that a protest breaks out or ends. In this case, $P_{i t}$ takes the value one if a protest starts (ends) on Day $t$ in Admin region $i$, episodes without a protest are coded zero from the beginning till the end, and ongoing protest days are coded as missing values (c. for instance Collier and Hoeffler, 2004). The "treatment" dummy $D_{i t}^{\tau}$ equals 1 if the Admin1 region $i$ experiences (at least) one assassination event $\tau$ days from date $t$. This definition implies that $\tau=0$ represents the day on which an event took place. Our specification accounts for region and day fixed effects, $\gamma_{i}$ and $\lambda_{t}$, as well as for country $\times$ month $\times$ year fixed effects $\left(\phi_{c, m, y}\right)$. Specifically, we use within country-month-year variation when estimating the linear probability model.

\footnotetext{
${ }^{50} \mathrm{http}$ // / www.geonames.org/source-code/javadoc/org/geonames/WebService.html
} 
The estimated coefficients of $\delta_{\tau}$ from equation are presented in Figure C.15. Each cell corresponds to a different dependent variable with column labels depicting the type of protest and rows capturing if the dependent variable considers incidence, start, or the end of protests.

The plots in the first row, reveal that protest incidence is higher in the days prior and the day of the event, although the coefficients are not statistically significant. This is in line with anecdotal evidence that increased protest activity precedes the assassination event and that the killings often take place during demonstrations against the mining operations. ${ }^{51}$ In the first day after the killing, the incidence of local protests significantly increases. Again, this is in line with anecdotal evidence that the local population mobilizes in the immediate aftermath of the killing of one of their community members. However, the incidence rate immediately drops after that and stays close to zero.

The second row, shows the results of the likelihood that a new protest episode will commence. We find that this likelihood is higher (although not statically significant) 5-6 days prior to the assassination event. It then increases on that given day and the following day, but drops to zero on the day after that and remains at zero form the remaining time. This result is also reflected by the plots in the third row, which plot the likelihood that a protest episode ends. We find that protest episodes systematically end on the day after the event. Taking these results together, reveals that the killing of an activist results in a very-short term, one day, protest by the local community but if at all leads to an overall end of local protest activity afterwards. We interpret this as an indication that the negative reactions of the stock market are not due to increased local protest mobilization that might interfere with the company's mining operation.

Figure C.16 in the Appendix presents the estimated effect relative to the day before the assassination event. ${ }^{52}$

\section{Tax Revenues, Local Actors, and Assassinations}

Given the losses from assassinations, why do publicly traded mining companies continue to be associated with these events? Multinationals are sprawling and complex, and the boundaries of the multinational are blurry. Their upstream operations may be operated by actors whose incentives differ to their owners.

Local parties benefiting from mining projects may have an incentive to suppress or eliminate opposition, and may not bear the risk of these actions. Domestic government and state-aligned paramilitaries are examples of such agents, where uninterrupted production will result in higher royalties and tax revenues. The relative gains of engaging in malfeasance can be higher for mining operations that earn significant revenue from mining projects. If so, the likelihood of observing an assassination should be increasing in the share of taxes paid to a host-country .

We explore this by constructing new data on the local public finance of mining companies. We do so by collecting reports published by the Extractive Industries Transparency Initiative (EITI)-itself

\footnotetext{
${ }^{51}$ Recall, as we do not find any pre-trends in our main results, the stock price does not seem to systematically reflect his increased protest activity.

${ }^{52}$ In particular, the difference-in-differences estimate between event date -1 and $\tau$ is calculated as $\delta_{\tau}-\delta_{-1}$.
} 
an international civil society organization. Using these reports, we construct annual measures of tax shares paid to host governments by mining firms.

As members of the EITI, nations commit to disclosing payments from local companies to the government; these revenue streams ordinarily cover payments from subsidiaries and joint venture. We consequently must determine the ownership structures to match EITI records with our assassination event dataset.

Specifically, we hand-code ownership shares using information published in annual reports of publicly traded companies and-if not available-we rely on Bureau van Dijk's Orbis database. As a convention, private companies are coded as their own owner, i.e. we do not account for ownership shares of private individuals. Tax revenues of subsidiaries and joint ventures are distributed to owners in accordance with their shares. ${ }^{53}$ For instance, in 2014, Anglo American owned 81.90 percent of the Peruvian mining company Anglo American Quellaveco S.A. and Mitsubishi owned 18.10 percent. Consequently, 202,232 USD of the 246,925 USD in taxes and royalties to the Peruvian government are attributed to Anglo American while the remainder is attributed to Mitsubishi. For each country-year pair (report), revenues are subsequently aggregated at the owner-level and divided by the total amount of tax revenues from the mining industry to obtain the tax share. Summary statistics on the tax shares, disaggregated by event-country are presented in Table 5 .

One caveat with EITI records is that they cover a limited set of countries and years in our assassination dataset. We code ownership shares for all years available in the EITI database for countries which have experienced at least one assassination event in the past. It is worth noting, that we are not limited to public companies in this analysis. Thus we are able to additionally match private companies to assassinations in our data. For completeness, we retain potentially interesting cross-country variation and do not exclude countries if an assassination event falls outside of EITI coverage period.

We use a linear probability model to estimate the relationship between a company's tax share and the likelihood to observe an assassination event. Specifically, we estimate the following:

$$
\text { assassination }_{i c y}=\beta_{1} \mathrm{~T}_{i c y}+\gamma_{c y}+\epsilon_{i c y}
$$

where assassination $_{i c y}$ is a dummy variable that takes the value of one if an assassination event in country $c$ in year $y$ is associated with company $i$ and $\mathrm{T}_{i c y}$ corresponds to the tax share of company $i$ in country $c$ in year $y$. In our baseline specification we include country $\times$ year effects $\left(\gamma_{c y}\right)$, which account for time-varying economic and political developments in countries. Standard errors are clustered at the company $\times$ country level.

Table 6 shows a positive relationship between the tax share and the probability of observing an assassination event. Column 1 presents the significant and positive unconditional correlation coefficient of 13.8 percentage points. The magnitude of the coefficient increases to 17.4 percentage points after we account for differences in the mining industry and average prevalence of assassinations

\footnotetext{
${ }^{53}$ Note that we account for changes in ownership shares over time as well as for acquisitions.
} 
with country fixed effects (Column 2). Adding year effects has little effect on our estimates. This seems reasonable, as the tax share is-by construction-expressed in relative terms.

According to our preferred specification (Table 6 Column 4), a hypothetical mining company (and sole tax payer) is associated with an 18 percentage points higher probability of an assassination. This translates to an average effect of about 1.1 percentage points, as the average tax share in the sample is 5.9 percent, which constitutes a 26 percent increase in the average probability of observing an event. ${ }^{54}$

These estimates should be interpreted with care, This exercise is correlations and we cannot entirely rule out confounders. For example, journalists may have an incentive to report assassinations related to notable companies, or those that are most compelling to readers. Since tax revenues are expected to be proportional to the value of projects owned by companies in the event country, reporting could simultaneously increase with the tax share. We attempt to deal with reverse causality in Appendix Table D.10. Across specifications, we show an insignificant, positive impact of assassination events on the change in tax shares ( $\Delta$ Tax Share).

\section{Conclusion}

We study the power of human rights publicity and its impact on multinationals. To answer this question, we turn to salient, well-publicized events at the heart of current advocacy: the assassination of environmental activists. We zoom into the sector at the center of this conflict, the global mining sector. Our study evaluates the impact of publicizing human rights violations on value of the multinational companies connected with violations. To do so, we compile a new database on 354 assassinations and extrajudicial killings of activists and link them to the publicly listed mining companies implicated in the events. We then combine this data with daily stock market returns of those companies and use event study methodology to estimate the effect of the killings on the abnormal daily returns of companies' stocks.

Our results show that publicity of human rights abuse has substantial negative effects on multinationals. Following assassinations, we estimate significant negative abnormal returns for firms associated with these events. Negative effects appear on the (trading) day after an assassination occurs. These negative effects are amplified for the ten days after the event, and continue. We show these patterns using two types of event studies. Both methods yield similar results, and are robust to alternative test statistics-for standard event study estimates—and across alternative OLS specifications.

Our estimates show that killings of activists lead to statistically significant lower returns with a cumulative median loss of over USD 100 million in the 10 days following the event. We highlight the critical role of the media in making information available to a broader public in this context and show that the stock market's negative reaction to publicizing the assassinations is more pronounced during days which are not dominated by other news-worthy events.

We highlight the role of the media and institutional investors in driving our results. We consider the importance of the media and the salience of events in two ways. We examine this channel by considering the likelihood that news of human rights events reaches financial decision-makers

\footnotetext{
${ }^{54}$ The average probability to observe an assassination event in the sample is 4.16 percent.
} 
and ask how the impact of human rights events varies over the news cycle. Using daily "news pressure" data (Eisensee and Strömberg, 2007), we find that the penalty of human rights news is mediated by the strength of the new cycle. Furthermore, we show the visibility of the multinationals in this coverage - that is, the firm names-also matter. We compare abnormal returns for companies named in connection to assassinations versus merely operating closely (geographically proximate) to events. We find that firms operating in the vicinity of events-though not named in media coverage-do not experience significant penalties, relative companies explicitly named in the media. The human rights tactics of "naming-and-shaming" may thus carry currency.

Additionally, we show that informationally sensitive, institutional investors may play important roles in our effects. We find institutional investors that follow event-based trading strategies-such as hedge-funds-divest in mining companies after assassination events. These results dovetail with work on the role institutional investors play in promoting social responsibility (Dyck et al., 2019), especially in emerging markets with weak institutions (Dyck et al., 2008).

We believe that our results contribute to emerging work on the political economy of multinationals, and the political economy of human rights more broadly. Our findings show that informational campaigns by civil society have in fact an impact on multinational corporations. Being linked to human rights abuses can significantly influence a companies' stock market value.

Our results highlight the potential of human rights reporting, advocacy and journalism. As well, it has implications for the investment industry. In particular, as institutional investors incorporate ESG concerns into their portfolio. Some blame the lack of quantitative evidence of the financial implications of human rights violations as the main barrier to elevate human rights concerns in actual investment decisions (Business and Human Rights Clinic, 2018). Our study provides a better understanding of the material consequences of human rights violations and quantifies their effect on the associated company's valuation. This can help investment managers to better incorporate human rights impacts in their long-term investment strategy and might ultimately help that stock prices better reflect human rights violations associated with the underlying company's operations. 


\section{Figures}

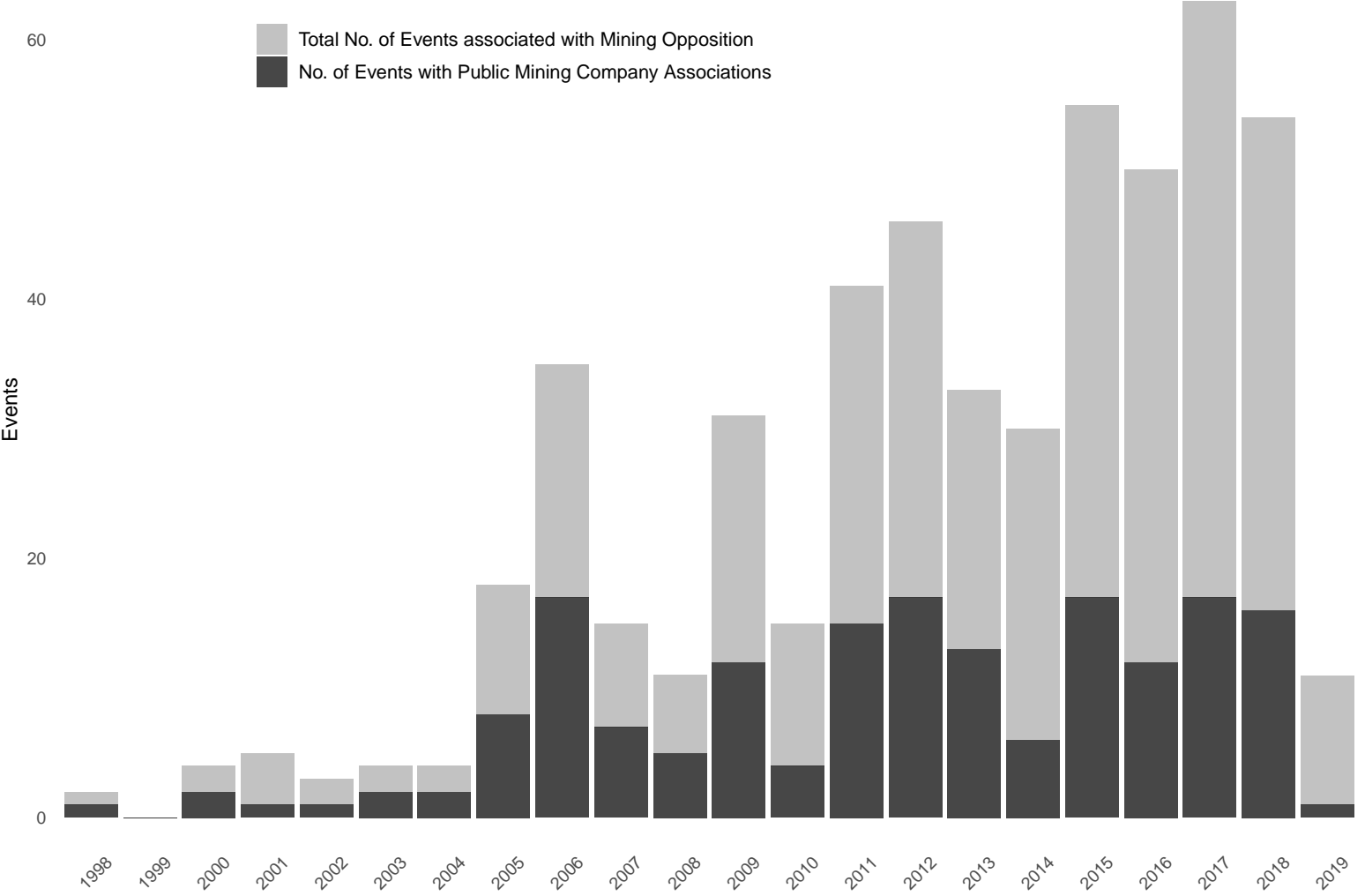

Figure 2: Distribution of Assassination Events over Time. 


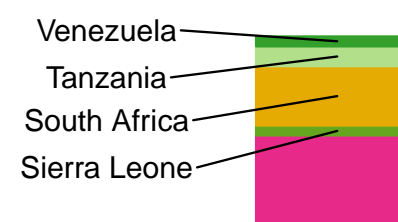

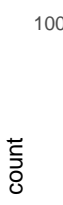

Philippines
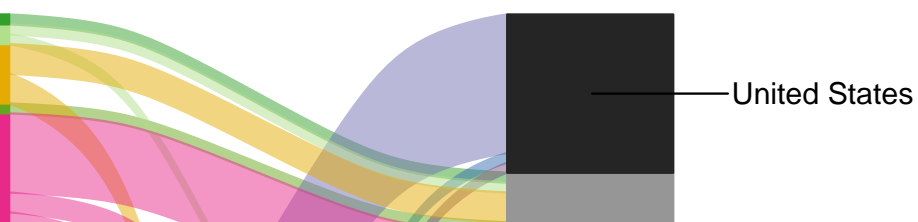

Papua New Guinea -

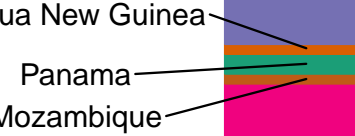

Mexico-

Indonesia

Peru

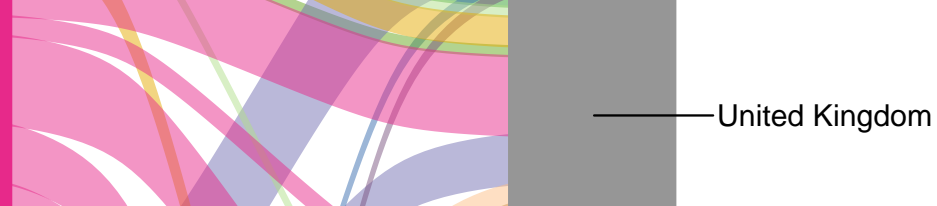

India-

Honduras -

Guatemala

Ghana

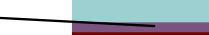

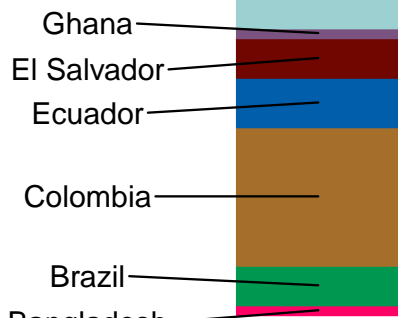

Bangladesh

Event Country

Headquarter

Number of flows: 43 Original Dataframe reduced to $25.1 \%$
Maximum weight of a single flow $9.9 \%$

Figure 3: Event Country Activity and Company Headquarter Locations 

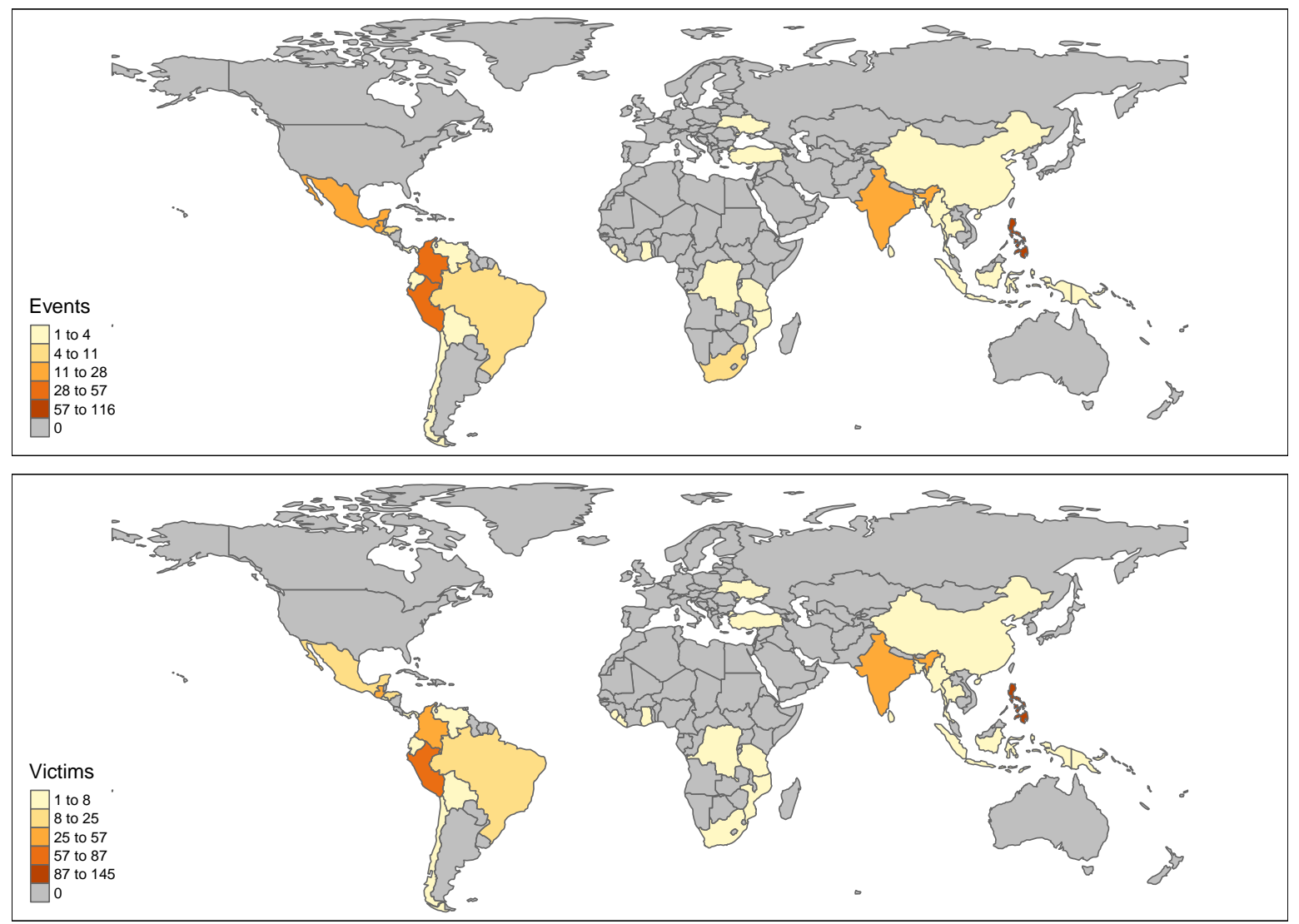

Figure 4: The Spatial Distribution of Assassination Events. 


\section{Ecuador indigenous leader found dead days before planned Lima protest \\ Shuar leader José Isidro Tendetza Antún missing since 28 November \\ Activists believe death linked to opposition to state Chinese mine project}

Jonathan Watts, Latin America correspondent, and Dan Collyns in Lima

Sun 7 Dec 2014 09.59 AEDT

The body of an indigenous leader who was opposed to a major mining project in Ecuador has been found bound and buried, days before he planned to take his campaign to climate talks in Lima.

The killing highlights the violence and harassment facing environmental activists in Ecuador, following the confiscation last week of a bus carrying climate campaigners who planned to denounce president Rafael Correa at the United Nations conference.

The victim, José Isidro Tendetza Antún, a former vice-president of the Shuar Federation of Zamora, had been missing since 28 November, when he was last seen on his way to a meeting of protesters against the

Mirador copper and gold mine. After a tip-off on Tuesday, his son Jorge unearthed the body from a grave marked "no name". The arms and legs were trussed by a blue rope.

Event date

Mining opposition
Mining Project/Company

Name(s) and associations of the victim(s)
"Assassination"/Violent death

Figure 5: Extracting Events and Company Associations from NGO and Media Reports - Example Case 


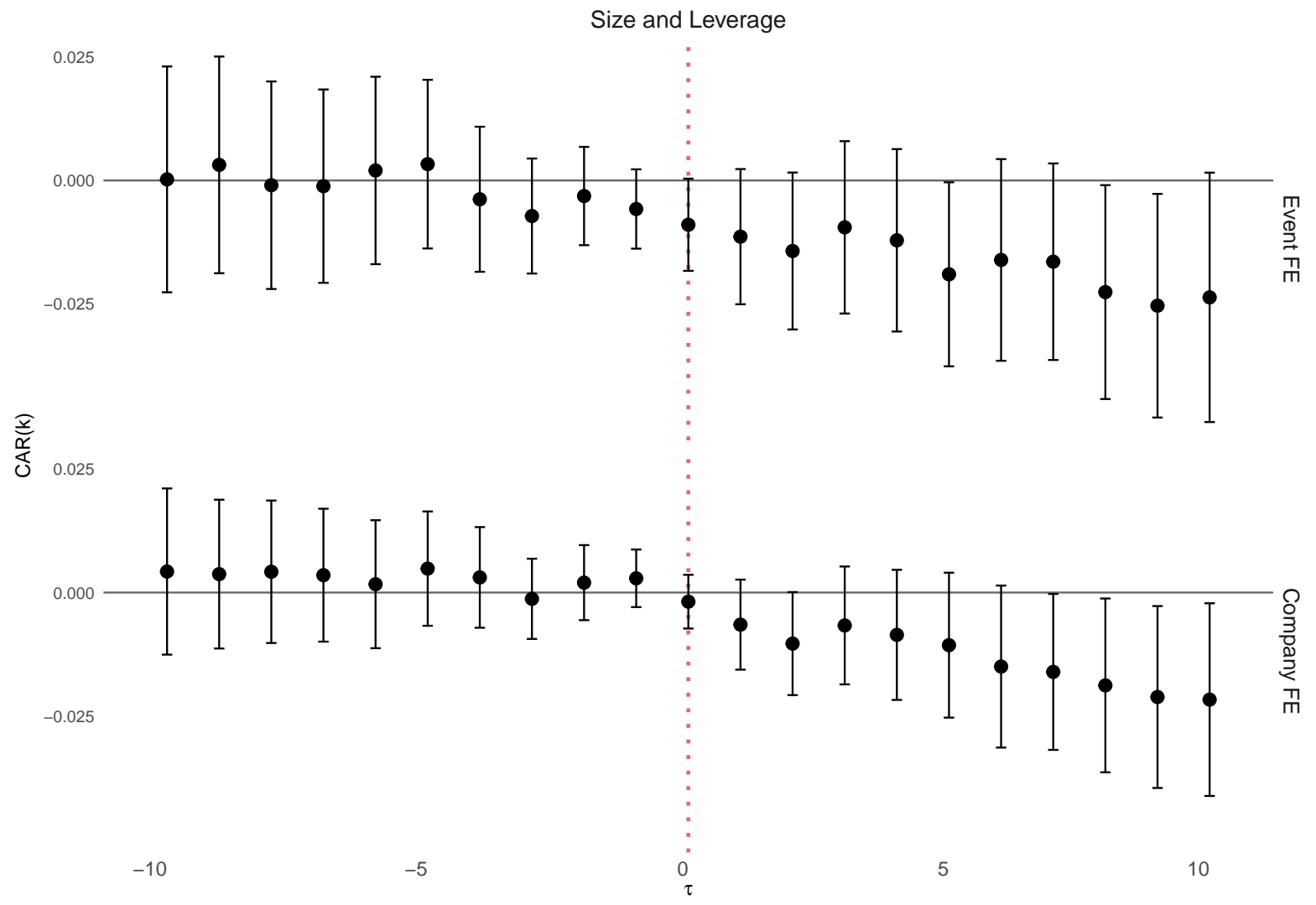

Figure 6: The Treatment Effect of Assassination Events on Mining Companies.

Notes: The coefficients when regressing the respective cumulative abnormal return (CAR) on an indicator for being tied to an assassination event is represented by the black dots. The horizontal axis label denotes the trading days before and after the event on $\tau=0$. CARs are aggregated backwards before the event date and forwards starting with the event date. E.g. -5 refers to the CAR between -1 and -5 while 5 refers to the CAR between 0 and 5 . The top panel displays the point estimates for $\hat{\delta}$ when event fixed effects are included, the bottom panel estimates for the specification with company fixed effects. In total the coefficients of 42 regressions are displayed. 95\% confidence intervals using robust standard errors clustered on the event-level are depicted. 


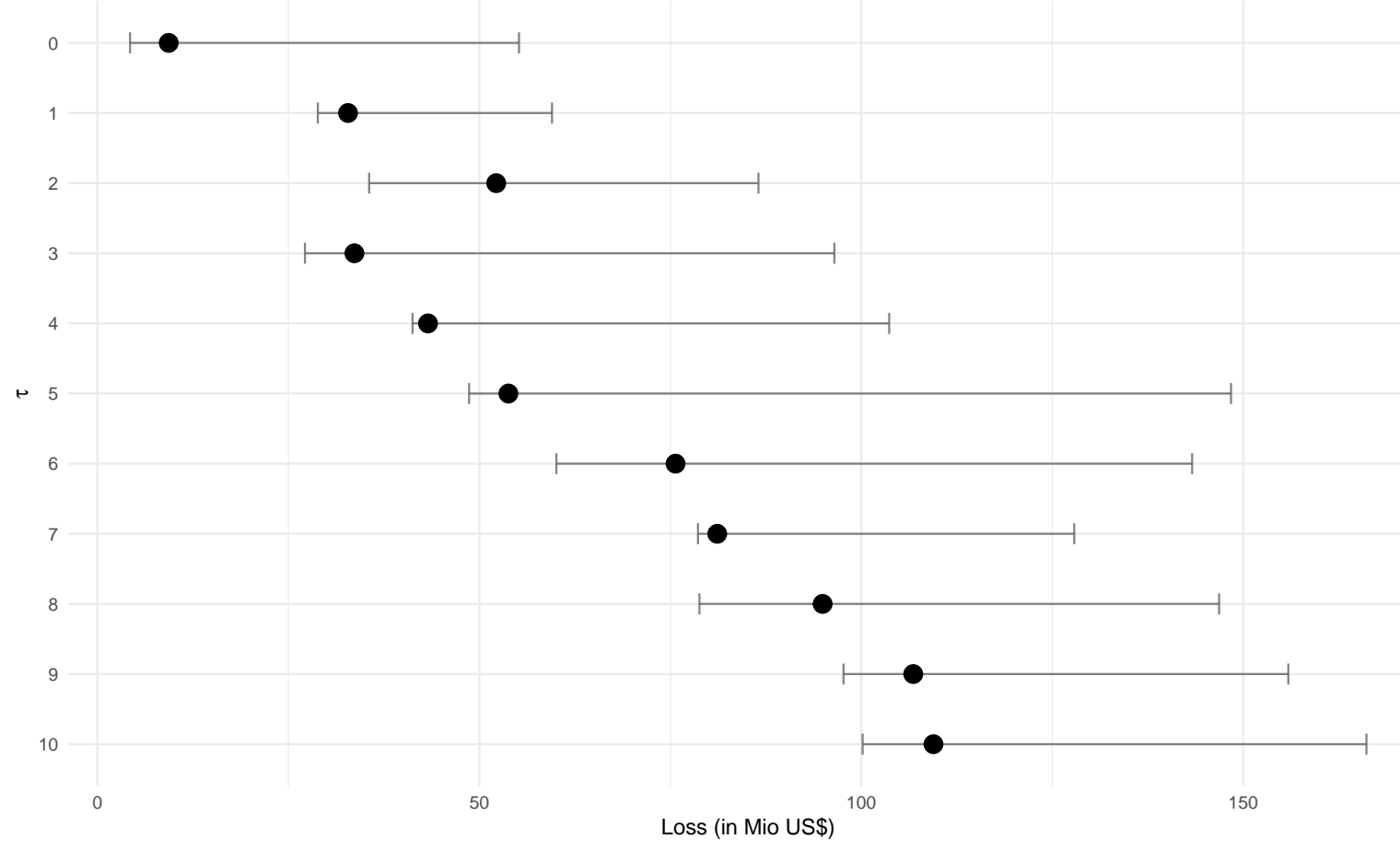

Figure 7: The estimated Economic Value of Assassination Events.

Notes: Dots correspond to the estimated loss in market capitalization of the median company for our event fixed effects specification. The grey bars display the estimated minimum and maximum loss in market capitalization for the median company across specifications. 


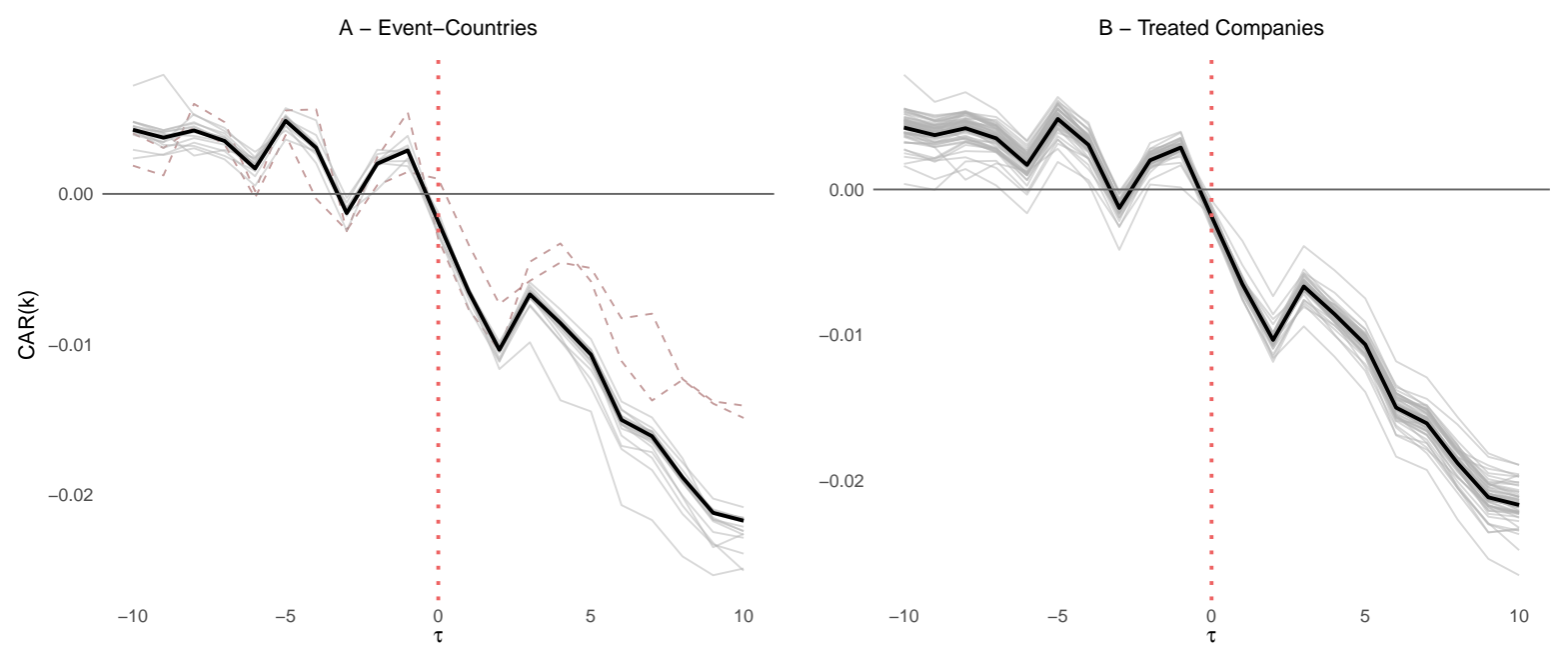

Figure 8: Robustness of Baseline Results - Leave-One-Out.

Notes: The thick black line in Panel-A and Panel-B corresponds to the event fixed effect specification's coefficient estimates for being tied to an assassination in the full sample. Panel-A presents the estimated coefficients when one country is consecutivley dropped from the sample. The (red) dashed lines highlight the estimated coefficients when dropping events in the Philippines, respectively Peru from the sample. Panel-B displays the estimated coefficients when one treated company at a time is dropped from the sample. 


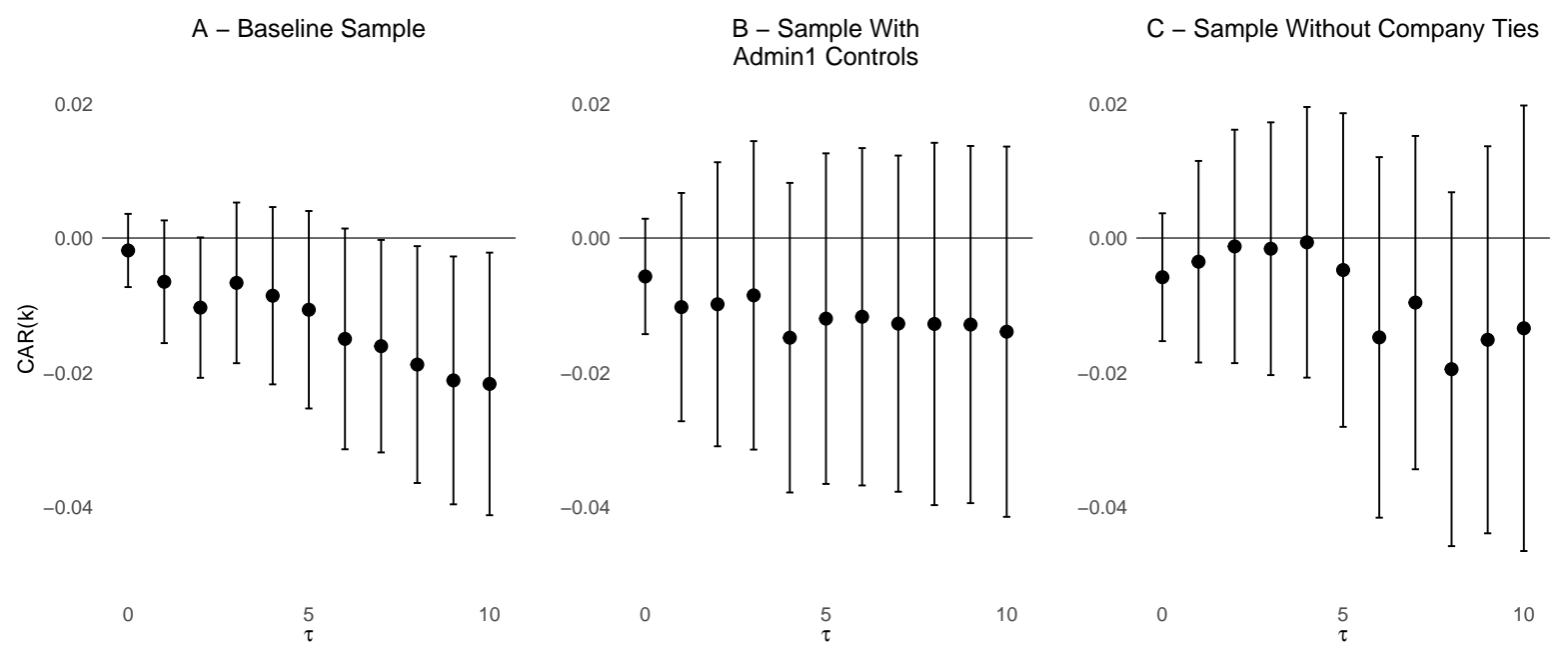

Figure 9: Vicinity vs. Media Ties.

Notes: The black dots correspond to the coefficient estimates for being tied to an assassination in our event fixed effect specfication. Panel-A presents the baseline sample estimates, while Panel-B presents the results when altering the control group to companies active in the Admin1 region of the assassination event. Panel-C shows the coefficient estimates for the sample with no public company assaciations; all companies within the same Admin1 region of the event are considered as treated, while all remaining companies in the event-country constitute the control group. 95\% confidence intervals using robust standard errors clustered on the event-level are depicted. 

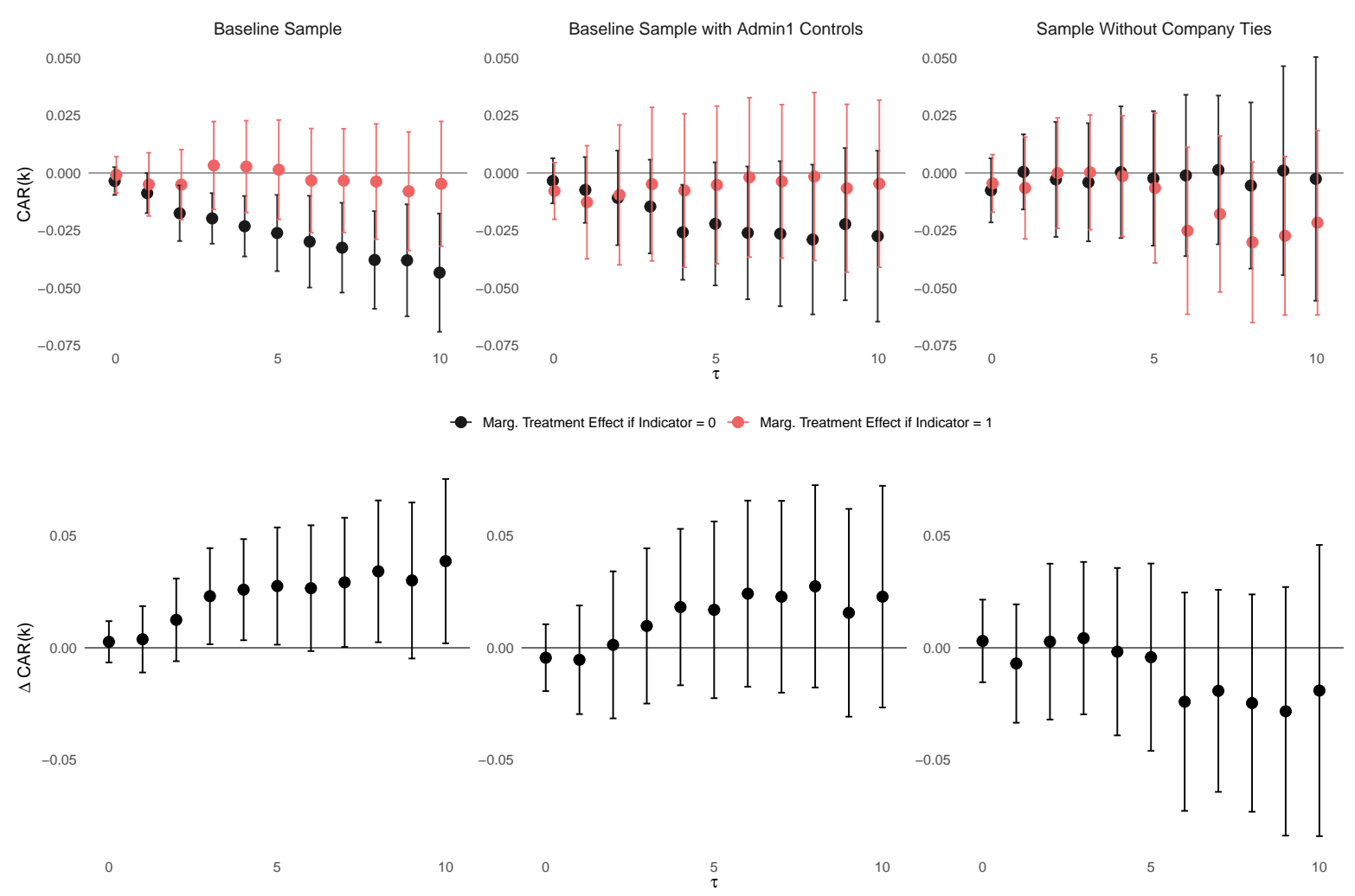

Figure 10: The Influence of News Pressure on the Event Day

Notes: The top panel displays the heterogeneous marginal treatment effect of assassination events on the respective cumulative abnormal return (CAR). The difference in treatment effects is presented in the bottom panel. The horizontal axis label denotes the trading days relative to the event day $\tau=0$. CARs are forwards starting with the event date. E.g. 5 refers to the CAR between days 0 and 5. Columns present regression specifications with the assassination indicator interacted with an indicator variable for high news pressure defined as an above median news pressure day. The first column presents the baseline sample estimates, while the second column presents the results when altering the control group to companies active in the Admin 1 region of the assassination event. The third column shows the coefficient estimates for the sample with no public company assaciations; all companies within the same Admin1 region of the event are considered as treated, while all remaining companies in the event-country constitute the control group. 95\% confidence intervals using robust standard errors clustered on the event-level are displayed in the top and bottom panel. 


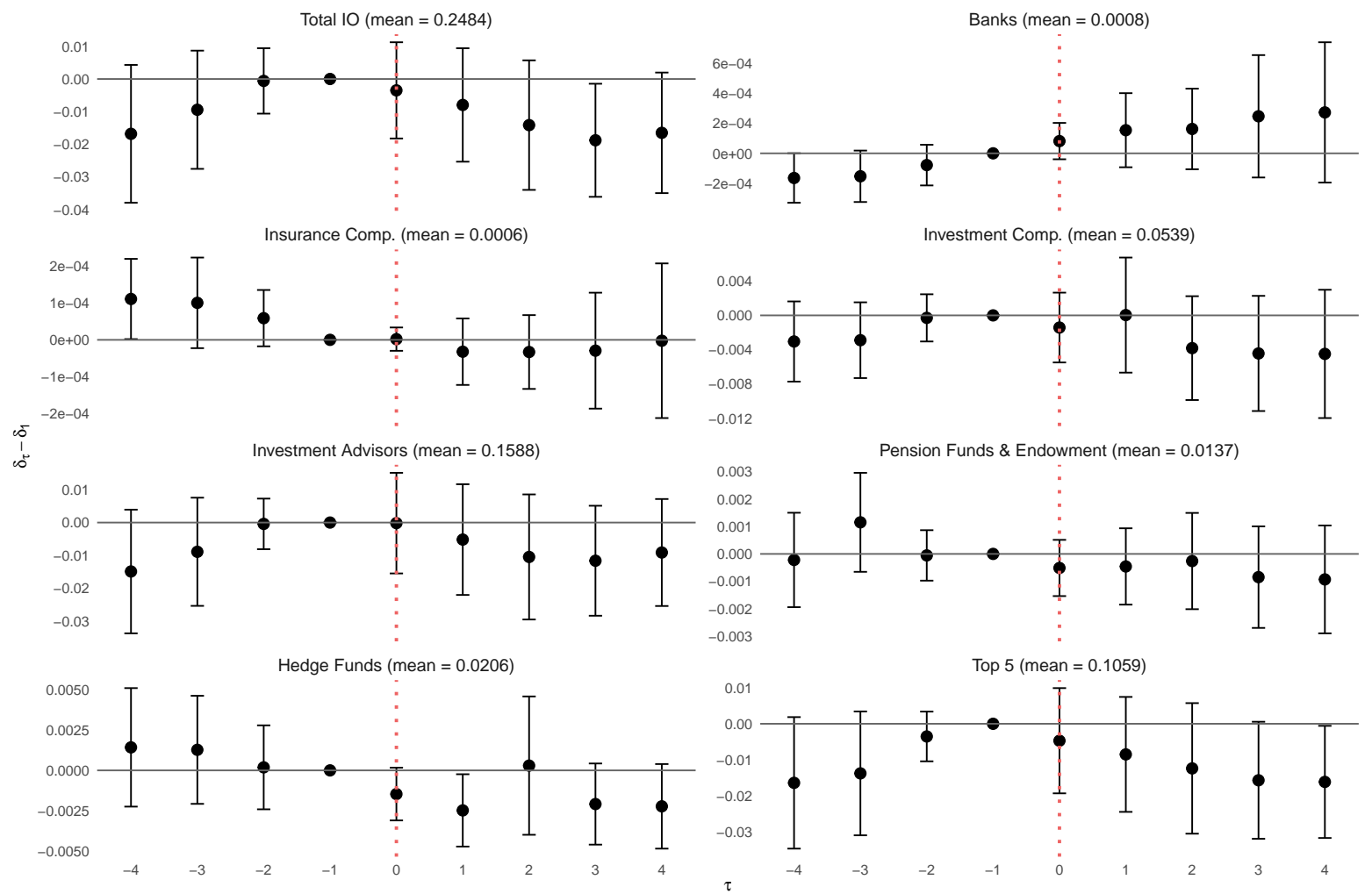

Figure 11: The Effect of Assassination Events on Institutional Investor Holdings

Notes: The figure shows the effect of an assassination event on institutional investor's holding position. Each cell displays the estimated effect relative to the quarter before the event $(\tau=-1)$. The mean institutional investor holding position of companies that experienced at least one event during the sample period is presented in parantheses. $95 \%$ confidence intervals using robust standard errors clustered on the company-level are displayed. 


\section{Tables}

Table 1: Assassination Summary Data

\begin{tabular}{|c|c|c|c|c|c|c|c|c|}
\hline \multirow[b]{2}{*}{ Country } & \multicolumn{2}{|c|}{ Events } & \multirow{2}{*}{$\begin{array}{c}\text { Victims } \\
\text { Total }\end{array}$} & \multirow{2}{*}{$\begin{array}{c}\begin{array}{c}\text { Assassination } \\
\text { Attempts }\end{array} \\
\text { Total }\end{array}$} & \multicolumn{2}{|c|}{$\begin{array}{l}\text { Company-Event } \\
\text { Pairs }\end{array}$} & \multicolumn{2}{|c|}{$\begin{array}{c}\text { Distinct Company } \\
\text { Entities }\end{array}$} \\
\hline & Total & w/o Ties & & & Total & Public & Total & Public \\
\hline Bangladesh & 1 & 0 & 3 & 0 & 1 & 1 & 1 & 1 \\
\hline Bolivia & 1 & 0 & 1 & 0 & 1 & 1 & 1 & 1 \\
\hline Brazil & 11 & 7 & 11 & 0 & 4 & 4 & 2 & 2 \\
\hline Chile & 1 & 1 & 1 & 0 & 0 & 0 & 0 & 0 \\
\hline China & 1 & 0 & 4 & 0 & 1 & 0 & 1 & 0 \\
\hline Colombia & 40 & 21 & 46 & 1 & 28 & 18 & 17 & 8 \\
\hline DR Congo & 2 & 2 & 6 & 0 & 0 & 0 & 0 & 0 \\
\hline Ecuador & 4 & 0 & 4 & 1 & 6 & 5 & 4 & 3 \\
\hline El Salvador & 6 & 0 & 7 & 0 & 6 & 6 & 1 & 1 \\
\hline Gambia & 1 & 0 & 2 & 0 & 1 & 0 & 1 & 0 \\
\hline Ghana & 1 & 0 & 1 & 0 & 1 & 1 & 1 & 1 \\
\hline Guatemala & 28 & 3 & 48 & 6 & 28 & 19 & 10 & 6 \\
\hline Honduras & 9 & 4 & 12 & 1 & 6 & 2 & 6 & 2 \\
\hline India & 25 & 15 & 57 & 0 & 12 & 9 & 10 & 7 \\
\hline Indonesia & 4 & 1 & 5 & 0 & 5 & 3 & 5 & 3 \\
\hline Liberia & 1 & 1 & 1 & 0 & 0 & 0 & 0 & 0 \\
\hline Mexico & 21 & 4 & 25 & 0 & 20 & 17 & 12 & 9 \\
\hline Mozambique & 1 & 0 & 1 & 0 & 1 & 1 & 1 & 1 \\
\hline Myanmar & 4 & 1 & 4 & 0 & 4 & 0 & 4 & 0 \\
\hline Panama & 1 & 0 & 2 & 0 & 2 & 2 & 2 & 2 \\
\hline Papua New Guinea & 1 & 0 & 4 & 0 & 1 & 1 & 1 & 1 \\
\hline Peru & 57 & 5 & 87 & 4 & 79 & 65 & 29 & 19 \\
\hline Philippines & 116 & 57 & 145 & 1 & 85 & 57 & 43 & 27 \\
\hline Sierra Leone & 1 & 0 & 1 & 0 & 1 & 1 & 1 & 1 \\
\hline South Africa & 7 & 0 & 8 & 3 & 7 & 7 & 4 & 4 \\
\hline Sri Lanka & 1 & 1 & 1 & 0 & 0 & 0 & 0 & 0 \\
\hline Tanzania & 1 & 0 & 1 & 1 & 2 & 2 & 2 & 2 \\
\hline Thailand & 3 & 2 & 3 & 0 & 1 & 0 & 1 & 0 \\
\hline Turkey & 1 & 0 & 2 & 0 & 1 & 0 & 1 & 0 \\
\hline Ukraine & 1 & 1 & 1 & 0 & 0 & 0 & 0 & 0 \\
\hline Venezuela & 2 & 1 & 2 & 0 & 2 & 2 & 2 & 2 \\
\hline World & 354 & 127 & 496 & 18 & 306 & 224 & 147 & 87 \\
\hline
\end{tabular}

Notes: $\quad$ Events "w/o Ties" refer to events for which reports established a connection between the assassination (attempt) and the victim's opposition to mining, but no specific mining project or company was mentioned. The "Distinct Company Entities" entries correspond to the number of unique companies associated with assassination events in the respective country or on a world-wide scale. 
Table 2: Summary Table - Financial Data

\begin{tabular}{llccccc}
\hline Group & Variable & Mean & St.dev. & Min & Max & Observations \\
\hline Treatment & Raw return & 0.0007 & 0.0029 & -0.0041 & 0.0233 & 171 \\
Control & Raw return & 0.0011 & 0.0038 & -0.0593 & 0.0476 & 4692 \\
Treatment & Abnormal return & -0.0002 & 0.0010 & -0.0044 & 0.0043 & 171 \\
Control & Abnormal return & 0.0000 & 0.0014 & -0.0317 & 0.0149 & 4692 \\
Treatment & Size & 15.2984 & 2.6828 & 7.7807 & 20.6501 & 166 \\
Control & Size & 12.9156 & 3.2477 & 4.3307 & 20.6965 & 4512 \\
Treatment & Leverage & 0.0022 & 0.0019 & 0.0000 & 0.0072 & 165 \\
Control & Leverage & 0.1907 & 0.5757 & 0.0000 & 16.8088 & 4124 \\
Treatment & Profitability & -0.0002 & 0.0046 & -0.0440 & 0.0063 & 162 \\
Control & Profitability & -0.2659 & 2.2810 & -51.3538 & 17.9823 & 4389 \\
\hline
\end{tabular}

Notes: $\quad$ Raw and abnormal returns for each security are previously averaged over the period from $\tau=-280$ to $\tau=+20$. Firm characterisitcs - i.e. size, leverage, and profitability - are based on the values in the event year. 
Table 3: The Effect of Assassinations on Stock Returns

\begin{tabular}{lcccccc}
\hline & & & \multicolumn{4}{c}{ p-value } \\
\cline { 4 - 7 } & Mean & SD & Normality & BMP & ADJ-BMP & GRANK \\
\hline CAR0to0 & -0.0009 & 0.0034 & 0.789 & 0.406 & 0.432 & 0.700 \\
CAR0to1 & -0.0066 & 0.0047 & 0.161 & 0.067 & 0.083 & 0.217 \\
CAR0to2 & -0.0074 & 0.0058 & 0.202 & 0.102 & 0.122 & 0.140 \\
CAR0to3 & -0.0040 & 0.0067 & 0.547 & 0.186 & 0.211 & 0.048 \\
CAR0to4 & -0.0061 & 0.0075 & 0.415 & 0.119 & 0.141 & 0.037 \\
CAR0to5 & -0.0078 & 0.0082 & 0.344 & 0.137 & 0.160 & 0.061 \\
CAR0to6 & -0.0104 & 0.0087 & 0.233 & 0.064 & 0.080 & 0.033 \\
CAR0to7 & -0.0132 & 0.0094 & 0.160 & 0.032 & 0.043 & 0.016 \\
CAR0to8 & -0.0148 & 0.0099 & 0.135 & 0.027 & 0.037 & 0.011 \\
CAR0to9 & -0.0201 & 0.0105 & 0.055 & 0.013 & 0.019 & 0.001 \\
CAR0to10 & -0.0200 & 0.0110 & 0.070 & 0.023 & 0.031 & 0.004 \\
\hline
\end{tabular}

Notes: The number of company-event pairs $N$ is 167 . The respective average cumulative abnormal return (CAR) and its standard deviation (SD) is presented in columns 1 and 2 (c. equations (5) and (6) in Section 3.1). A minimum of 8 trading days during the event window from 0 to 10 is required. The estimation window spans from day -280 to -30 with a minimum of 200 trading days. Columns $3-6$ show the $p$-value of the respective test-statistic. For details on the applied test-statistics see Appendix A.1. 
Table 4: The Effect of Assassination Events on ESG Scores

\begin{tabular}{|c|c|c|c|c|c|c|}
\hline \multirow[b]{2}{*}{ Dep. Variable: } & \multicolumn{4}{|c|}{ Asset4 z-Scores } & \multicolumn{2}{|c|}{ Dyck et al. (2019) } \\
\hline & Overall ESG & Overall ESGC & Human Rights & Community & Human Rights & Community \\
\hline Assassination & $\begin{array}{c}0.0061 \\
(0.0300)\end{array}$ & $\begin{array}{l}-0.0143 \\
(0.0396)\end{array}$ & $\begin{array}{c}-0.0496 \\
(0.0813)\end{array}$ & $\begin{array}{c}0.1136 \\
(0.0780)\end{array}$ & $\begin{array}{c}-0.0143 \\
(0.0278)\end{array}$ & $\begin{array}{l}-0.0078 \\
(0.0189)\end{array}$ \\
\hline Company Controls & $x$ & $x$ & $x$ & $x$ & $x$ & $x$ \\
\hline Company FE & $X$ & $x$ & $x$ & $X$ & $X$ & $x$ \\
\hline Year FE & $X$ & $x$ & $x$ & $x$ & $x$ & $x$ \\
\hline R-squared & 0.815 & 0.793 & 0.676 & 0.740 & 0.754 & 0.751 \\
\hline Observations & 53805 & 53805 & 23864 & 53541 & 53313 & 44895 \\
\hline
\end{tabular}

Notes: $\quad$ Rank based Asset4 z-Scores provided by Thomson Reuter are presented in columns 1 to 4 . Columns 5 and 6 present indicator based scores following the procedure outlined in Dyck et al. (2019) and detailed in Section B.2 in the Appendix. Robust standard errors clustered on the company-level in parentheses: ${ }^{*} p<0.1,{ }^{* *} p<0.05,{ }^{* * *}$ $\mathrm{p}<0.01$. 
Table 5: EITI Tax Revenue Share Data

\begin{tabular}{lccccccc}
\hline Country & Years & Observations & Mean & St.dev. & Min & Max & Assassinations \\
\hline Colombia & 5 & 45 & 0.1111 & 0.1096 & 0.0001 & 0.3378 & 5 \\
Ghana & 13 & 138 & 0.0942 & 0.1170 & 0.0000 & 0.4927 & 0 \\
Guatemala & 2 & 23 & 0.0870 & 0.2781 & 0.0000 & 0.9901 & 3 \\
Honduras & 3 & 15 & 0.2000 & 0.2023 & 0.0062 & 0.5156 & 0 \\
Mozambique & 7 & 213 & 0.0329 & 0.1138 & 0.0000 & 0.9311 & 0 \\
Papua New Guinea & 5 & 40 & 0.1250 & 0.1822 & 0.0000 & 0.6291 & 1 \\
Peru & 13 & 331 & 0.0393 & 0.0796 & 0.0000 & 0.7864 & 28 \\
Philippines & 5 & 144 & 0.0347 & 0.0661 & 0.0000 & 0.4379 & 7 \\
Sierra Leone & 11 & 132 & 0.0833 & 0.1026 & 0.0006 & 0.4671 & 1 \\
\hline
\end{tabular}

Notes: The number of events corresponds to the assassination events that can be matched to both, private and publicly traded mining companies with EITI tax records. 
Table 6: Tax Revenue Shares and the Likelihood to observe Assassinations

\begin{tabular}{|c|c|c|c|c|}
\hline & \multicolumn{4}{|c|}{ Dependent Variable: Assassination } \\
\hline & (1) & (2) & (3) & (4) \\
\hline \multirow[t]{2}{*}{ Tax share } & $0.138^{*}$ & $0.174^{* *}$ & $0.174^{* *}$ & $0.181^{* *}$ \\
\hline & $(0.073)$ & $(0.073)$ & $(0.074)$ & $(0.075)$ \\
\hline Country FE & & $x$ & $x$ & \\
\hline Year FE & & & $x$ & \\
\hline Country $\times$ Year FE & & & & $x$ \\
\hline R-square & 0.006 & 0.051 & 0.080 & 0.143 \\
\hline Observations & 1081 & 1081 & 1081 & 1081 \\
\hline
\end{tabular}

Notes: The Tax Share is defined as the taxes and royalties paid by a corporation to the host country government divided by the total tax and royalty revenues received from the mining industry. Robust standard errors clustered on the company-country level in parentheses: ${ }^{*} \mathrm{p}<0.1,{ }^{* *} \mathrm{p}<0.05,{ }^{* * *} \mathrm{p}<0.01$. 


\section{References}

Acemoglu, D., Hassan, T. A., and Tahoun, A. (2017). The power of the street: evidence from Egypt's Arab Spring. Review of Financial Studies, 31(1):1-42.

Acemoglu, D., Johnson, S., Kermani, A., Kwak, J., and Mitton, T. (2016). The value of connections in turbulent times: Evidence from the United States. Journal of Financial Economics, 121(2):368-391.

Acemoglu, D. and Robinson, J. A. (2020). The narrow corridor: States, societies, and the fate of liberty. Penguin Books.

Aggarwal, R., Erel, I., Ferreira, M., and Matos, P. (2011). Does governance travel around the world? Evidence from institutional investors. Journal of Financial Economics, 100(1):154-181.

Au, S.-Y., Dong, M., and Tremblay, A. (2019). Me Too: Does Workplace Sexual Harassment Hurt Firm Value? SSRN Electronic Journal.

Barrot, J.-N. and Sauvagnat, J. (2016). Input Specificity and the Propagation of Idiosyncratic Shocks in Production Networks. The Quarterly Journal of Economics, 131(3):1543-1592.

Berman, N., Couttenier, M., Rohner, D., and Thoenig, M. (2017). This mine is mine! How minerals fuel conflicts in africa. American Economic Review, 107(6):1564-1610.

Birz, G. and Lott Jr, J. R. (2011). The effect of macroeconomic news on stock returns: New evidence from newspaper coverage. Journal of Banking \& Finance, 35(11):2791-2800.

Boehmer, E., Masumeci, J., and Poulsen, A. B. (1991). Event-study methodology under conditions of event-induced variance. Journal of Financial Economics, 30(2):253-272.

Borelli-Kjaer, M., Moehl Schack, L., and Nielsson, U. (2021). \#MeToo: Sexual harassment and company value. Journal of Corporate Finance, 67:101875.

Brysk, A. (1993). From above and below: Social movements, the international system, and human rights in Argentina. Comparative Political Studies, 26(3):259-285.

Bushee, B. J., Core, J. E., Guay, W., and Hamm, S. J. W. (2010). The role of the business press as an information intermediary. Journal of Accounting Research, 48(1):1-19.

Business and Human Rights Clinic (2018). Pension Funds and Human Rights: A Study of Human Rights Considerations of Pension Funds. Technical report, New York City, NY.

Business and Human Rights Resource Centre (2021). Just recovery in peril: Human Rights Defenders face increasing risk during COVID-19. Technical report.

Butt, N., Lambrick, F., Menton, M., and Renwick, A. (2019). The supply chain of violence. Nature Sustainability, 2(8):742-747.

Campa, P. (2018). Press and leaks: Do newspapers reduce toxic emissions? Journal of Environmental Economics and Management, 91:184-202. 
Capelle-Blancard, G. and Petit, A. (2019). Every little helps? ESG news and stock market reaction. Journal of Business Ethics, 157(2):543-565.

Cella, C., Ellul, A., and Giannetti, M. (2013). Investors' Horizons and the Amplification of Market Shocks. Review of Financial Studies, 26(7):1607-1648.

Cengiz, D., Dube, A., Lindner, A., and Zipperer, B. (2019). The effect of minimum wages on lowwage jobs. The Quarterly Journal of Economics, 134(3):1405-1454.

Chaney, E. (2008). Assessing pacification policy in Iraq: Evidence from Iraqi financial markets. Journal of Comparative Economics, 36(1):1-16.

Chen, T., Dong, H., and Lin, C. (2020). Institutional shareholders and corporate social responsibility. Journal of Financial Economics, 135(2):483-504.

Christensen, D. and Hausman, D. K. (2016). Measuring the Economic Effect of Alien Tort Statute Liability. The Journal of Law, Economics, and Organization, 32(4):794-815.

Clark, David and Regan, Patrick (2016). Mass Mobillization Data project protests against governments, all countries, 1990-2020. https://dataverse.harvard.edu/dataverse/MMdata https://doi.org/10.7910/DVN/HTTWYL, Binghamton University.

Collier, P. and Hoeffler, A. (2004). Greed and grievance in civil war. Oxford economic papers, 56(4):563595.

Cousins, P., Dutordoir, M., Lawson, B., and Neto, J. Q. F. (2020). Shareholder Wealth Effects of Modern Slavery Regulation. Management Science, forthcoming.

Couttenier, M. and Hatte, S. (2016). Mass media effects on non-governmental organizations. Journal of Development Economics, 123:57-72.

Cui, B. and Docherty, P. (2020). Stock Price Overreaction to ESG Controversies. MCFS Working Paper 01-20.

Dai, L., Parwada, J. T., and Zhang, B. (2015). The governance effect of the media's news dissemination role: Evidence from insider trading. Journal of Accounting Research, 53(2):331-366.

DellaVigna, S. and La Ferrara, E. (2010). Detecting Illegal Arms Trade. American Economic Journal: Economic Policy, 2(4):26-57.

DeMeritt, J. H. R. (2012). International Organizations and Government Killing: Does Naming and Shaming Save Lives? International Interactions, 38(5):597-621.

Do, Q.-A., Galbiati, R., Marx, B., and Ortiz Serrano, M. A. (2020). J'accuse! Antisemitism and financial markets in the time of the Dreyfus affair. CEPR Discussion Papers 14826.

Doyle, C. and Whitmore, A. (2014). Indigenous peoples and the extractive sector: towards a rights respecting engagement. Baguio: Tebtebba, PIPLinks and Middlesex University.

Dube, A., Kaplan, E., and Naidu, S. (2011). Coups, corporations, and classified information. Quarterly Journal of Economics, 126(3). 
Dyck, A., Lins, K. V., Roth, L., and Wagner, H. F. (2019). Do institutional investors drive corporate social responsibility? International evidence. Journal of Financial Economics, 131(3):693-714.

Dyck, A., Morse, A., and Zingales, L. (2010). Who blows the whistle on corporate fraud? Journal of Finance, 65(6):2213-2253.

Dyck, A., Volchkova, N., and Zingales, L. (2008). The Corporate Governance Role of the Media: Evidence from Russia. The Journal of Finance, 63(3):1093-1135.

Eisensee, T. and Strömberg, D. (2007). News droughts, news floods, and U. S. disaster relief. Quarterly Journal of Economics, 122(2):693-728.

Enikolopov, R., Petrova, M., and Sonin, K. (2018). Social Media and Corruption. American Economic Journal: Applied Economics, 10(1):150-174.

Fang, L. and Peress, J. (2009). Media coverage and the cross-section of stock returns. Journal of Finance, 64(5):2023-2052.

Ferraz, C. and Finan, F. (2008). Exposing corrupt politicians: the effects of Brazil's publicly released audits on electoral outcomes. Quarterly Journal of Economics, 123(2):703-745.

Ferreira, M. A. and Matos, P. (2008). The colors of investors' money: The role of institutional investors around the world. Journal of Financial Economics, 88(3):499-533.

Fisman, R. (2001). Estimating the value of political connections. American Economic Review, 91(4):10951102.

Fukuyama, F. (2016). Governance: What Do We Know, and How Do We Know It? Annual Review of Political Science, 19:89.

Gao, P., Lee, C., and Murphy, D. (2020). Financing dies in darkness? The impact of newspaper closures on public finance. Journal of Financial Economics, 135(2):445-467.

Gargano, A., Rossi, A. G., and Wermers, R. (2017). The Freedom of Information Act and the Race Toward Information Acquisition. Review of Financial Studies, 30(6):2179-2228.

Girardi, D. (2020). Partisan Shocks and Financial Markets: Evidence from Close National Elections. American Economic Journal: Applied Economics, 12(4):224-252.

Global Justice Now (2018). Ending corporate impunity - The struggle to bring about a binding UN treaty on transnational corporations and human rights. Technical report, London.

Greene, B. B. (1983). A Note on Relevant Comparisons of Corporations and Countries. The American Journal of Economics and Sociology, 42(1):39-43.

Griffin, J. M., Hirschey, N. H., and Kelly, P. J. (2011). How important is the financial media in global markets? Review of Financial Studies, 24(12):3941-3992.

Guidolin, M. and La Ferrara, E. (2007). Diamonds are forever, wars are not: Is conflict bad for private firms? American Economic Review, 97(5):1978-1993. 
Guidolin, M. and La Ferrara, E. (2010). The economic effects of violent conflict: Evidence from asset market reactions. Journal of Peace Research, 47(6):671-684.

Hafner-Burton, E. M. (2008). Sticks and stones: Naming and shaming the human rights enforcement problem. International Organization, 62(4):689-716.

Hale, T. (2020). Transnational Actors and Transnational Governance in Global Environmental Politics. Annual Review of Political Science, 23(1):203-220.

Hamm, B., Schax, A., and Scheper, C. (2013). Human rights impact assessment of the Tampakan copper-gold project. Mindanao, Philippines, Aachen/Luzern: Bischöfliches Hilfswerk MISEREOR eV \& Fastenopfer.

Harrison, A. and Scorse, J. (2010). Multinationals and Anti-sweatshop Activism. American Economic Review, 100(1):247-73.

Hearon, A., Zorob, M., Regalia, S., and Business \& Human Rights Resource Centre (2020). Corporate Human Rights Litigation: Trends from 200 Seminal Lawsuits.

Hendershott, T., Livdan, D., and Schürhoff, N. (2015). Are institutions informed about news? Journal of Financial Economics, 117(2):249-287.

Herron, M. C. (2000). Estimating the Economic Impact of Political Party Competition in the 1992 British Election. American Journal of Political Science, 44(2):326-337.

Hill Jr, D. W., Moore, W. H., and Mukherjee, B. (2013). Information Politics Versus Organizational Incentives: When Are Amnesty International's "Naming and Shaming" Reports Biased? International Studies Quarterly, 57(2):219-232.

Holden, W. N. and Jacobson, R. D. (2012). Mining and Natural Hazard Vulnerability in the Philippines: Digging to Development or Digging to Disaster? Anthem Press.

Huang, A. G., Tan, H., and Wermers, R. (2020). Institutional Trading around Corporate News: Evidence from Textual Analysis. Review of Financial Studies, 33(10):4627-4675.

Huber, K., Lindenthal, V., and Waldinger, F. (2021). Discrimination, managers, and firm performance: Evidence from "aryanizations" in nazi germany. Journal of Political Economy, 129(9):2455-2503.

Imai, S., Gardner, L., and Weinberger, S. (2017). The'Canada Brand': Violence and Canadian mining companies in Latin America. Osgoode Legal Studies Research Paper, (17).

Kappel, V., Schmidt, P., and Ziegler, A. (2009). Human rights abuse and corporate stock performance-An event study analysis.

Keck, M. E. and Sikkink, K. (1998). Activists beyond borders : advocacy networks in international politics. Ebook central. Ithaca, New York.

Keck, M. E. and Sikkink, K. (1999). Transnational advocacy networks in international and regional politics. International Social Science Journal, 51(159):89-101. 
Keith, K. A., Handler, A., Pinkham, M., Magliozzi, C., McDuffie, J., and O'Connor, B. (2017). Identifying civilians killed by police with distantly supervised entity-event extraction. arXiv preprint arXiv:1707.07086.

Khagram, S., Riker, J. V., and Sikkink, K. (2002). Restructuring world politics : transnational social movements, networks and norms. Social movements, protest, and contention. University of Minnesota Press, Minneapolis.

Klymak, M. (2020). The trade effects of the information provision about forced and child labor. TRiSS Working Paper Series TRiSS-WPS-05-2020, Dublin, Ireland.

Knight, B. (2006). Are policy platforms capitalized into equity prices? Evidence from the Bush/Gore 2000 Presidential Election. Journal of Public Economics, 90(4-5):751-773.

Knutsen, C. H., Kotsadam, A., Olsen, E. H., and Wig, T. (2017). Mining and local corruption in Africa. American Journal of Political Science, 61(2):320-334.

Kolari, J. W. and Pynnönen, S. (2010). Event study testing with cross-sectional correlation of abnormal returns. Review of Financial Studies, 23(11):3996-4025.

Kolari, J. W. and Pynnönen, S. (2011). Nonparametric rank tests for event studies. Journal of Empirical Finance, 18(5):953-971.

Krüger, P. (2015). Corporate goodness and shareholder wealth. Journal of Financial Economics, 115(2):304-329.

Kuhnen, C. M. and Niessen, A. (2012). Public opinion and executive compensation. Management Science, 58(7):1249-1272.

Larreguy, H., Marshall, J., and Snyder James M, J. (2020). Publicizing malfeasance: When the local media structure facilitates electoral accountability in Mexico. The Economic Journal.

Li, W. and Lie, E. (2006). Dividend changes and catering incentives. Journal of Financial Economics, 80(2):293-308.

Liu, B. and McConnell, J. J. (2013). The role of the media in corporate governance: Do the media influence managers' capital allocation decisions? Journal of Financial Economics, 110(1):1-17.

Luechinger, S. and Moser, C. (2014). The value of the revolving door: Political appointees and the stock market. Journal of Public Economics, 119:93-107.

MacKinlay, A. C. (1997). Event studies in economics and finance. Journal of Economic Literature, 35(1):13-39.

Mccahery, J. A., Sautner, Z., and Starks, L. T. (2016). Behind the Scenes: The Corporate Governance Preferences of Institutional Investors. Journal of Finance, 71(6):2905-2932.

MCENTIRE, K. J. O., LEIBY, M., and KRAIN, M. (2015). Human Rights Organizations as Agents of Change: An Experimental Examination of Framing and Micromobilization. American Political Science Review, 109(3):407-426. 
McGrew, A. and Held, D., editors (2002). Governing globalization: power, authority and global governance. Polity Press.

Meernik, J., Aloisi, R., Sowell, M., and Nichols, A. (2012). The Impact of Human Rights Organizations on Naming and Shaming Campaigns. Journal of Conflict Resolution, 56(2).

Miller, G. S. (2006). The press as a watchdog for accounting fraud. Journal of Accounting Research, 44(5):1001-1033.

Murdie, A. and Peksen, D. (2014). The impact of human rights INGO shaming on humanitarian interventions. Journal of Politics, 76(1):215-228.

Olken, B. A. (2009). Do Television and Radio Destroy Social Capital? Evidence from Indonesian Villages. American Economic Journal: Applied Economics, 1(4):1-33.

Palomino, F., Renneboog, L., and Zhang, C. (2009). Information salience, investor sentiment, and stock returns: The case of British soccer betting. Journal of Corporate Finance, 15(3):368-387.

Patell, J. M. (1976). Corporate forecasts of earnings per share and stock price behavior: Empirical test. Journal of Accounting Research, pages 246-276.

Peksen, D., Peterson, T. M., and Drury, A. C. (2014). Media-driven Humanitarianism? News Media Coverage of Human Rights Abuses and the Use of Economic Sanctions. International Studies Quarterly, 58(4):855-866.

Peress, J. (2014). The Media and the Diffusion of Information in Financial Markets: Evidence from Newspaper Strikes. Journal of Finance, 69(5):2007-2043.

Prat, A. and Strömberg, D. (2013). The Political Economy of Mass Media. In Acemoglu, D., Dekel, E., and Arellano, M., editors, Advances in Economics and Econometrics: Tenth World Congress: Volume 2: Applied Economics, volume 2 of Econometric Society Monographs, pages 135-187. Cambridge University Press, Cambridge.

Puckett, A. and Yan, X. S. (2011). The Interim Trading Skills of Institutional Investors. Journal of Finance, 66(2):601-633.

Qin, B., Strömberg, D., and Wu, Y. (2017). Why Does China Allow Freer Social Media? Protests versus Surveillance and Propaganda. Journal of Economic Perspectives, 31(1):117-140.

Ramos, H., Ron, J., and Thoms, O. N. (2007). Shaping the northern media's human rights coverage, 1986-2000. Journal of Peace Research, 44(4).

Ruggie, J. G. (2013). Just Business: Multinational Corporations and Human Rights. Norton Global Ethics Series. W. W. Norton.

Ruggie, J. G. (2018). Multinationals as global institution: Power, authority and relative autonomy. Regulation \& Governance, 12(3):317-333.

Scholte, J. A. (2002). Civil Society and Democracy in Global Governance. Global Governance, 8(3):281304. 
Schrempf-Stirling, J. and Wettstein, F. (2017). Beyond Guilty Verdicts: Human Rights Litigation and its Impact on Corporations' Human Rights Policies. Journal of Business Ethics, 145(3):545-562.

Sending, O. J. and Neumann, I. B. (2006). Governance to Governmentality: Analyzing NGOs, States, and Power. International Studies Quarterly, 50(3):651-672.

Shapira, R. and Zingales, L. (2017). Is Pollution Value-Maximizing? The DuPont Case. Technical Report 23866.

Snyder, J. M. and Strömberg, D. (2010). Press Coverage and Political Accountability. Journal of Political Economy, 118(2):355-408.

Spohr, M. (2016). Human rights risks in mining: A baseline study. MPFPR, Bundesanstalt für Geowissenschaften und Rohstoffe (BGR).

UN Working Group on Business and Human Rights (2021). Taking Stock of Investor Implementation of the UN Guiding Principles on Business and Human Rights. Adendum report of the Working Group on the issue of human rights and transnational corporations and other business enterprises A/HRC/47/39/Add.2, Geneva, Switzerland.

Wagner, A. F., Zeckhauser, R. J., and Ziegler, A. (2018). Company stock price reactions to the 2016 election shock: Trump, taxes, and trade. Journal of Financial Economics, 130(2):428-451.

Zeume, S. (2017). Bribes and Firm Value. The Review of Financial Studies, 30(5):1457-1489.

Zingales, L. (2017). Towards a Political Theory of the Firm. The Journal of Economic Perspectives, 31(3):113-130. 


\section{A Technical Appendix}

\section{A.1 Test Statistics}

For ease of notation (and without loss of generality), we present test statistics for one particular aggregation period from $\tau_{1}$ to $\tau_{2}$ in this section, where $T_{1}<\tau_{1} \leq \tau_{2} \leq T_{2}{ }^{55}$

\section{Normality}

Following MacKinlay (1997), the null hypothesis $H_{0}$ of no event effect under the assumption of normally distributed security returns and absence of clustering can be tested using

$$
\theta_{1}=\frac{\overline{C A R}}{\sigma(\overline{C A R})} \sim N(0,1),
$$

with $\overline{C A R}$ and $\sigma(\overline{C A R})$ defined in (5) and (6).

\section{BMP}

Given the estimated abnormal and cumulative abnormal returns and their sample variance in (3)(6), the scaled abnormal (SAR) and cumulative abnormal (SCAR) returns during the event window $\tau=T_{1}+1, \ldots, T_{2}$ are defined as: ${ }^{56}$

$$
\begin{aligned}
S A R_{i e \tau} & =\frac{\widehat{A R}_{i e \tau}}{\sigma\left(\widehat{A R}_{i e \tau}\right)} \\
S C A R_{i e} & =\frac{\widehat{C A R}_{i e}}{\sigma\left(\widehat{C A R}_{i e}\right)} .
\end{aligned}
$$

Boehmer et al. (1991) define the following test-static:

$$
t_{B M P}=\frac{\overline{S C A R} \sqrt{N}}{\sigma\left(S C A R_{i e}\right)},
$$

where $\overline{S C A R}$ constitutes the average scaled abnormal return on event day $\tau$ and $\sigma\left(S C A R_{i e}\right)$ the cross-sectional standard deviation of the SCAR: ${ }^{57}$

$$
\begin{aligned}
\overline{S C A R} & =\frac{1}{N} \sum_{j=1}^{N} S C A R_{i e} \\
\sigma\left(S C A R_{i e}\right) & =\sqrt{\frac{1}{N-1} \sum_{j=1}^{N}\left(S C A R_{i e}-\overline{S C A R}\right)^{2} .}
\end{aligned}
$$

The rescaling of the SCARs by the cross-sectional standard deviation makes the BMP $t$-statistic robust to event-induced volatility.

\section{ADJ-BMP}

Kolari and Pynnönen (2010) relax the assumption of no clustering by allowing for covariance between the SARs. Under the assumption of equal variance of SARs, the authors show that the "true"

\footnotetext{
${ }^{55}$ This allows us to drop the suffix $\left(\tau_{1}, \tau_{2}\right)$.

${ }^{56}$ Note that the definition for SARs is equivalent during the estimation window $\tau=T_{0}+1, \ldots, T_{1}$.

${ }^{57}$ Note that (A.4)-(A.6) are equivalently calculated for the $S A R$.
} 
cross-sectional variance of the SARs in this setting boils down to:

$$
s^{2}\left(S A R_{i e}\right)=\frac{\sigma^{2}\left(S A R_{i e}\right)}{N}(1+(N-1) \bar{r}),
$$

where $\sigma^{2}\left(S A R_{i e}\right)$ is given in (A.6) and $\bar{r}$ is the average of the sample cross-correlations of the ARs during the estimation window. Using the variance formula in (A.7) the adjusted BMP (ADJ-BMP) $t$ statistic is:

$$
t_{A D J-B M P}=\frac{\overline{S A R}}{S\left(S A R_{i e}\right)}=\frac{\overline{S A R} \sqrt{N}}{\sigma\left(S A R_{i e}\right) \sqrt{1+(N-1) \bar{r}}}=t_{B M P} \sqrt{\frac{1-\bar{r}}{1+(N-1) \bar{r}}}
$$

The test statistic is equivalent for SCARs under the assumption of the square-root rule of the standard deviation of returns over different return periods (s. Kolari and Pynnönen, 2010, p. 4003).

\section{GRANK}

Kolari and Pynnönen (2011) re-standardize the SCARs defined in (A.3) using the cross-section standard deviation of the SCARs defined in (A.6) to transform the SCAR to a random variable with zero mean and unit variance just as the other SARs defined in (A.2) ${ }^{58}$

$$
S C A R_{i e}^{*}=\frac{S C A R_{i e}}{\sigma\left(S C A R_{i e}\right)} .
$$

This allows Kolari and Pynnönen (2011) to define the generalized standardized abnormal return $\left(G S A R_{i e \tau}\right)$ as:

$$
G S A R_{i e \tau}= \begin{cases}S C A R_{i e}^{*} & \text { for } \tau=\tau_{1}, \ldots, \tau 2 \\ S A R_{i e \tau} & \text { for } \tau=T_{0}+1, \ldots, T_{1} .\end{cases}
$$

Intuitively, the CAR period is treated as if there was only one day, the "cumulative return day" at $\tau=0$ (Kolari and Pynnönen, 2011). The demeaned standardized abnormal ranks $\left(U_{i e \tau}\right)$ of the GSARs are:

$$
U_{i e \tau}=\frac{\operatorname{Rank}\left(G S A R_{i e \tau}\right)}{T+1}-\frac{1}{2}
$$

where $\tau \in \mathcal{T}=\left\{T_{0}+1, \ldots T_{1}, 0\right\}$ and $T$ is equal to the length of the estimation window plus the "cumulative return day", i.e. $T=L_{1}+1=T_{1}-T_{0}+1$.

Since $U_{i e \tau}$ constitutes the demeaned rank of the GSAR, the null hypothesis of having no mean event effect, i.e. $H_{0}: E[\overline{C A R}]=0$, is equal to the expected rank of the GSAR being equal to zero for all company-event pairs on the "cumulative return day" $\left(E\left[U_{i e 0}\right]=0\right)$. Kolari and Pynnönen (2011) show that the t-statistic for testing this null hypothesis is:

$$
t_{\text {GRANK }}=Z\left(\frac{T-2}{T-1-Z^{2}}\right)^{\frac{1}{2}}
$$

where

$$
Z=\frac{\bar{U}_{0}}{\sigma(\bar{U})}
$$

\footnotetext{
${ }^{58}$ In case of event-day clustering, it may be preferable to use the cross-correlation robust standard deviation $s^{2}\left(S C A R_{i e}\right)$. Kolari and Pynnönen (2010) note however that this substitution should not substantially alter the results for rank tests (s. footnote 7 on p. 4008).
} 
with

$$
\begin{aligned}
\sigma(\bar{U}) & =\sqrt{\frac{1}{T} \sum_{t \in \mathcal{T}} \frac{N_{\tau}}{N} \bar{U}_{\tau}^{2}} \\
\bar{U}_{\tau} & =\frac{1}{N_{\tau}} \sum_{j=1}^{N} U_{i e \tau}
\end{aligned}
$$

where $N_{\tau}$ is the number of non-missing (valid) GSARs available at $\tau \in \mathcal{T}=\left\{T_{0}+1, \ldots T_{1}, 0\right\}$ and $N$ is the number of all company-event pairs. 


\section{B Data Appendix}

\section{B.1 Assassination Dataset}

In this appendix we describe in detail the compilation and coding of assassination events. The list of 354 extra-judicial killings of mining activists was retrieved from a range of sources that can broadly be categorized into:

1. We obtain information from NGOs and human rights associations such as "Global Witness" and "Amnesty International", "Front Line Defenders" or "Bulatlat".

2. We use international full-text newspaper archives (e.g. Gale full-texts collections of the International Herald Tribune and Associated Press wire archives) and prominent APIs (e.g. Guardian) to locate events via algorithmic searches. Specifically, we query the APIs and news archives for articles that contain a combination of "activist" keywords (activist, campaigner, indigenous, etc. and additionally variations of mining) and "assassination" keywords (kill, assassin, abduct, etc.). Both keyword lists were chosen semi-automatically by looking up cosine similarities from the web2vec word vectors pre-trained on the Google News data set (c. for instance Keith et al., 2017). ${ }^{59}$ The (deduplicated) list of returned articles is then manually inspected for relevant events. Note that we also experimented with training text classification models to automatically detect relevant articles. The specificity of our events in combination with the infrequent reporting, however, does not allow for the construction of a sufficient training corpus. Moreover, the data collection process revealed that many assassination events are covered by local newspapers or NGO reports, usually not available in news archives and APIs. These supplementary sources are described below.

3. We search local newspapers such as "La Republica" in Peru, "El Universo" in Ecuador, "El Pais" in Mexico or "El Espectador" in Colombia.

4. We rely on published books (e.g. Holden and Jacobson, 2012; Doyle and Whitmore, 2014) and studies (e.g. Imai et al., 2017; Spohr, 2016; Hamm et al., 2013). These sources often provide supplementary information on cases such as event classifications - i.e. mining, deforestation - and mining project/company associations. For instance, Holden and Jacobson (2012) provide a list of mining projects and their owners at the time in chapter 2 that can be matched with the mining projects mentioned in association with killings of anti-mining activists in chapter 5 .

After locating assassination events of opposition leaders, indigenous and tribal leaders, and local environmentalists we ensure that the event is indeed linked to the victim's opposition to a mining project, i.e. we require at least one source to state that opposition to mining is the (suspected) reason for the attack. In particular, for 211 of the 565 killings of activists we collected we are not able to establish a link to mining opposition. These 211 cases either comprise assassinations in relation to other sectors such as logging, pipelines, and hydro dams or the source articles provides no conclusive information on the characteristics of the victim's activism. Next, we establish company "ties" for the 354 "mining related" events. We implement the following matching procedure:

\footnotetext{
${ }^{59}$ The Google News data set comprises about 100 billion words. The pre-trained web2vec word vectors can be found here: https://code.google.com/archive/p/word2vec/.
} 
1. If a mining company is named in at least one article we check if the reported company is publicly traded. As a convention, we consider only the "downstream" publicly treated companies for the case that the named mining company is not the global ultimate owner, except if the global corporate owner is specifically tied to the event in one of the articles. For instance, if the article states that the assassination is linked to a mining project owned by AngloGold Ashanti, a publicly traded mining company ultimately owned by Anglo American, we do not classify Anglo American as being "associated" with the event unless a source article specifically mentions Anglo American as well. Moreover, we cross-validate-to the best of our abilities-if the company was active in the country at the time of the event by inspectingamong others-annual reports. For the case that the named company is privately owned, we record the company name and do not further discern the ownership structure by private individuals.

2. If the stated mining company is not publicly traded, we examine if the company constitutes a subsidiary or joint venture of publicly traded companies at the time of the event by consulting-among others-company websites, annual reports, SEC documents and business registers. In case no company but a specific mining project could be identified, we rely on the aforementioned sources to establish the ownership structure of the mining project at the time of the event. In both cases, all owners are matched to the respective event. If a private company is the (partial) owner of a subsidiary/joint venture, the name of the company is recorded, not the name of the private owners of the company.

Apart from the company information, we hand-code (i) the precise event date, (ii) the name and number of the victims (iii) the geolocation of the assassination event ${ }^{60}$ (iv) the event "circumstances" (e.g. if the assassination attempt was successful or if it happened during a protest) (v) and-if known-the perpetrator (e.g. police, paramilitary forces, private security guards, hitmen).

\section{B.2 ESG Scores Dyck et al. (2019)}

We follow Dyck et al. (2019) to create "equally weighted" indicator variables from based on the ASSET4 ESG environmental and social indicator values. In particular, for questions with a positive direction (i.e., a "yes" answer or a greater number is associated with better social performance), we translate the answers to $\mathrm{Y} / \mathrm{N}$ questions into $0(\mathrm{~N})$ and $1(\mathrm{Y})$; the answers to double $\mathrm{Y} / \mathrm{N}$ questions into $0(\mathrm{NN}), 0.5$ (YN or $\mathrm{NY}$ ), and $1(\mathrm{YY})$; and the answers to numerical questions into 0 (value is less (or equal) than zero; or value is less (or equal) than the median; see also column "Translation Numeric Values") and 1 (value is greater than zero; or value is greater than the median; see also column "Translation Numeric Values"). For questions with a negative direction (i.e., a "no" answer or a lower number is associated with better social performance), the opposite coding applies. ${ }^{61}$

\footnotetext{
${ }^{60}$ For most assassination events, we are able to establish the exact assassination location. If the location is not known precisely, but only at the municipality level, we pick (approximately) the centroid of the municipality.

${ }^{61}$ Note that we compared to Dyck et al. (2019) do not consider the indicator "Total Donations" (so_so_co_o01_v) due to almost exclusively missing values and use the "Effective Tax Rate" indicator instead of "Income Taxes", as the latter was not available in the current Asset4 database (data last retrieved on 26 September 2021).
} 
Table B.1: Social Indicator Variables

\begin{tabular}{|c|c|c|c|c|c|}
\hline & & Description & Direction & $\begin{array}{l}\text { Question } \\
\text { Type }\end{array}$ & $\begin{array}{l}\text { Translation } \\
\text { Numeric } \\
\text { Values }\end{array}$ \\
\hline A. & $\begin{array}{l}\text { Community } \\
\text { Category }\end{array}$ & & & & \\
\hline 1) & $\begin{array}{l}\text { Bribery, Cor- } \\
\text { ruption, Fraud } \\
\text { Controversies } \\
\text { (so_so_co_o10_v) }\end{array}$ & $\begin{array}{l}\text { Is the company under the } \\
\text { spotlight of the media be- } \\
\text { cause of a controversy linked } \\
\text { to bribery and corruption, po- } \\
\text { litical contributions, improper } \\
\text { lobbying, money laundering, } \\
\text { parallel imports or any tax } \\
\text { fraud? }\end{array}$ & Negative & $\mathrm{Y} / \mathrm{N}$ & \\
\hline 2) & $\begin{array}{l}\text { Business Ethics } \\
\text { Compliance } \\
\text { (so_so_co_o11_v) }\end{array}$ & $\begin{array}{l}\text { All real or estimated penal- } \\
\text { ties, fines from lost court } \\
\text { cases, settlements or cases } \\
\text { not yet settled regarding con- } \\
\text { troversies linked to business } \\
\text { ethics in general, political } \\
\text { contributions or bribery and } \\
\text { corruption, price-fixing or } \\
\text { anti-competitive behaviour, } \\
\text { tax fraud, parallel imports } \\
\text { or money laundering in U.S. } \\
\text { dollars. }\end{array}$ & Negative & Number & Zero \\
\hline 3) & $\begin{array}{l}\text { Corporate Respon- } \\
\text { sibility Awards } \\
\text { (so_so_co_dp074) }\end{array}$ & $\begin{array}{l}\text { Has the company received an } \\
\text { award for its social, ethical, } \\
\text { community, or environmental } \\
\text { activities or performance? }\end{array}$ & Positive & $\mathrm{Y} / \mathrm{N}$ & \\
\hline 4) & $\begin{array}{l}\text { Crisis Management } \\
\text { (so_so_co_o08_v) }\end{array}$ & $\begin{array}{l}\text { Does the company report on } \\
\text { crisis management systems or } \\
\text { reputation disaster recovery } \\
\text { plans to reduce or minimize } \\
\text { the effects of reputation } \\
\text { disasters? }\end{array}$ & Positive & $\mathrm{Y} / \mathrm{N}$ & \\
\hline
\end{tabular}

Continued on next page 
Table B.1: Social Indicator Variables (Continued)

\begin{tabular}{|c|c|c|c|c|c|}
\hline 5) & $\begin{array}{l}\text { Critical Countries, } \\
\text { Indigenous People } \\
\text { Controversies } \\
\text { (so_so_co_o06_v) }\end{array}$ & $\begin{array}{l}\text { Is the company under the } \\
\text { spotlight of the media be- } \\
\text { cause of a controversy linked } \\
\text { to activities in critical, un- } \\
\text { democratic countries that } \\
\text { do not respect fundamental } \\
\text { human rights or to disrespect- } \\
\text { ing the rights of indigenous } \\
\text { people? }\end{array}$ & Negative & $\mathrm{Y} / \mathrm{N}$ & \\
\hline 6) & $\begin{array}{l}\text { Donations } \\
\text { in General } \\
(\text { so_so_co_o02_v) }\end{array}$ & $\begin{array}{l}\text { Does the company make } \\
\text { cash donations? AND Does } \\
\text { the company make in-kind } \\
\text { donations, foster employee } \\
\text { engagement in voluntary } \\
\text { work or provide fund- } \\
\text { ing of community-related } \\
\text { projects through a corporate } \\
\text { foundation? }\end{array}$ & Positive & $\begin{array}{l}\text { Double } \\
\mathrm{Y} / \mathrm{N}\end{array}$ & \\
\hline 7) & $\begin{array}{l}\text { Implementation } \\
\text { (so_so_co_d02_v) }\end{array}$ & $\begin{array}{l}\text { Does the company describe } \\
\text { the implementation of its } \\
\text { community policy through } \\
\text { a public commitment from a } \\
\text { senior management or board } \\
\text { member? AND Does the } \\
\text { company describe the imple- } \\
\text { mentation of its community } \\
\text { policy through the processes } \\
\text { in place? }\end{array}$ & Positive & $\begin{array}{l}\text { Double } \\
\mathrm{Y} / \mathrm{N}\end{array}$ & \\
\hline 8) & $\begin{array}{l}\text { Improvements } \\
\text { (so_so_co_d04_v) }\end{array}$ & $\begin{array}{l}\text { Does the company set specific } \\
\text { objectives to be achieved on } \\
\text { its reputation or its relations } \\
\text { with communities? }\end{array}$ & Positive & $\begin{array}{l}\text { Double } \\
\mathrm{Y} / \mathrm{N}\end{array}$ & \\
\hline 9) & $\begin{array}{l}\text { Effective Tax Rate } \\
\text { (so_so_co_o03_v) }\end{array}$ & $\begin{array}{l}\text { The Effective Tax Rate is } \\
\text { defined as Income Taxes } \\
\text { (Credit) divided by Income } \\
\text { Before Taxes and expressed } \\
\text { as a percentage. If the Income } \\
\text { Tax is a credit, the result is a } \\
\text { Not Meaningful (NM) }\end{array}$ & Positive & Number & Median \\
\hline
\end{tabular}

Continued on next page 
Table B.1: Social Indicator Variables (Continued)

\begin{tabular}{|c|c|c|c|c|c|}
\hline 10) & $\begin{array}{l}\text { Monitoring } \\
\text { (so_so_co_d03_v) }\end{array}$ & $\begin{array}{l}\text { Does the company monitor } \\
\text { its reputation or its relations } \\
\text { with communities? }\end{array}$ & Positive & $\mathrm{Y} / \mathrm{N}$ & \\
\hline 11) & $\begin{array}{l}\text { Patent Infringement } \\
\text { (so_so_co_o07_v) }\end{array}$ & $\begin{array}{l}\text { All real or estimated penal- } \\
\text { ties, fines from lost court } \\
\text { cases, settlements or cases } \\
\text { not yet settled regarding con- } \\
\text { troversies linked to patents } \\
\text { and intellectual property } \\
\text { infringement in U.S. dollars. }\end{array}$ & Negative & Number & Zero \\
\hline 12) & $\begin{array}{l}\text { Policy } \\
(\text { so_so_co_d01_v) }\end{array}$ & $\begin{array}{l}\text { Does the company have } \\
\text { a policy to strive to be a } \\
\text { good corporate citizen or } \\
\text { endorse the Global Sullivan } \\
\text { Principles? AND Does the } \\
\text { company have a policy to } \\
\text { respect business ethics or has } \\
\text { the company signed the UN } \\
\text { Global Compact or follow the } \\
\text { OECD guidelines? }\end{array}$ & Positive & $\begin{array}{l}\text { Double } \\
\mathrm{Y} / \mathrm{N}\end{array}$ & \\
\hline 13) & $\begin{array}{l}\text { Public Health } \\
\text { Controversies } \\
(\text { so_so_co_o09_v) }\end{array}$ & $\begin{array}{l}\text { Is the company under the } \\
\text { spotlight of the media } \\
\text { because of a controversy } \\
\text { linked to public health or } \\
\text { industrial accidents harming } \\
\text { the health \& safety of third } \\
\text { parties (non-employees and } \\
\text { non-customers)? }\end{array}$ & Positive & $\mathrm{Y} / \mathrm{N}$ & \\
\hline
\end{tabular}

B. Human Rights

\begin{tabular}{|c|c|c|c|c|}
\hline 1) & $\begin{array}{l}\text { Child Labour } \\
\text { Controversies } \\
\text { (so_so_hr_o03_v) }\end{array}$ & $\begin{array}{l}\text { Is the company under the } \\
\text { direct or indirect (through } \\
\text { suppliers) spotlight of the me- } \\
\text { dia because of a controversy } \\
\text { linked to child labour? }\end{array}$ & Negative & $\mathrm{Y} / \mathrm{N}$ \\
\hline 2) & $\begin{array}{l}\text { Freedom of Associ- } \\
\text { ation Controversies } \\
\text { (so_so_hr_o02_v) }\end{array}$ & $\begin{array}{l}\text { Is the company under the } \\
\text { direct or indirect (through } \\
\text { suppliers) spotlight of the } \\
\text { media because of a contro- } \\
\text { versy linked to freedom of } \\
\text { association? }\end{array}$ & Negative & $\mathrm{Y} / \mathrm{N}$ \\
\hline
\end{tabular}


Table B.1: Social Indicator Variables (Continued)

\begin{tabular}{|c|c|c|c|c|}
\hline 3) & $\begin{array}{l}\text { Human Rights } \\
\text { Controversies } \\
\text { (so_so_hr_o04_v) }\end{array}$ & $\begin{array}{l}\text { Is the company under the } \\
\text { direct or indirect (through } \\
\text { suppliers) spotlight of the me- } \\
\text { dia because of a controversy } \\
\text { linked to general human } \\
\text { rights issues? }\end{array}$ & Negative & $\mathrm{Y} / \mathrm{N}$ \\
\hline 4) & $\begin{array}{l}\text { Implementation } \\
\text { (so_so_hr_d02_v) }\end{array}$ & $\begin{array}{l}\text { Does the company describe } \\
\text { the implementation of its } \\
\text { human rights policy? }\end{array}$ & Positive & $\mathrm{Y} / \mathrm{N}$ \\
\hline 5) & $\begin{array}{l}\text { Improvements } \\
\text { (so_so_hr_d04_v) }\end{array}$ & $\begin{array}{l}\text { Does the company set specific } \\
\text { objectives to be achieved on } \\
\text { its human rights policy? }\end{array}$ & Positive & $\mathrm{Y} / \mathrm{N}$ \\
\hline 6) & $\begin{array}{l}\text { Monitoring } \\
\text { (so_so_hr_dp021) }\end{array}$ & $\begin{array}{l}\text { Does the company monitor } \\
\text { human rights in its or its } \\
\text { suppliers' facilities? }\end{array}$ & Positive & $\mathrm{Y} / \mathrm{N}$ \\
\hline 7) & $\begin{array}{l}\text { Policy } \\
\text { (so_so_hr_d01_v) }\end{array}$ & $\begin{array}{l}\text { Does the company have } \\
\text { a policy to guarantee the } \\
\text { freedom of association uni- } \\
\text { versally applied independent } \\
\text { of local laws? AND Does the } \\
\text { company have a policy for } \\
\text { the exclusion of child, forced } \\
\text { or compulsory labour? }\end{array}$ & Positive & $\begin{array}{l}\text { Double } \\
\mathrm{Y} / \mathrm{N}\end{array}$ \\
\hline 8) & $\begin{array}{l}\text { Suppliers Social } \\
\text { Impact (so_so_- } \\
\text { hr_dp026 AND } \\
\text { so_so_hr_dp029) }\end{array}$ & $\begin{array}{l}\text { Does the company report or } \\
\text { show to use human rights } \\
\text { criteria in the selection or } \\
\text { monitoring process of its sup- } \\
\text { pliers or sourcing partners? } \\
\text { AND Does the company } \\
\text { report or show to be ready } \\
\text { to end a partnership with a } \\
\text { sourcing partner if human } \\
\text { rights criteria are not met? }\end{array}$ & Positive & $\begin{array}{l}\text { Double } \\
\mathrm{Y} / \mathrm{N}\end{array}$ \\
\hline
\end{tabular}




\section{Additional Figures}

\section{Broadcaster gunned down in the Philippines}

October 19, 2011 1:35 PMEDT

New York, October 19, 2011-A radio commentator and anti-mining tribal activist who was scheduled to launch a new radio station program in a few days was gunned down in the southern Philippines on October 14, news reports said.

Roy Bagtikan Gallego was shot several times by men on a motorcycle as he was riding his motorcycle in Lianga town in Surigao del Sur province, in the southern Philippines, news reports said. The journalist was due to start a new block-time program with 92.7 Smile FM San Francisco, the reports said. Block-timing is a practice whereby a broadcaster leases air time from a radio station and is responsible for bringing in advertising money to cover the expenses of the program. A number of block-time commentators have been killed in the Philippines, according to CPJ research. In 2010, Gallego had hosted a similar program on DxSF San Francisco Radio, news reports said.

"Roy Bagtikan Gallego's death must be investigated and the perpetrators prosecuted," said Bob Dietz, CPJ's Asia program coordinator. "Gallego's death is emblematic of a much larger problem. In the Philippines, journalism and political activism are often conjoined, and the government must address the murders of journalists who use local media to take on controversial issues that threaten not only their lives but the strength of the nation's media."

Local police say they are investigating the death of Gallego, but have reached no conclusions on a possible motive and have not identified suspects, news reports said. Gallego, also a tribal leader of the Manobo tribe, had led the fight against small- and large-scale mining operators whose activities he claimed violated the rights of indigenous people in the region.
Event date

Mining opposition

Mining Project/Company

Name(s) and associations of the victim(s)

"Assassination"/Violent death

Figure C.1: Example Case: Mining Opposition without Company Associations.

Notes: The source article can be found here: https://cpj.org/2011/10/broadcaster-gunneddown-in-philippines / 

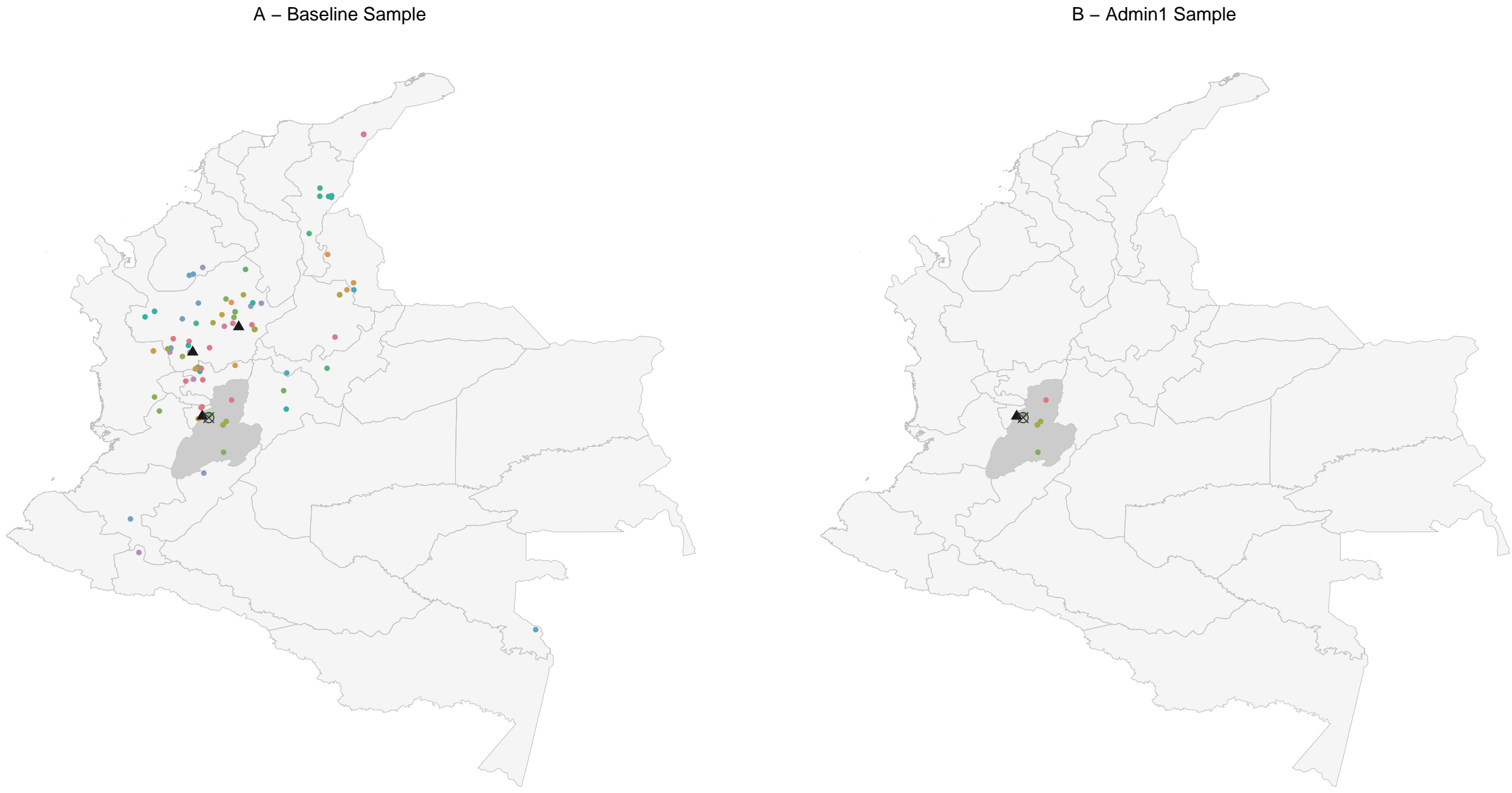

Figure C.2: The Construction of the Control Group - An Example Case from Colombia.

Notes: The map displays the Admin1 regions of mainland Colombia. The dark grey area corresponds to the Admin1 region, where the assassination event took place, while the location itself is marked by the black circle cross. Triangles (dots) correspond to mining projects owned by companies linked to the assassnation event (or not), with colours differentiating corporate owner(s). Panel A displays all mining projects in the SNL database with ownership information in the event year (here: 2013). Panel B restricts the mining projects to the ones present in the Admin1 region of the assassination location. 


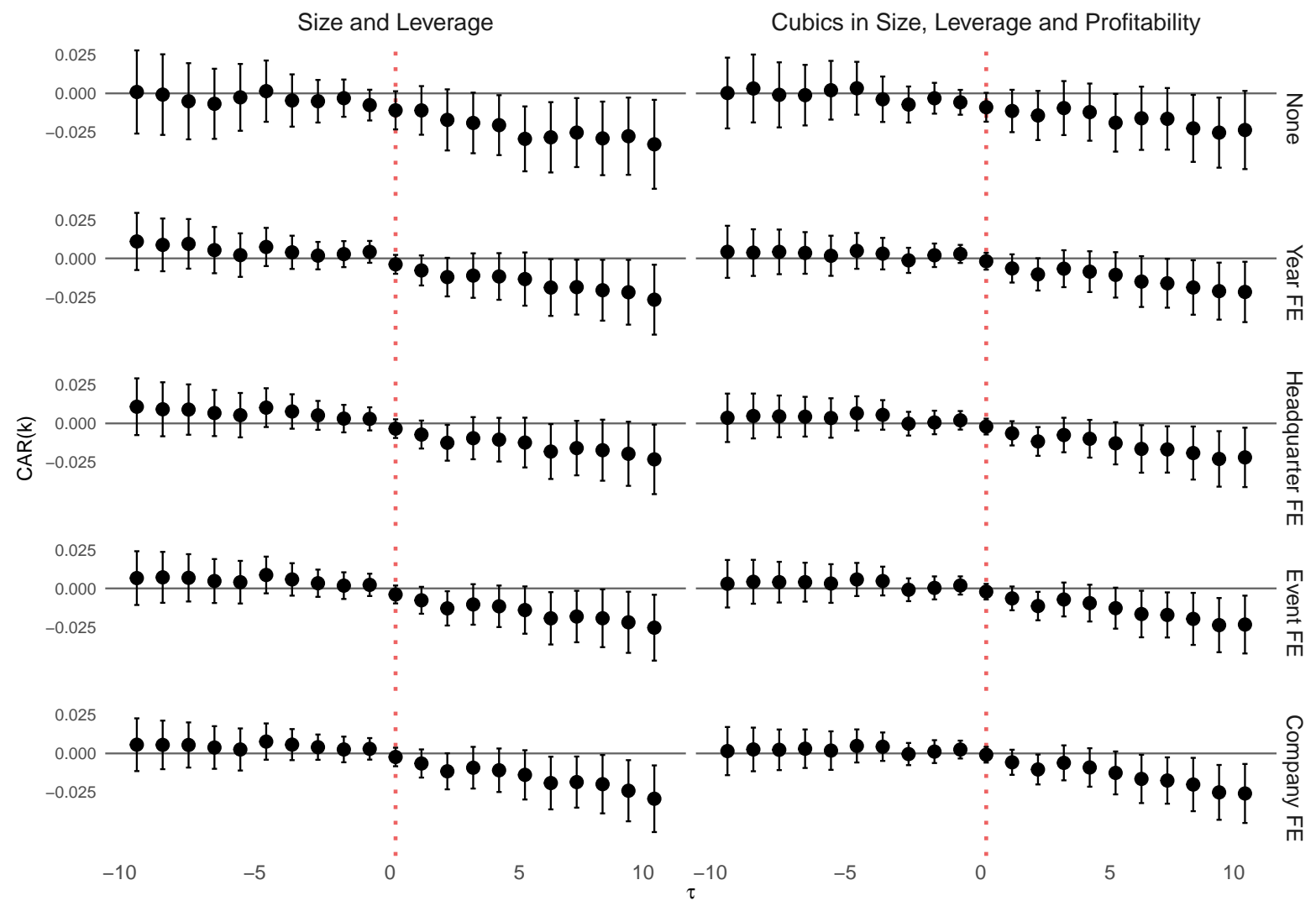

Figure C.3: The Treatment Effect of Assassination Events on Mining Companies.

Notes: The coefficients when regressing the respective cumulative abnormal return (CAR) on an indicator for being tied to an assassination event is represented by the black dots. The horizontal axis label denotes the trading days before and after the event on $\tau=0$. CARs are aggregated backwards before the event date and forwards starting with the event date. E.g. -5 refers to the CAR between -1 and -5 while 5 refers to the CAR between 0 and 5 . Each cell corresponds to a different regression specification, with columns capturing control variable definitions and rows the inclusion of various fixed effects. In total the coefficients of 210 regressions are displayed. 95\% confidence intervals using robust standard errors clustered on the event-level are depicted. 


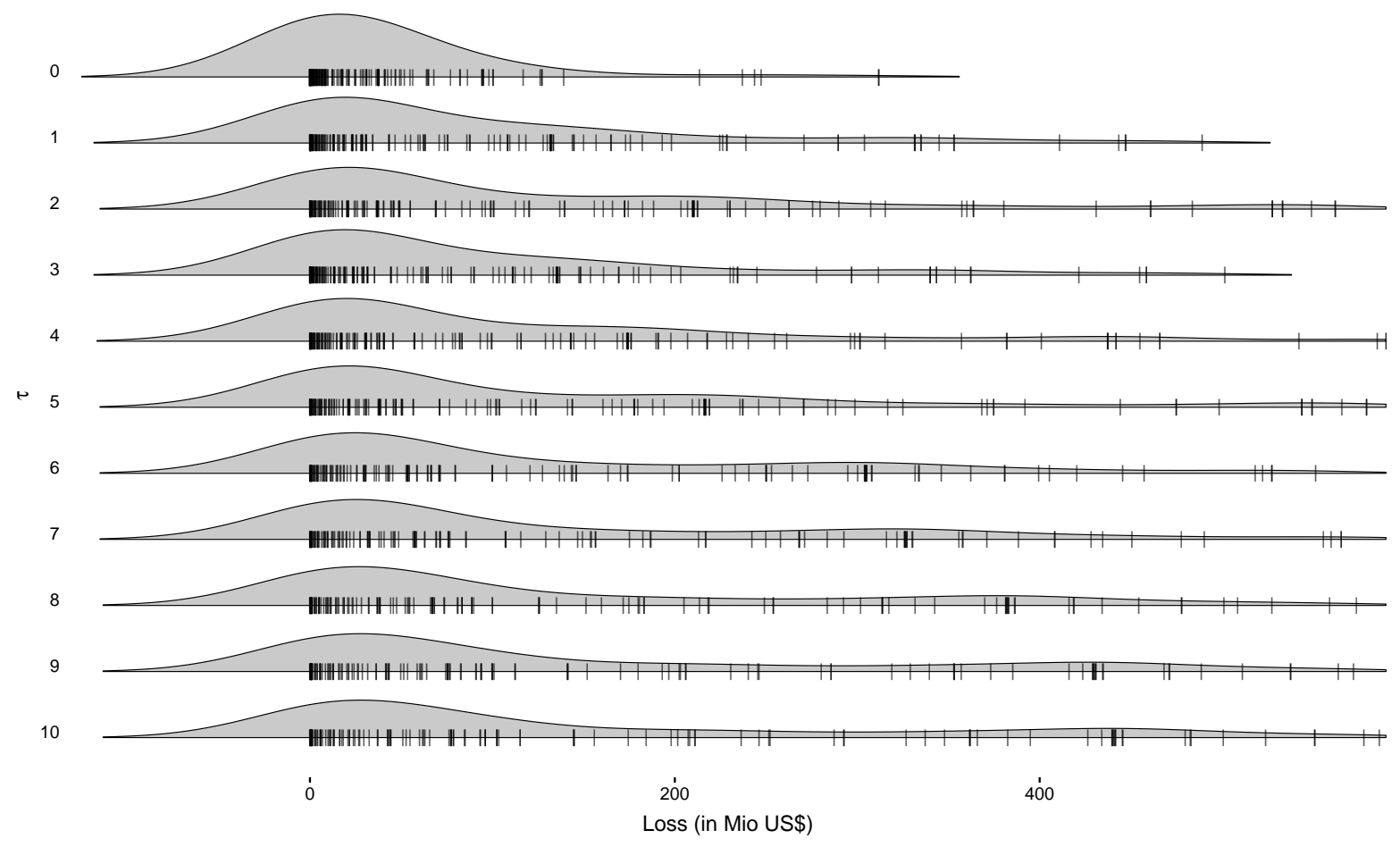

Figure C.4: The Distribution of the Economic Value of Assassination Events.

Notes: The distribution of market capitalization losses across companies for the baseline specification is displayed. For illustrative purposes losses above the 90th percentile are not displayed in Panel-B. 


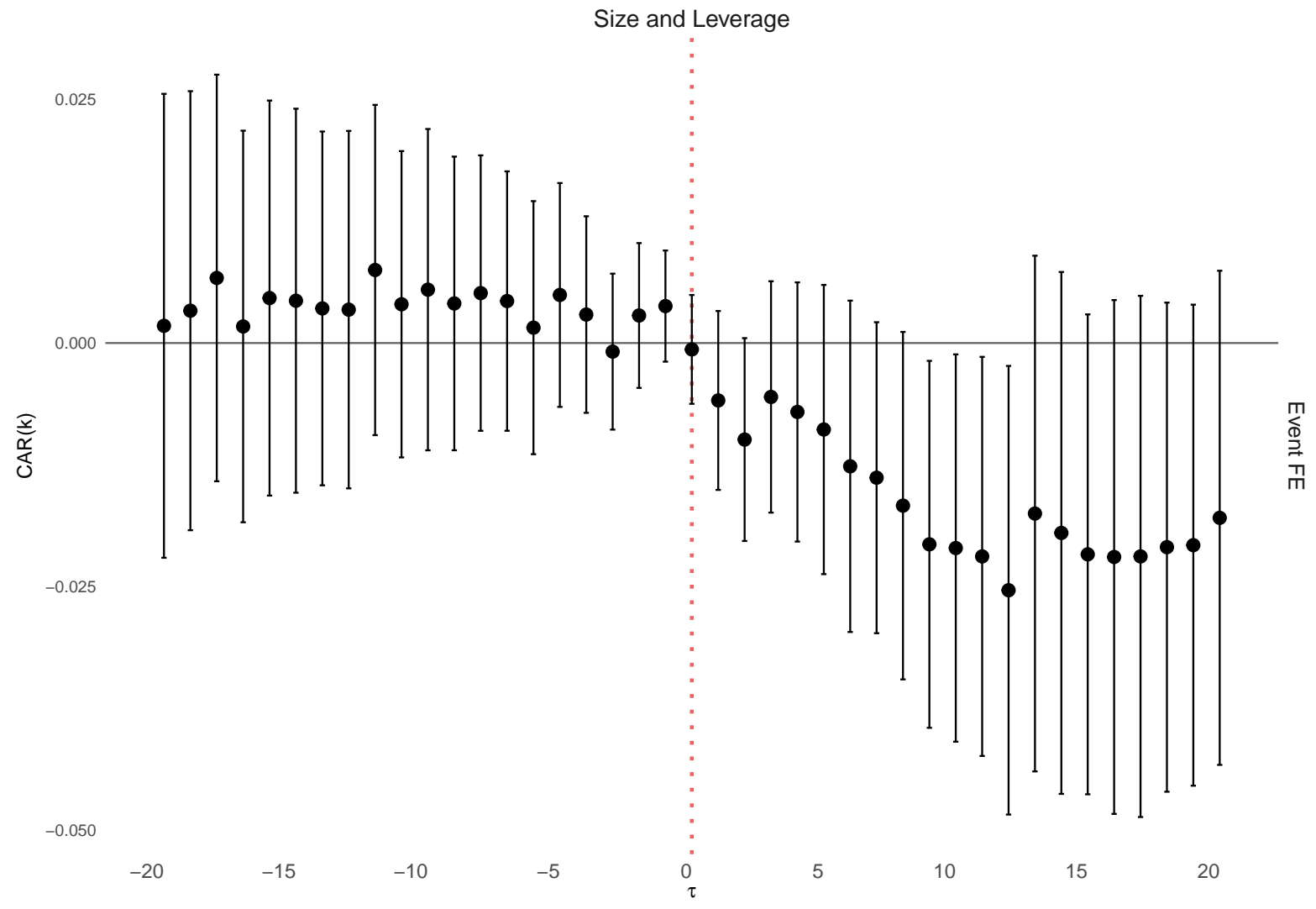

Figure C.5: The Treatment Effect of Assassination Events on Mining Companies - Wide Event Window.

Notes: The coefficients when regressing the respective cumulative abnormal return (CAR) on an indicator for being tied to an assassination event is represented by the black dots for our event fixed effects specification. Each dot corresponds to a seperate regression coefficient estimate. The horizontal axis label denotes the trading days before and after the event on $\tau=0$. CARs are aggregated backwards before the event date and forwards starting with the event date. E.g. -5 refers to the CAR between -1 and -5 while 5 refers to the CAR between 0 and $5.95 \%$ confidence intervals using robust standard errors clustered on the event-level are depicted. 


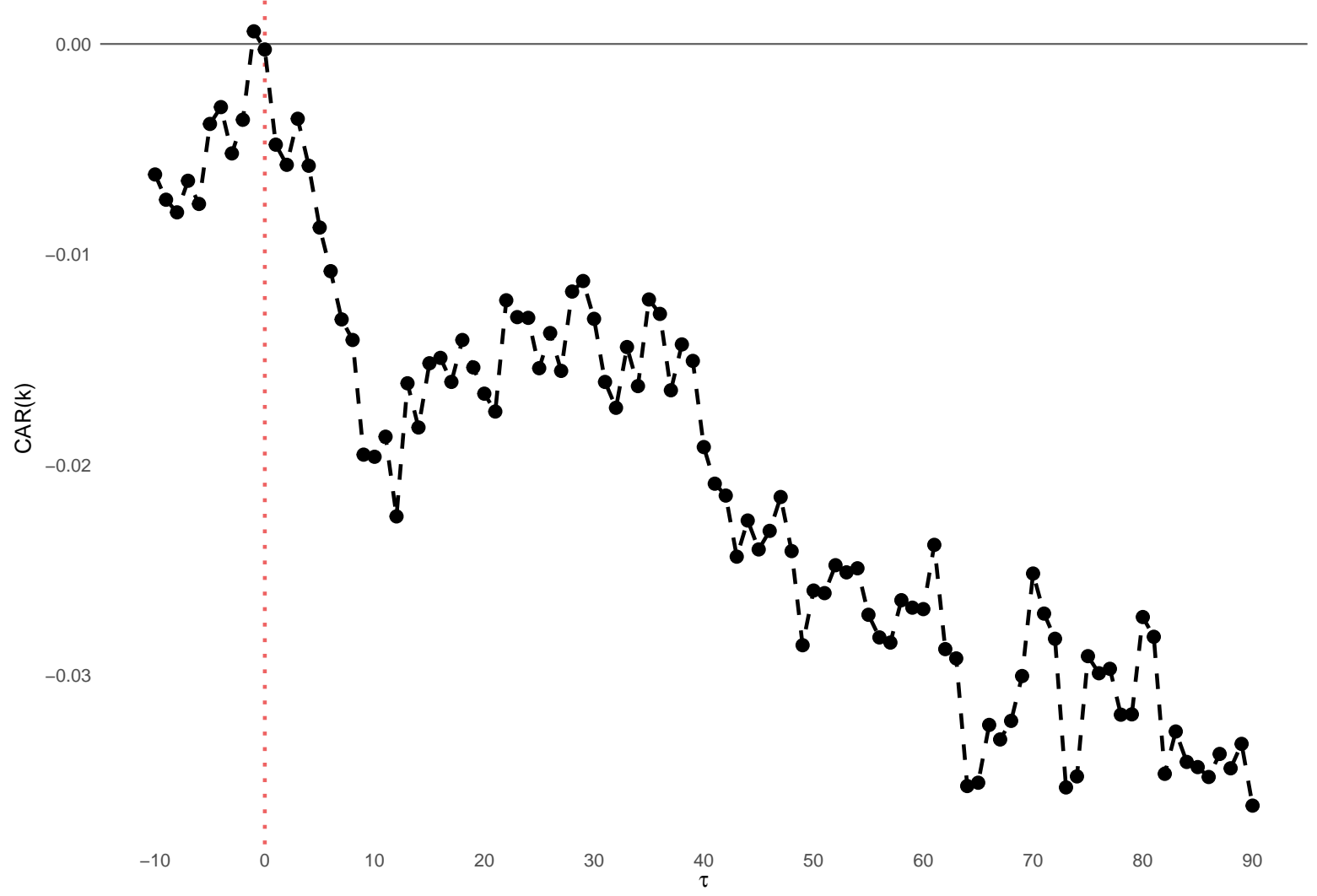

Figure C.6: The Long-Run Average Cumulative Abnormal Returns of Associated Companies.

Notes: Underlying the Market Model, the average cumulative abnormal return (CAR) of mining companies associated with assassination events are displayed. CARs are aggregated backwards before the event date and forwards starting with the event date. E.g. -5 refers to the CAR between -1 and -5 while 5 refers to the CAR between 0 and 5 . Companies have to be traded 70 out of the 91 days following the event and 8 out 10 days prior to the event. 

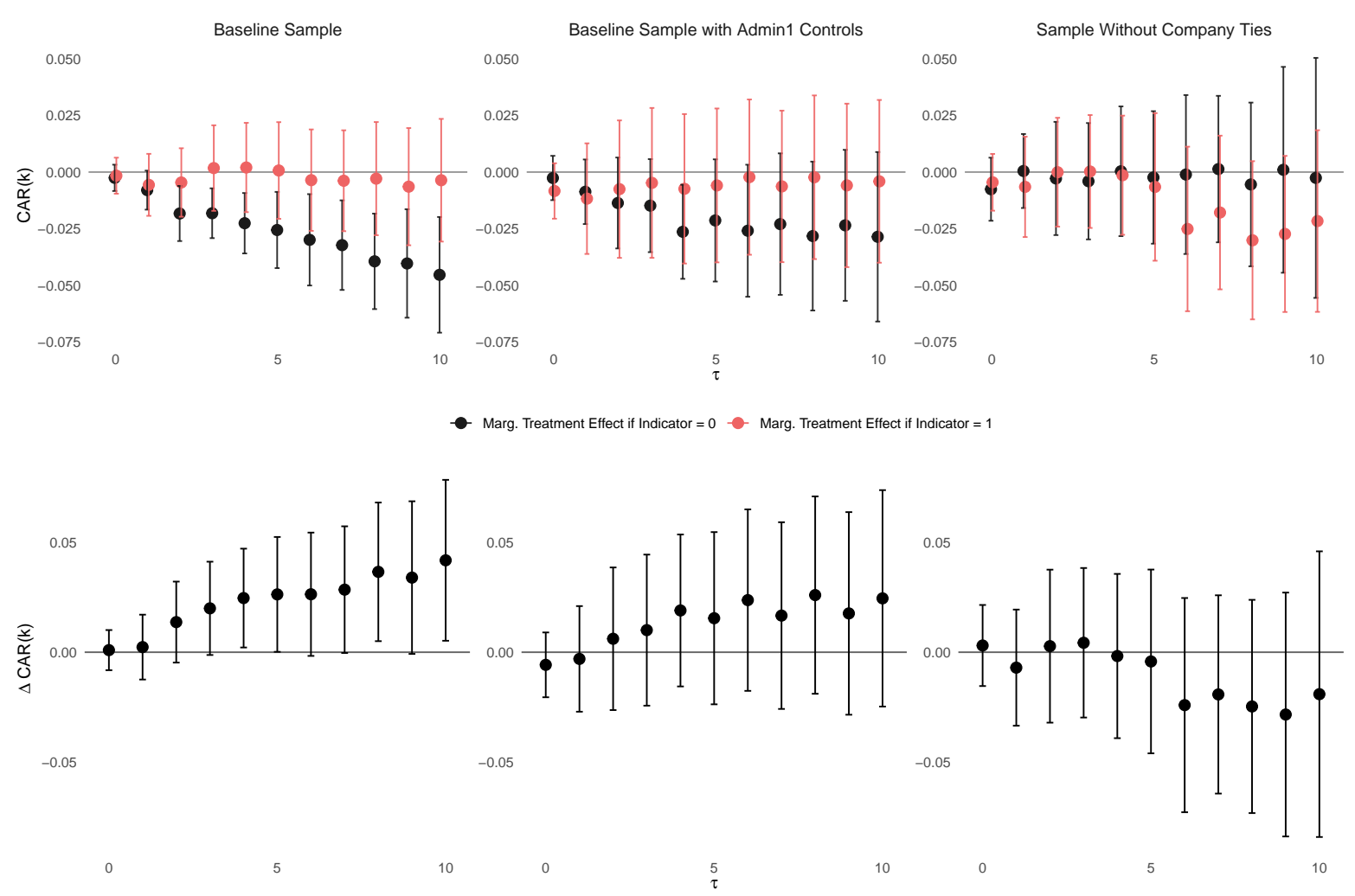

Figure C.7: The Influence of News Pressure on the Event Day - Robustness: Detrended

Notes: The top panel displays the heterogeneous marginal treatment effect of assassination events on the respective cumulative abnormal return (CAR). The difference in treatment effects is presented in the bottom panel. The horizontal axis label denotes the trading days relative to the event day $\tau=0$. CARs are forwards starting with the event date. E.g. 5 refers to the CAR between days 0 and 5 . Columns present regression specifications with the assassination indicator interacted with an indicator variable for high news pressure defined as an above median detrended news pressure day. The first column presents the baseline sample estimates, while the second column presents the results when altering the control group to companies active in the Admin 1 region of the assassination event. The third column shows the coefficient estimates for the sample with no public company assaciations; all companies within the same Admin1 region of the event are considered as treated, while all remaining companies in the event-country constitute the control group. 95\% confidence intervals using robust standard errors clustered on the event-level are displayed in the top and bottom panel. 

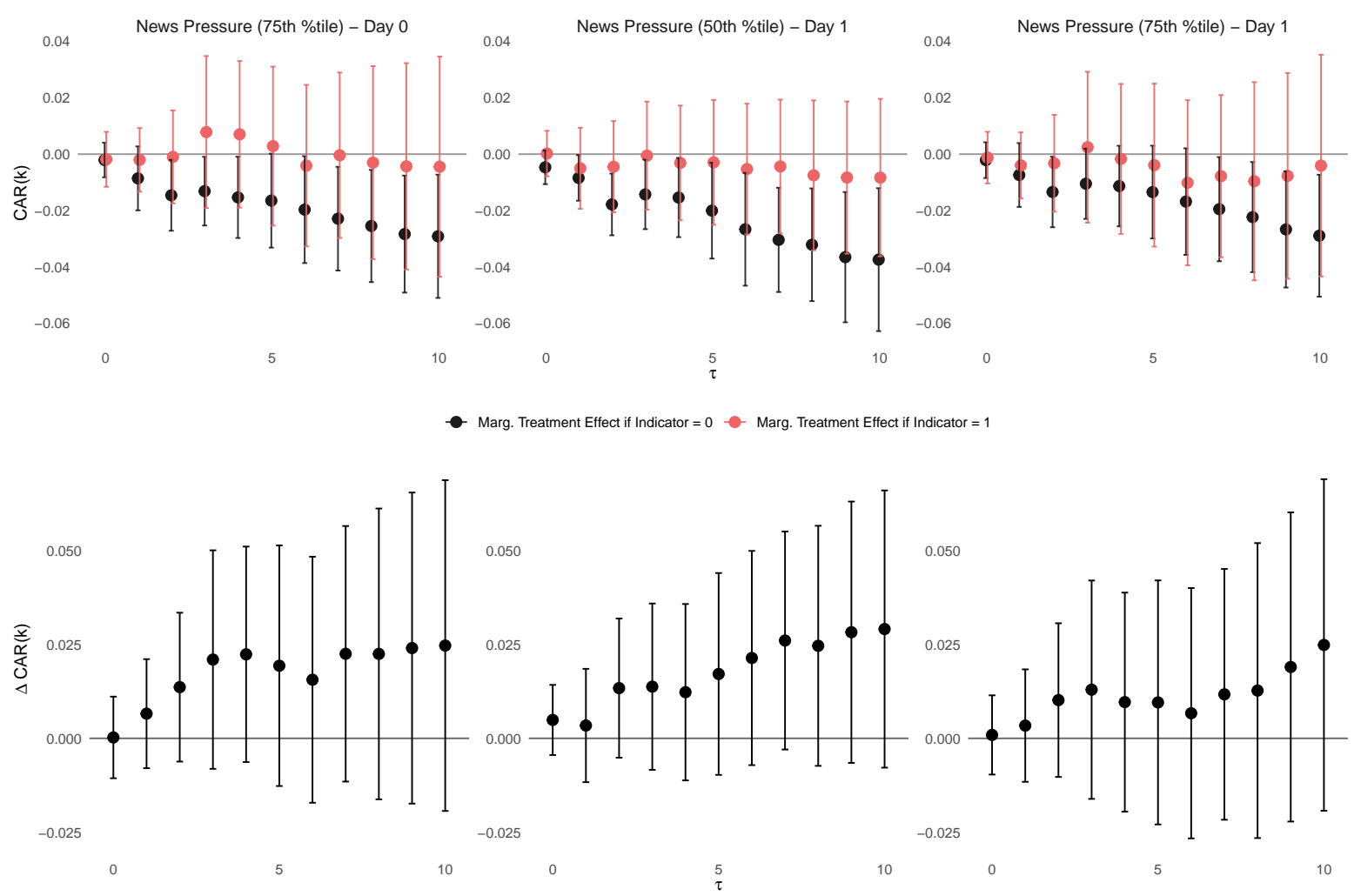

Figure C.8: The Influence of News Pressure - Robustness: 75th Percentile and Day 1

Notes: The top panel displays the heterogeneous marginal treatment effect of assassination events on the respective cumulative abnormal return (CAR). The difference in treatment effects is presented in the bottom panel. The horizontal axis label denotes the trading days relative to the event day $\tau=0$. CARs are forwards starting with the event date. E.g. 5 refers to the CAR between days 0 and 5. Columns present regression specifications with the assassination indicator interacted with an indicator variable for high news pressure defined as a news pressure day in the 75th percentile. The first column presents the baseline sample estimates, while the second column presents the results when altering the control group to companies active in the Admin 1 region of the assassination event. The third column shows the coefficient estimates for the sample with no public company assaciations; all companies within the same Admin1 region of the event are considered as treated, while all remaining companies in the event-country constitute the control group. 95\% confidence intervals using robust standard errors clustered on the event-level are displayed in the top and bottom panel. 

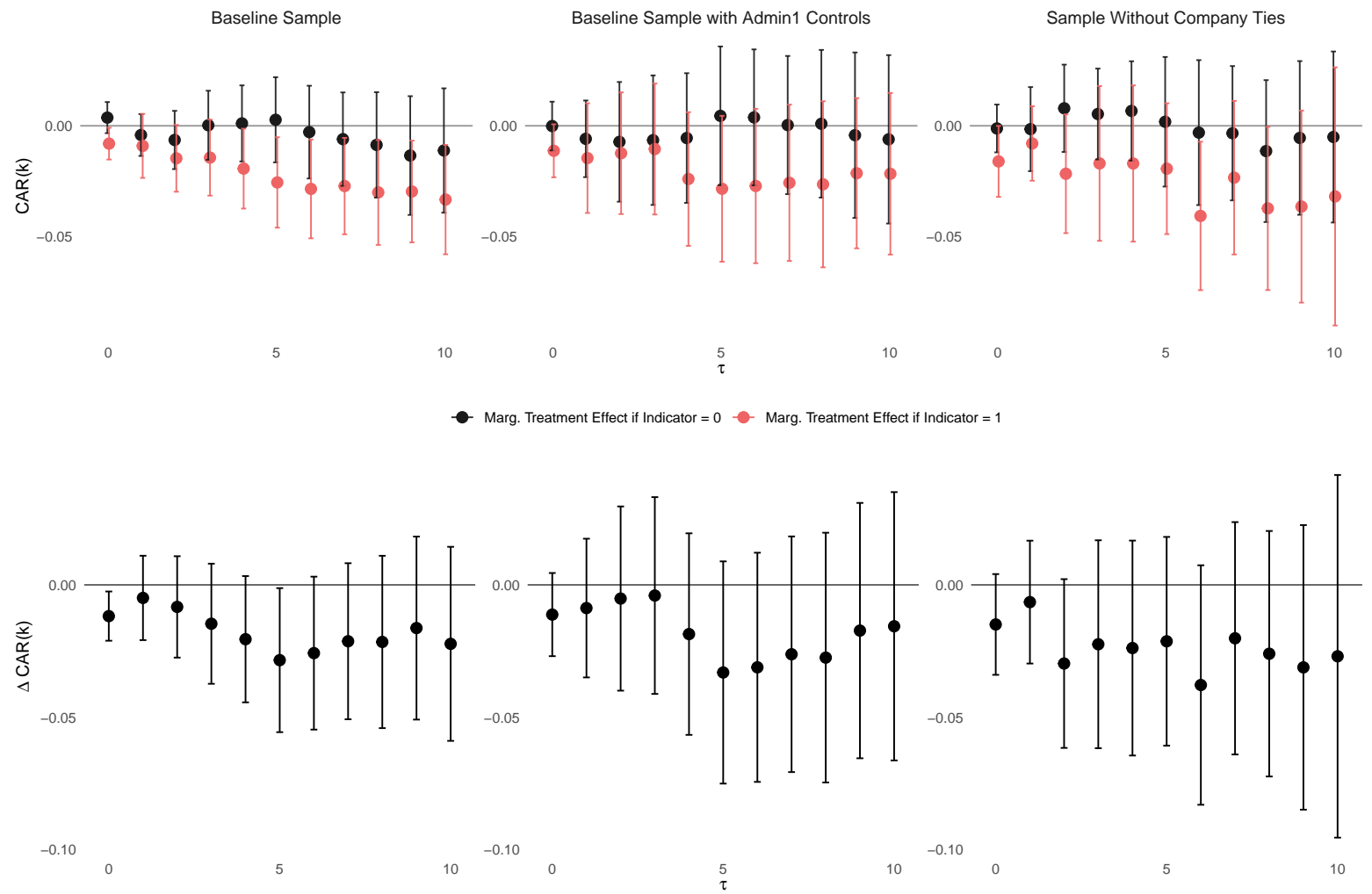

Figure C.9: The Influence of Oversight - EITI Membership

Notes: The top panel displays the heterogeneous marginal treatment effect of assassination events on the respective cumulative abnormal return (CAR). The difference in treatment effects is presented in the bottom panel. The horizontal axis label denotes the trading days relative to the event day $\tau=0$. CARs are forwards starting with the event date. E.g. 5 refers to the CAR between days 0 and 5 . Columns present regression specifications with the assassination indicator interacted with an indicator variable for EITI membership. The first column presents the baseline sample estimates, while the second column presents the results when altering the control group to companies active in the Admin1 region of the assassination event. The third column shows the coefficient estimates for the sample with no public company assaciations; all companies within the same Admin 1 region of the event are considered as treated, while all remaining companies in the event-country constitute the control group. 95\% confidence intervals using robust standard errors clustered on the event-level are displayed in the top and bottom panel. 

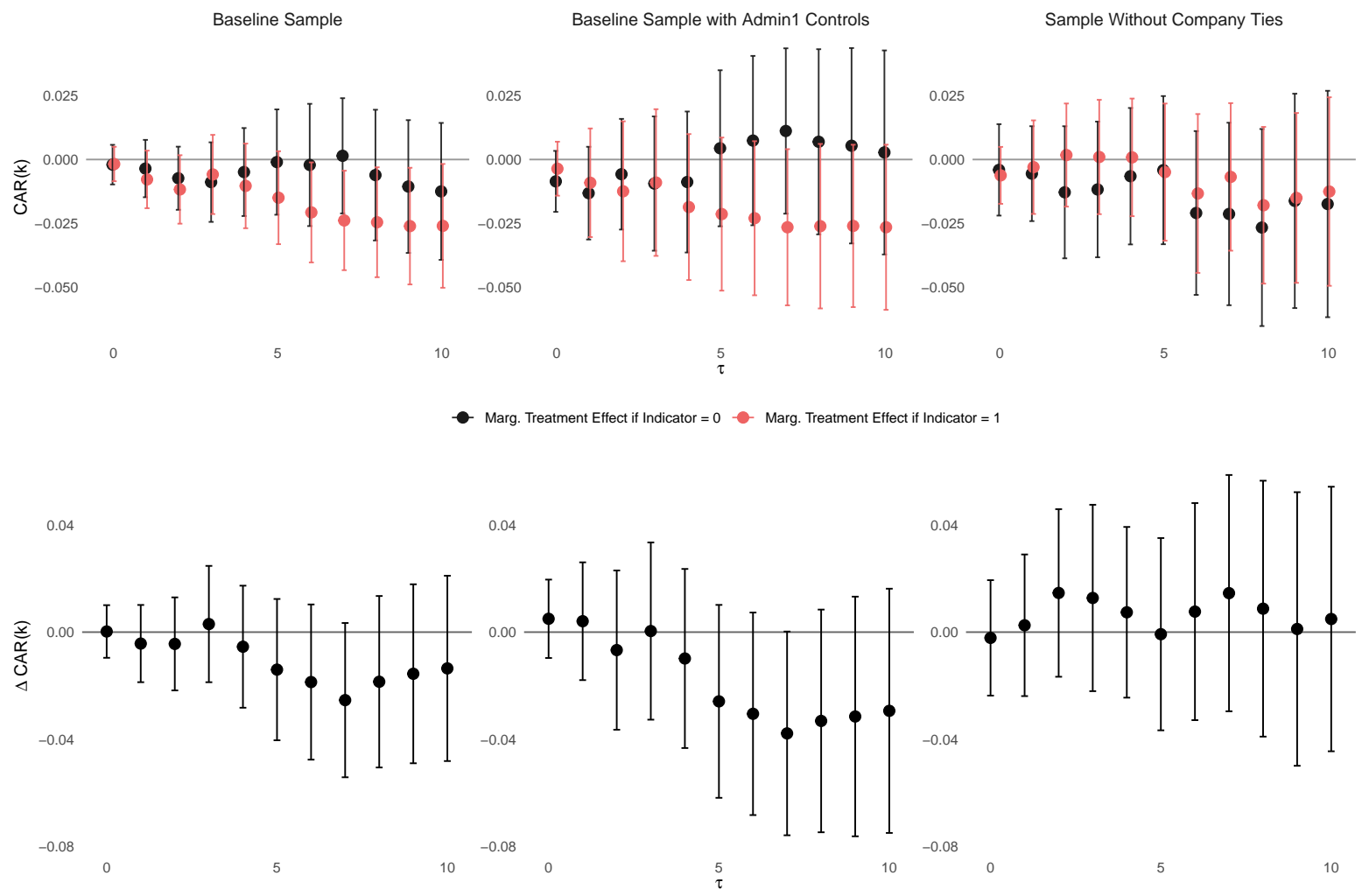

Figure C.10: The Influence of Oversight - Law and Order (HQ-Country)

Notes: The top panel displays the heterogeneous marginal treatment effect of assassination events on the respective cumulative abnormal return (CAR). The difference in treatment effects is presented in the bottom panel. The horizontal axis label denotes the trading days relative to the event day $\tau=0$. CARs are forwards starting with the event date. E.g. 5 refers to the CAR between days 0 and 5. Columns present regression specifications with the assassination indicator interacted with an indicator variable for above median ICRG Law and Order scores in the corporation's headquarter country. The first column presents the baseline sample estimates, while the second column presents the results when altering the control group to companies active in the Admin1 region of the assassination event. The third column shows the coefficient estimates for the sample with no public company assaciations; all companies within the same Admin1 region of the event are considered as treated, while all remaining companies in the event-country constitute the control group. 95\% confidence intervals using robust standard errors clustered on the event-level correspond to the error bars in the top panel and the ribbon in the bottom panel. 

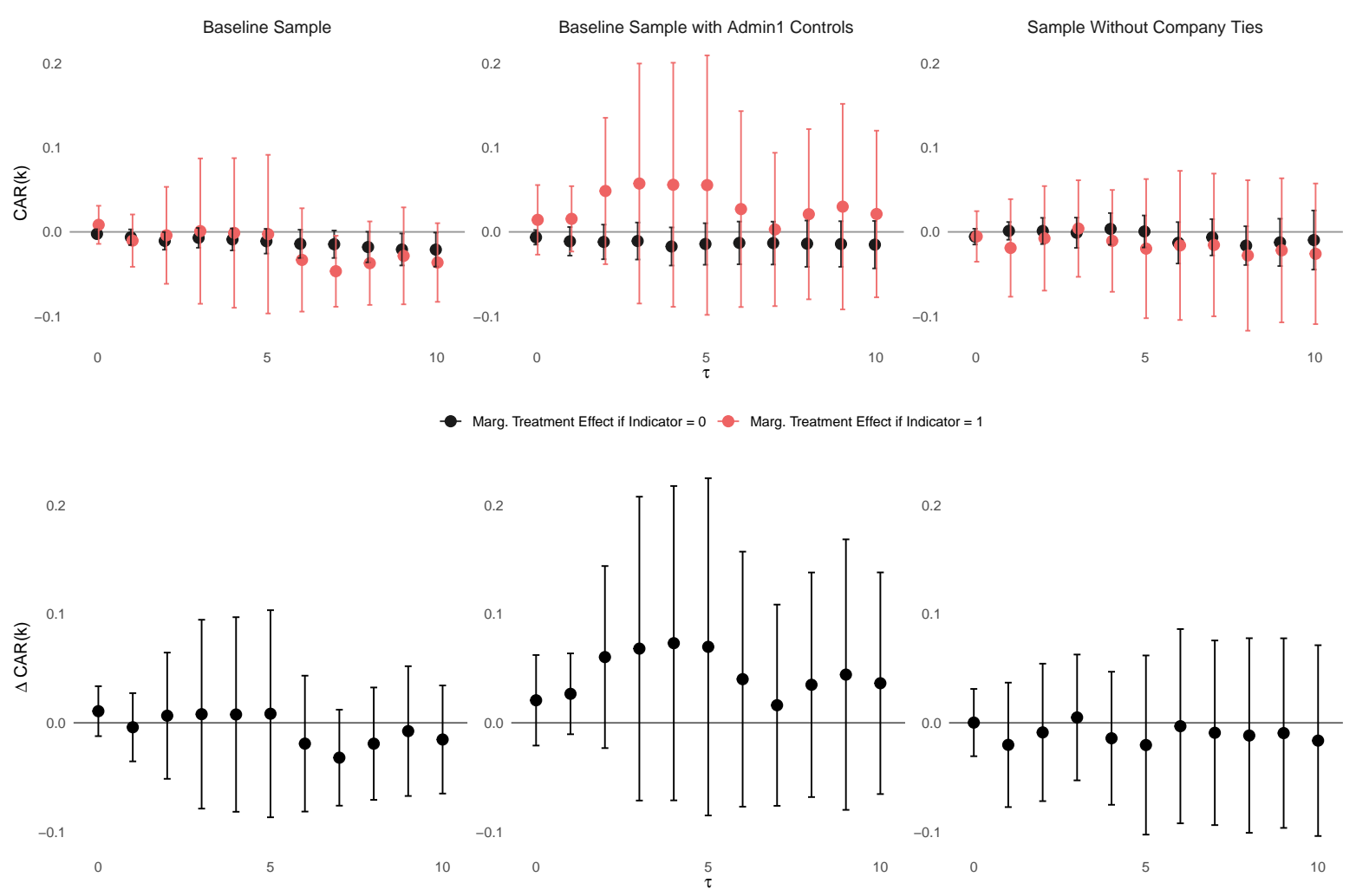

Figure C.11: The Influence of Oversight - Law and Order (Event-Country)

Notes: The top panel displays the heterogeneous marginal treatment effect of assassination events on the respective cumulative abnormal return (CAR). The difference in treatment effects is presented in the bottom panel. The horizontal axis label denotes the trading days relative to the event day $\tau=0$. CARs are forwards starting with the event date. E.g. 5 refers to the CAR between days 0 and 5 . Columns present regression specifications with the assassination indicator interacted with an indicator variable for above median ICRG Law and Order scores in the event country. The first column presents the baseline sample estimates, while the second column presents the results when altering the control group to companies active in the Admin1 region of the assassination event. The third column shows the coefficient estimates for the sample with no public company assaciations; all companies within the same Admin1 region of the event are considered as treated, while all remaining companies in the event-country constitute the control group. $95 \%$ confidence intervals using robust standard errors clustered on the event-level correspond to the error bars in the top panel and the ribbon in the bottom panel 


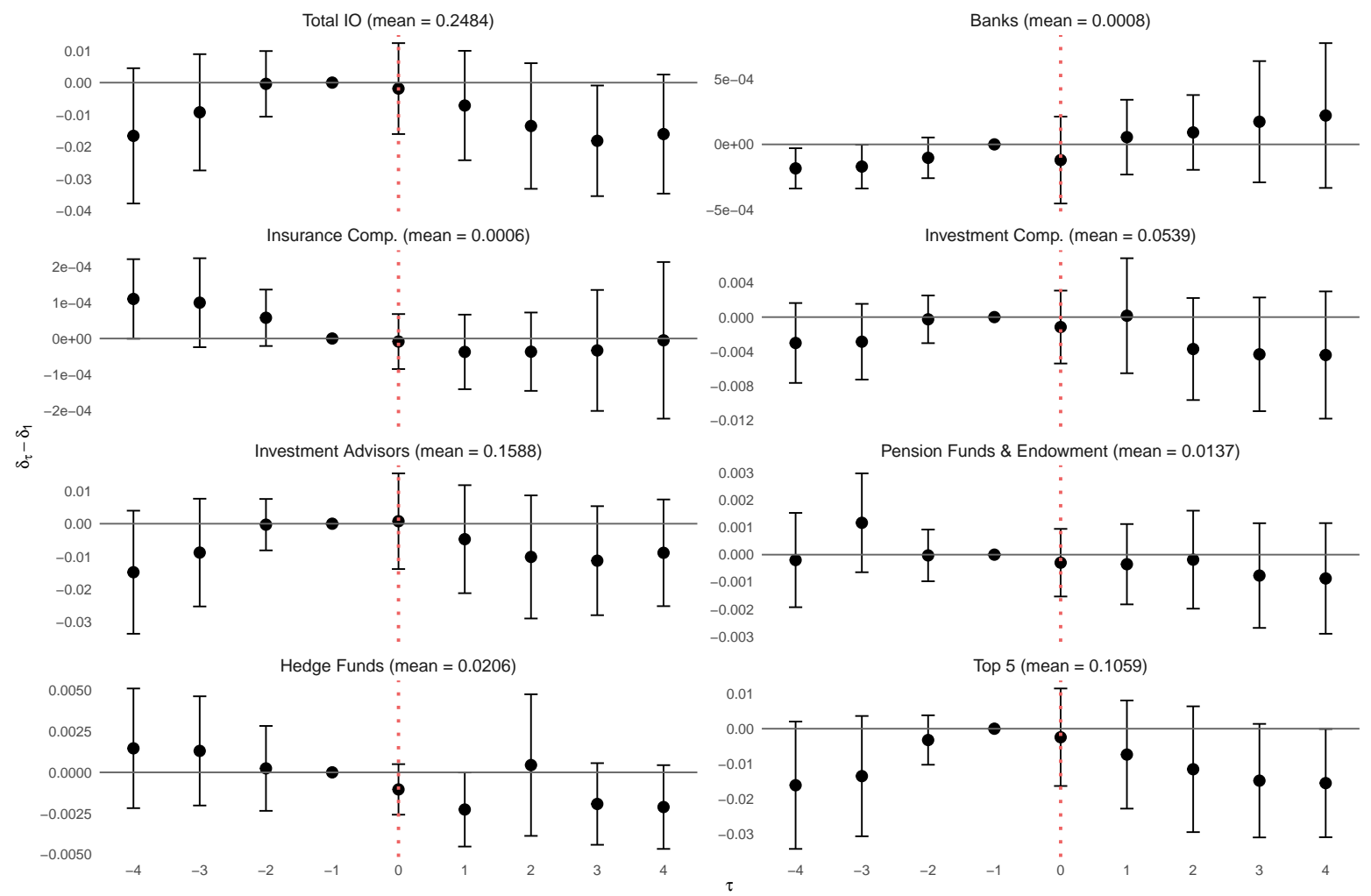

Figure C.12: The Effect of Assassination Events on Institutional Investor Holdings - Accounting for Overlapping Event Windows

Notes: The figure shows the effect of an assassination event on institutional investor's holding position. The control group consists of corporations which are active in the extractive sector according to their TRBC code. Each cell displays the estimated effect relative to the quarter before the event $(\tau=-1)$. The mean institutional investor holding position of companies that experienced at least one event during the sample period is presented in parantheses. $95 \%$ confidence intervals using robust standard errors clustered on the company-level are displayed.

\section{Additional Tables}




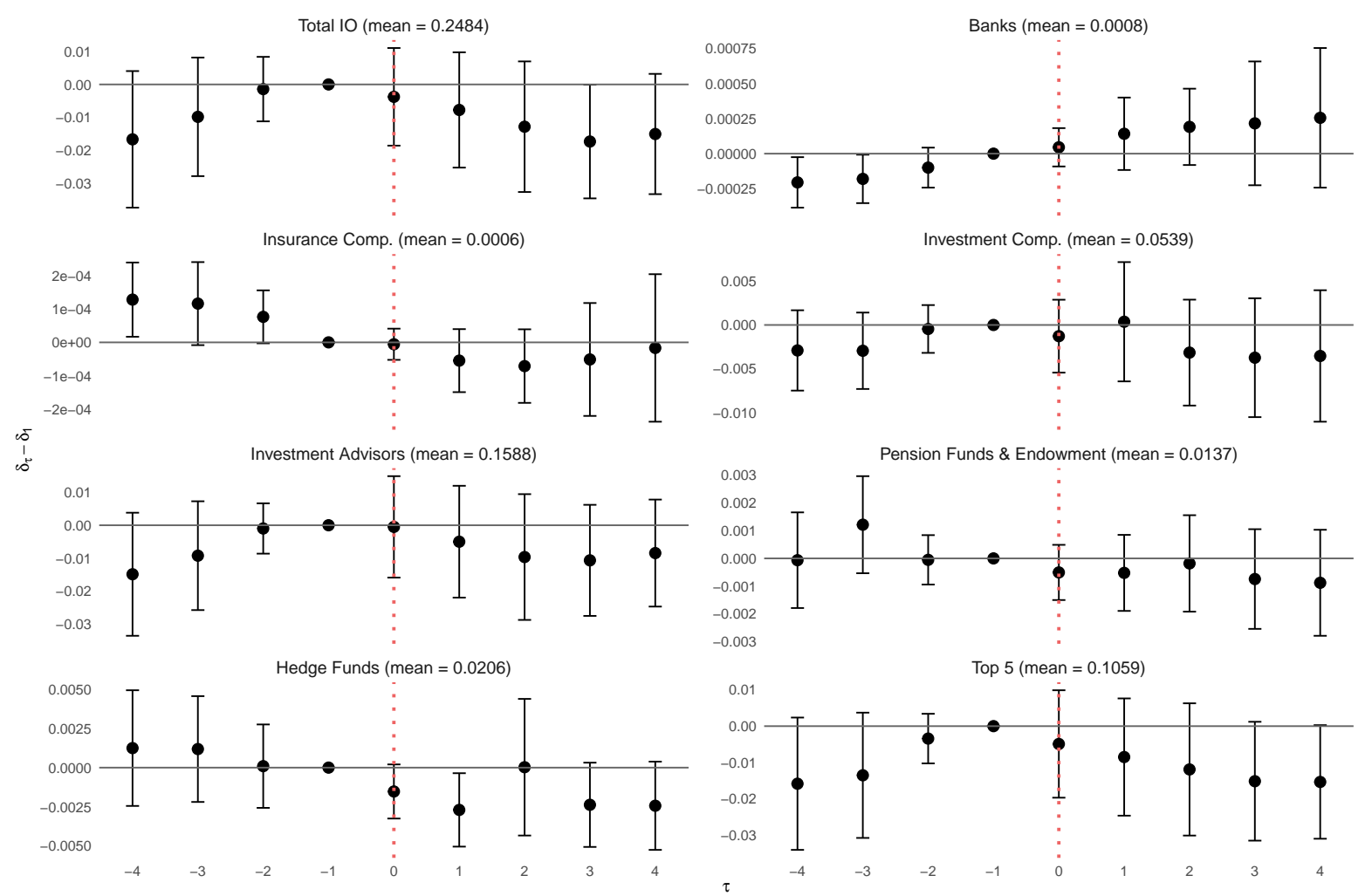

Figure C.13: The Effect of Assassination Events on Institutional Investor Holdings - Extractive Control Sample

Notes: The figure shows the effect of an assassination event on institutional investor's holding position. The control group consists of corporations which are active in the extractive sector according to their TRBC code. Each cell displays the estimated effect relative to the quarter before the event $(\tau=-1)$. The mean institutional investor holding position of companies that experienced at least one event during the sample period is presented in parantheses. $95 \%$ confidence intervals using robust standard errors clustered on the company-level are displayed. 


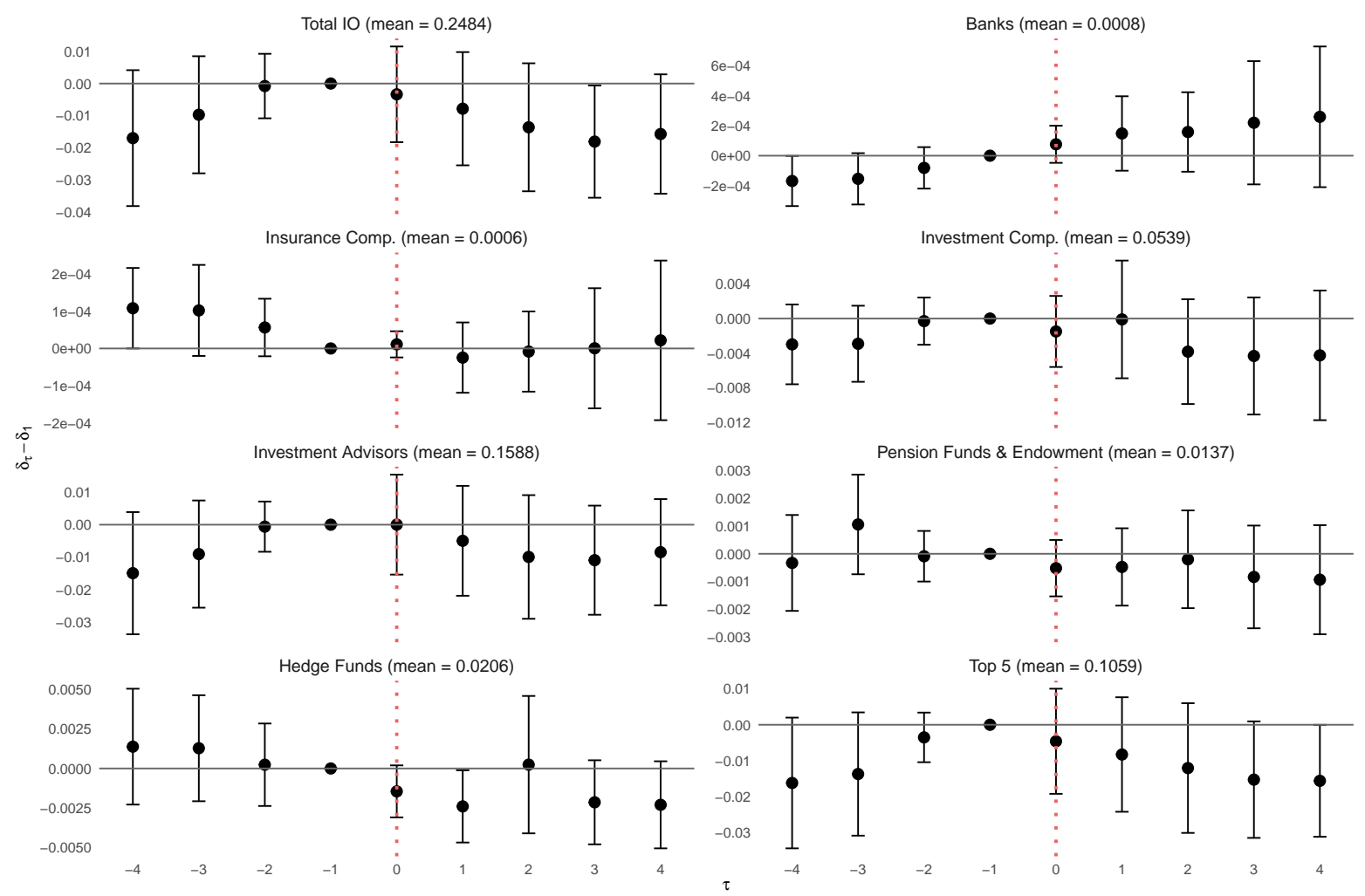

Figure C.14: The Effect of Assassination Events on Institutional Investor Holdings - Random Control Sample

Notes: The figure shows the effect of an assassination event on institutional investor's holding position. The control group consists of 1000 randomly selected corporations which are not active in the extractive sector according to their TRBC code. Each cell displays the estimated effect relative to the quarter before the event $(\tau=-1)$. The mean institutional investor holding position of companies that experienced at least one event during the sample period is presented in parantheses. 95\% confidence intervals using robust standard errors clustered on the company-level are displayed. 


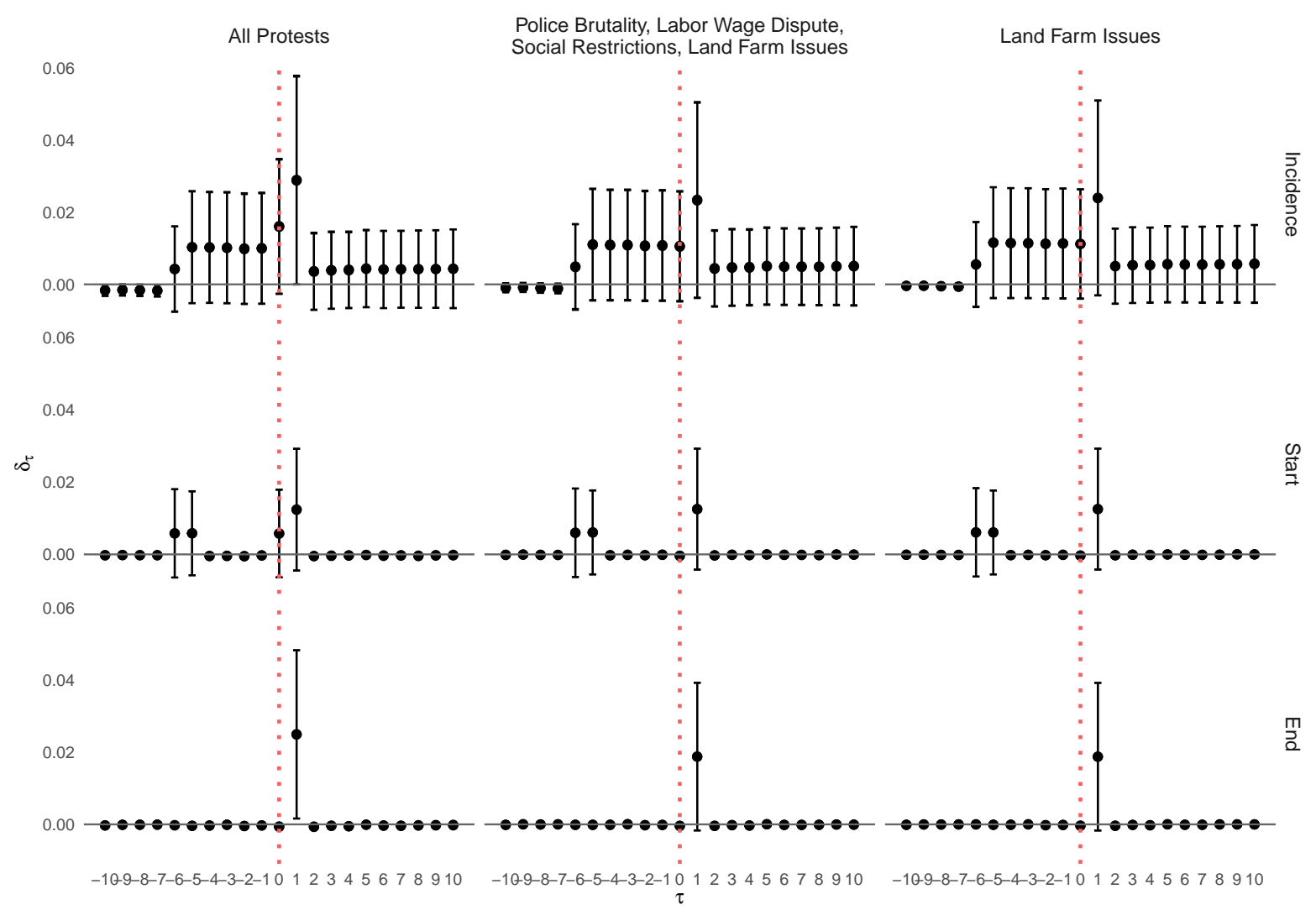

Figure C.15: The Effect of Assassination Events on Protest.

Notes: The figure shows the effect of assassination events on protest probability in an Admin1 region. The horizontal axis label denotes the days before and after the event on $\tau=0$. Each cell corresponds to a different dependent variable with column labels depicting the type of protest and rows capturing if the dependent variable considers incidence, start, or the end of protests. $95 \%$ confidence intervals using robust standard errors clustered on the Admin1 level are depicted. 


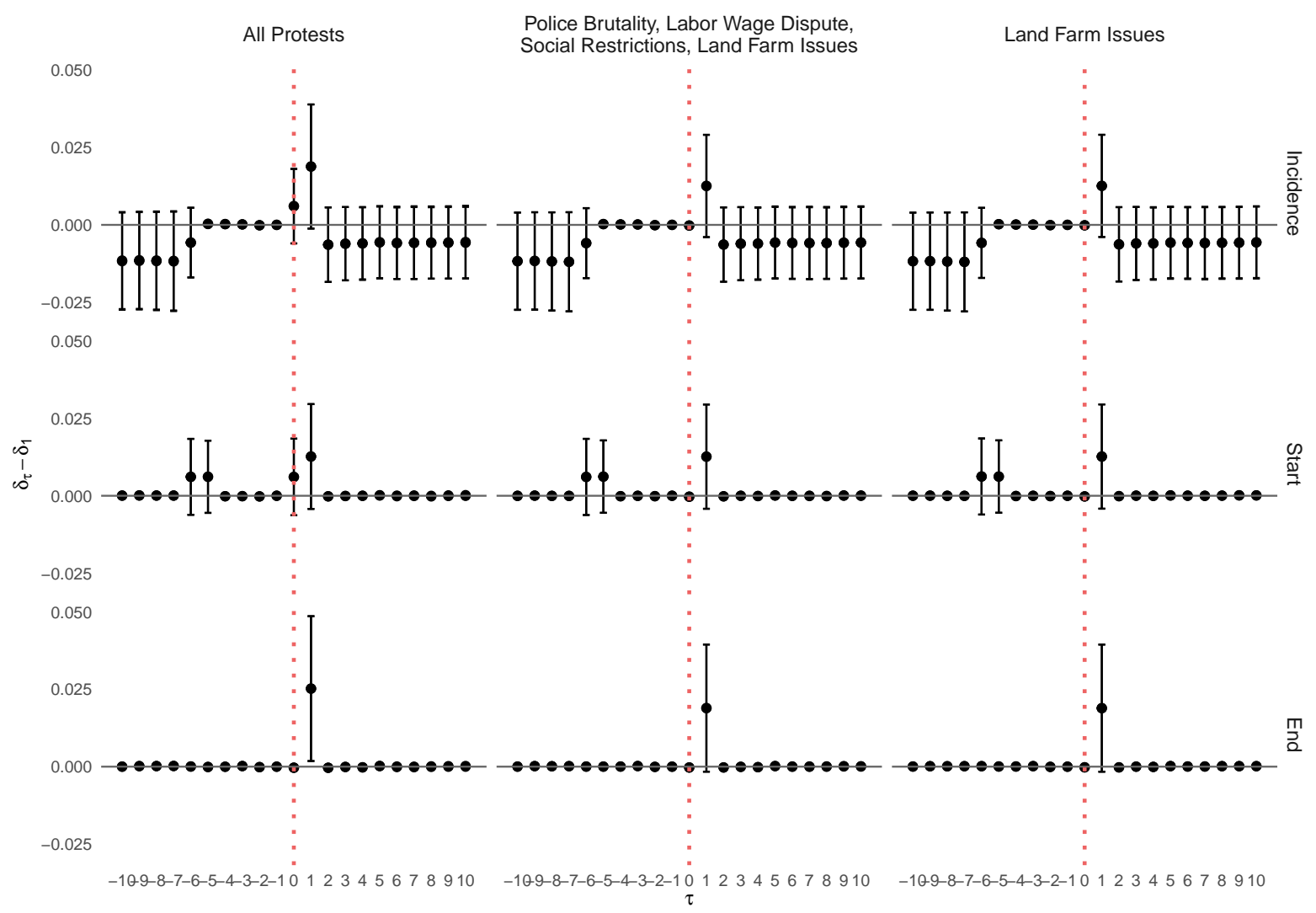

Figure C.16: The Effect of Assassination Events on Protest relative to the Day before the Event.

Notes: The figure shows the effect of assassination events on protest probability in an Admin1 region. The horizontal axis label denotes the days before and after the event on $\tau=0$. The estimated effect relative to the quarter before the event $(\tau=-1)$ is presented. Each cell corresponds to a different dependent variable with column labels depicting the type of protest and rows capturing if the dependent variable considers incidence, start, or the end of protests. $95 \%$ confidence intervals using robust standard errors clustered on the Admin1 level are depicted. 
Table D.1: The Effect of Assassinations on Frequently Traded Companies

\begin{tabular}{lcccccc}
\hline & & & \multicolumn{4}{c}{$\mathrm{p}$-value } \\
\cline { 4 - 7 } & Mean & SD & Normality & BMP & ADJ-BMP & GRANK \\
\hline CAR0to0 & -0.0002 & 0.0024 & 0.934 & 0.465 & 0.498 & 0.632 \\
CAR0to1 & -0.0054 & 0.0035 & 0.118 & 0.081 & 0.106 & 0.348 \\
CAR0to2 & -0.0047 & 0.0043 & 0.270 & 0.145 & 0.176 & 0.255 \\
CAR0to3 & -0.0035 & 0.0049 & 0.480 & 0.172 & 0.205 & 0.047 \\
CAR0to4 & -0.0038 & 0.0055 & 0.496 & 0.136 & 0.166 & 0.061 \\
CAR0to5 & -0.0040 & 0.0061 & 0.511 & 0.175 & 0.209 & 0.114 \\
CAR0to6 & -0.0062 & 0.0066 & 0.347 & 0.089 & 0.115 & 0.069 \\
CAR0to7 & -0.0092 & 0.0070 & 0.190 & 0.048 & 0.066 & 0.043 \\
CAR0to8 & -0.0110 & 0.0075 & 0.139 & 0.038 & 0.054 & 0.027 \\
CAR0to9 & -0.0153 & 0.0079 & 0.052 & 0.018 & 0.028 & 0.004 \\
CAR0to10 & -0.0155 & 0.0083 & 0.061 & 0.030 & 0.044 & 0.008 \\
\hline
\end{tabular}

Notes: The number of company-event pairs $N$ is 160 . The respective average cumulative abnormal return (CAR) and its standard deviation (SD) is presented in columns 1 and 2 (c. equations (5) and (6) in Section 3.1). A minimum of 11 trading days during the event window from 0 to 10 is required. The estimation window spans from day -280 to -30 with a minimum of 225 trading days. Columns $3-6$ show the $p$-value of the respective test-statistic. For details on the applied test-statistics see Appendix A.1.

Table D.2: Private Information and Pre-Trends

\begin{tabular}{lcccccc}
\hline & & & \multicolumn{4}{c}{ p-value } \\
\cline { 4 - 7 } & Mean & SD & Normality & BMP & ADJ-BMP & GRANK \\
\hline CAR-1to-1 & 0.0006 & 0.0034 & 0.870 & 0.782 & 0.783 & 0.706 \\
CAR-1to-2 & -0.0036 & 0.0048 & 0.447 & 0.236 & 0.237 & 0.231 \\
CAR-1to-3 & -0.0052 & 0.0058 & 0.370 & 0.157 & 0.158 & 0.129 \\
CAR-1to-4 & -0.0030 & 0.0068 & 0.656 & 0.412 & 0.413 & 0.240 \\
CAR-1to-5 & -0.0038 & 0.0076 & 0.618 & 0.520 & 0.521 & 0.303 \\
CAR-1to-6 & -0.0076 & 0.0083 & 0.360 & 0.487 & 0.488 & 0.234 \\
CAR-1to-7 & -0.0065 & 0.0090 & 0.470 & 0.562 & 0.563 & 0.292 \\
CAR-1to-8 & -0.0080 & 0.0095 & 0.401 & 0.413 & 0.415 & 0.157 \\
CAR-1to-9 & -0.0074 & 0.0101 & 0.462 & 0.569 & 0.570 & 0.216 \\
CAR-1to-10 & -0.0062 & 0.0106 & 0.560 & 0.801 & 0.802 & 0.364 \\
\hline
\end{tabular}

Notes: The number of company-event pairs $N$ is 170 . The respective average cumulative abnormal return (CAR) and its standard deviation (SD) is presented in columns 1 and 2 (c. equations (5) and (6) in Section 3.1). A minimum of 8 trading days during the event window from -1 to -10 is required. The estimation window spans from day -280 to -30 with a minimum of 200 trading days. Columns $3-6$ show the $p$-value of the respective teststatistic. For details on the applied test-statistics see Appendix A.1. 
Table D.3: The effect of assassination events on stock prices - OLS regression results.

\begin{tabular}{|c|c|c|c|c|c|c|c|c|c|c|}
\hline & (1) & (2) & (3) & (4) & (5) & (6) & (7) & (8) & (9) & (10) \\
\hline \multirow[t]{2}{*}{ CAR0to0 } & -0.0021 & -0.0020 & -0.0008 & -0.0019 & $-0.0090^{*}$ & -0.0039 & -0.0034 & -0.0023 & -0.0039 & $-0.0109^{*}$ \\
\hline & $(0.0026)$ & $(0.0026)$ & $(0.0026)$ & $(0.0028)$ & $(0.0047)$ & $(0.0029)$ & $(0.0031)$ & $(0.0030)$ & $(0.0031)$ & $(0.0062)$ \\
\hline \multirow[t]{2}{*}{ CAR0to1 } & $-0.0065^{*}$ & -0.0064 & -0.0057 & -0.0065 & -0.0114 & $-0.0077^{*}$ & -0.0072 & -0.0065 & -0.0078 & -0.0110 \\
\hline & $(0.0039)$ & $(0.0040)$ & $(0.0041)$ & $(0.0046)$ & $(0.0069)$ & $(0.0044)$ & $(0.0046)$ & $(0.0046)$ & $(0.0049)$ & $(0.0080)$ \\
\hline \multirow[t]{2}{*}{ CAR0to2 } & $-0.0114^{* *}$ & $-0.0117^{* *}$ & $-0.0104^{* *}$ & $-0.0104^{*}$ & $-0.0143^{*}$ & $-0.0129^{* *}$ & $-0.0125^{* *}$ & $-0.0116^{*}$ & $-0.0121^{*}$ & $-0.0172^{*}$ \\
\hline & $(0.0047)$ & $(0.0047)$ & $(0.0049)$ & $(0.0053)$ & $(0.0081)$ & $(0.0056)$ & $(0.0059)$ & $(0.0059)$ & $(0.0063)$ & $(0.0100)$ \\
\hline \multirow[t]{2}{*}{ CAR0to3 } & -0.0072 & -0.0075 & -0.0061 & -0.0067 & -0.0095 & -0.0104 & -0.0096 & -0.0093 & -0.0111 & $-0.0191^{*}$ \\
\hline & $(0.0056)$ & $(0.0057)$ & $(0.0057)$ & $(0.0060)$ & $(0.0088)$ & $(0.0066)$ & $(0.0069)$ & $(0.0068)$ & $(0.0073)$ & $(0.0099)$ \\
\hline \multirow[t]{2}{*}{ CAR0to4 } & -0.0095 & -0.0099 & -0.0091 & -0.0086 & -0.0121 & $-0.0116^{*}$ & -0.0105 & -0.0109 & -0.0117 & $-0.0206^{* *}$ \\
\hline & $(0.0060)$ & $(0.0062)$ & $(0.0063)$ & $(0.0067)$ & $(0.0094)$ & $(0.0068)$ & $(0.0072)$ & $(0.0071)$ & $(0.0076)$ & $(0.0098)$ \\
\hline \multirow[t]{2}{*}{ CAR0to5 } & $-0.0128^{*}$ & $-0.0129^{*}$ & $-0.0126^{*}$ & -0.0107 & $-0.0190^{* *}$ & $-0.0140^{*}$ & -0.0124 & $-0.0139^{*}$ & -0.0134 & $-0.0294^{* * *}$ \\
\hline & $(0.0067)$ & $(0.0069)$ & $(0.0070)$ & $(0.0074)$ & $(0.0094)$ & $(0.0077)$ & $(0.0081)$ & $(0.0081)$ & $(0.0087)$ & $(0.0106)$ \\
\hline \multirow[t]{2}{*}{ CAR0to6 } & $-0.0166^{* *}$ & $-0.0165^{* *}$ & $-0.0165^{* *}$ & $-0.0150^{*}$ & -0.0161 & $-0.0194^{* *}$ & $-0.0182^{* *}$ & $-0.0192^{* *}$ & $-0.0189 * *$ & $-0.0284^{* *}$ \\
\hline & $(0.0076)$ & $(0.0078)$ & $(0.0079)$ & $(0.0083)$ & (0.0103) & $(0.0086)$ & $(0.0090)$ & $(0.0086)$ & $(0.0093)$ & $(0.0115)$ \\
\hline \multirow[t]{2}{*}{ CAR0to7 } & $-0.0172^{* *}$ & $-0.0168^{* *}$ & $-0.0175^{* *}$ & $-0.0161^{* *}$ & -0.0165 & $-0.0182^{* *}$ & $-0.0160^{*}$ & $-0.0185^{* *}$ & $-0.0186^{* *}$ & $-0.0254^{* *}$ \\
\hline & $(0.0074)$ & $(0.0076)$ & $(0.0076)$ & $(0.0080)$ & $(0.0101)$ & $(0.0084)$ & $(0.0089)$ & $(0.0084)$ & $(0.0090)$ & $(0.0113)$ \\
\hline \multirow[t]{2}{*}{ CAR0to8 } & $-0.0197^{* *}$ & $-0.0192^{* *}$ & $-0.0201^{* *}$ & $-0.0188^{* *}$ & $-0.0226^{* *}$ & $-0.0193^{* *}$ & $-0.0173^{*}$ & $-0.0199 * *$ & $-0.0206^{* *}$ & $-0.0291^{* *}$ \\
\hline & $(0.0085)$ & $(0.0087)$ & $(0.0087)$ & $(0.0089)$ & $(0.0110)$ & $(0.0095)$ & $(0.0100)$ & $(0.0096)$ & $(0.0100)$ & $(0.0120)$ \\
\hline \multirow[t]{2}{*}{ CAR0to9 } & $-0.0238^{* * *}$ & $-0.0230^{* *}$ & $-0.0252^{* * *}$ & $-0.0212^{* *}$ & $-0.0254^{* *}$ & $-0.0219^{* *}$ & $-0.0197^{*}$ & $-0.0241^{* *}$ & $-0.0219^{* *}$ & $-0.0277^{* *}$ \\
\hline & $(0.0089)$ & $(0.0091)$ & $(0.0090)$ & $(0.0093)$ & $(0.0115)$ & $(0.0100)$ & $(0.0105)$ & $(0.0100)$ & $(0.0106)$ & $(0.0126)$ \\
\hline \multirow[t]{2}{*}{ CAR0to10 } & $-0.0234^{* *}$ & $-0.0220^{* *}$ & $-0.0259^{* * *}$ & $-0.0217^{* *}$ & $-0.0237^{*}$ & $-0.0254^{* *}$ & $-0.0233^{* *}$ & $-0.0293^{* * *}$ & $-0.0267^{* *}$ & $-0.0329^{* *}$ \\
\hline & $(0.0095)$ & $(0.0097)$ & $(0.0097)$ & $(0.0099)$ & $(0.0128)$ & $(0.0108)$ & $(0.0114)$ & $(0.0109)$ & $(0.0114)$ & $(0.0146)$ \\
\hline Size and Leverage & $X$ & $X$ & $X$ & $X$ & $X$ & $X$ & $X$ & $X$ & $X$ & $X$ \\
\hline Profitability & & & & & & $X$ & $X$ & $X$ & $X$ & $X$ \\
\hline Cubic Terms & & & & & & $X$ & $X$ & $X$ & $X$ & $X$ \\
\hline Headquarter FE & & $X$ & & & & & $X$ & & & \\
\hline Year FE & & & $X$ & & & & & $x$ & & \\
\hline Event FE & & & & $X$ & & & & & $X$ & \\
\hline Company FE & & & & & $X$ & & & & & $X$ \\
\hline Observations & 4177 & 4177 & 4175 & 4170 & 4090 & 4029 & 4029 & 4027 & 4022 & 3944 \\
\hline Clusters & 154 & 154 & 152 & 147 & 153 & 154 & 154 & 152 & 147 & 153 \\
\hline
\end{tabular}

Notes: $\quad$ Robust standard errors are clustered on the event-level in parentheses: ${ }^{*} \mathrm{p}<0.1,{ }^{* *} \mathrm{p}<0.5,{ }^{* * *} \mathrm{p}<0.01$. 
Table D.4: The effect of assassination events on stock prices - OLS robustness checks.

\begin{tabular}{|c|c|c|c|c|c|c|c|c|c|c|c|c|c|c|c|}
\hline & \multicolumn{5}{|c|}{ Excl. Attempts } & \multicolumn{5}{|c|}{ Excl. Protests } & \multicolumn{5}{|c|}{ Winsorized } \\
\hline & (1) & (2) & (3) & (4) & (5) & (6) & (7) & (8) & (9) & (10) & (11) & (12) & (13) & (14) & (15) \\
\hline CAR0to0 & $\begin{array}{c}-0.0024 \\
(0.0027)\end{array}$ & $\begin{array}{l}-0.0024 \\
(0.0028)\end{array}$ & $\begin{array}{c}-0.0012 \\
(0.0028)\end{array}$ & $\begin{array}{l}-0.0018 \\
(0.0029)\end{array}$ & $\begin{array}{l}-0.0093^{*} \\
(0.0053)\end{array}$ & $\begin{array}{c}-0.0034 \\
(0.0032)\end{array}$ & $\begin{array}{l}-0.0036 \\
(0.0032)\end{array}$ & $\begin{array}{l}-0.0014 \\
(0.0031)\end{array}$ & $\begin{array}{c}-0.0015 \\
(0.0031)\end{array}$ & $\begin{array}{c}-0.0094 \\
(0.0067)\end{array}$ & $\begin{array}{c}-0.0004 \\
(0.0023)\end{array}$ & $\begin{array}{c}-0.0005 \\
(0.0024)\end{array}$ & $\begin{array}{c}0.0007 \\
(0.0023)\end{array}$ & $\begin{array}{c}0.0005 \\
(0.0025)\end{array}$ & $\begin{array}{c}-0.0039 \\
(0.0032)\end{array}$ \\
\hline \multirow[t]{2}{*}{ CAR0to1 } & -0.0068 & -0.0068 & -0.0062 & -0.0064 & -0.0123 & $-0.0091^{* *}$ & $-0.0093^{* *}$ & $-0.0074^{* *}$ & $-0.0083^{* *}$ & -0.0096 & $-0.0046^{*}$ & $-0.0046^{*}$ & -0.0037 & -0.0045 & -0.0048 \\
\hline & $(0.0042)$ & $(0.0043)$ & $(0.0044)$ & $(0.0050)$ & (0.0079) & $(0.0036)$ & $(0.0036)$ & $(0.0036)$ & $(0.0037)$ & $(0.0073)$ & $(0.0027)$ & $(0.0027)$ & $(0.0027)$ & $(0.0029)$ & $(0.0043)$ \\
\hline \multirow[t]{2}{*}{ CAR0to2 } & $-0.0109^{* *}$ & $-0.0111^{* *}$ & $-0.0101^{*}$ & $-0.0095^{*}$ & -0.0142 & $-0.0126^{* *}$ & $-0.0129^{* *}$ & $-0.0105^{*}$ & $-0.0097^{*}$ & $-0.0156^{*}$ & $-0.0082^{* *}$ & $-0.0086^{* *}$ & $-0.0072^{*}$ & $-0.0076^{*}$ & -0.0054 \\
\hline & $(0.0050)$ & $(0.0051)$ & $(0.0052)$ & $(0.0057)$ & $(0.0091)$ & $(0.0053)$ & $(0.0055)$ & $(0.0053)$ & $(0.0054)$ & $(0.0093)$ & $(0.0039)$ & $(0.0039)$ & $(0.0040)$ & $(0.0041)$ & $(0.0049)$ \\
\hline \multirow[t]{2}{*}{ CAR0to3 } & -0.0063 & -0.0067 & -0.0054 & -0.0054 & -0.0070 & -0.0069 & -0.0070 & -0.0039 & -0.0048 & -0.0081 & $-0.0087^{* *}$ & $-0.0092^{* *}$ & $-0.0078^{*}$ & $-0.0083^{* *}$ & -0.0054 \\
\hline & $(0.0060)$ & $(0.0061)$ & $(0.0062)$ & $(0.0065)$ & $(0.0098)$ & $(0.0071)$ & $(0.0073)$ & $(0.0070)$ & $(0.0070)$ & $(0.0101)$ & $(0.0040)$ & $(0.0040)$ & $(0.0041)$ & $(0.0041)$ & $(0.0057)$ \\
\hline \multirow[t]{2}{*}{ CAR0to4 } & -0.0096 & -0.0100 & -0.0088 & -0.0076 & -0.0106 & -0.0062 & -0.0061 & -0.0030 & -0.0028 & -0.0061 & $-0.0102^{* *}$ & $-0.0109^{* *}$ & $-0.0097^{* *}$ & $-0.0095^{*}$ & $-0.0102^{*}$ \\
\hline & $(0.0065)$ & $(0.0067)$ & $(0.0067)$ & $(0.0072)$ & $(0.0103)$ & $(0.0080)$ & $(0.0082)$ & $(0.0081)$ & $(0.0082)$ & $(0.0105)$ & $(0.0046)$ & $(0.0047)$ & $(0.0047)$ & $(0.0049)$ & $(0.0058)$ \\
\hline \multirow[t]{2}{*}{ CAR0to5 } & $-0.0131^{*}$ & $-0.0134^{*}$ & $-0.0125^{*}$ & -0.0102 & $-0.0177^{*}$ & -0.0125 & -0.0123 & -0.0092 & -0.0076 & -0.0173 & $-0.0141^{* * *}$ & $-0.0146^{* * *}$ & $-0.0140^{* * *}$ & $-0.0120^{* *}$ & $-0.0132^{* *}$ \\
\hline & $(0.0072)$ & $(0.0074)$ & $(0.0075)$ & $(0.0080)$ & $(0.0104)$ & $(0.0087)$ & $(0.0090)$ & $(0.0090)$ & $(0.0091)$ & (0.0109) & $(0.0052)$ & $(0.0052)$ & $(0.0053)$ & $(0.0055)$ & $(0.0062)$ \\
\hline \multirow[t]{2}{*}{ CAR0to6 } & $-0.0184^{* *}$ & $-0.0186^{* *}$ & $-0.0177^{* *}$ & $-0.0161^{*}$ & -0.0162 & -0.0160 & -0.0160 & -0.0124 & -0.0122 & -0.0132 & $-0.0172^{* * *}$ & $-0.0175^{* * *}$ & $-0.0175^{* * *}$ & $-0.0165^{* *}$ & -0.0118 \\
\hline & $(0.0080)$ & $(0.0082)$ & $(0.0083)$ & $(0.0088)$ & $(0.0110)$ & $(0.0098)$ & $(0.0099)$ & $(0.0099)$ & $(0.0101)$ & $(0.0116)$ & $(0.0061)$ & $(0.0062)$ & $(0.0062)$ & $(0.0064)$ & $(0.0071)$ \\
\hline \multirow[t]{2}{*}{ CAR0to7 } & $-0.0195^{* *}$ & $-0.0196^{* *}$ & $-0.0189^{* *}$ & $-0.0172^{* *}$ & -0.0172 & $-0.0181^{*}$ & $-0.0179^{*}$ & -0.0149 & -0.0145 & -0.0160 & $-0.0182^{* * *}$ & $-0.0183^{* * *}$ & $-0.0186^{* * *}$ & $-0.0176^{* * *}$ & $-0.0132^{*}$ \\
\hline & $(0.0077)$ & $(0.0079)$ & $(0.0079)$ & $(0.0085)$ & (0.0107) & $(0.0096)$ & $(0.0097)$ & $(0.0095)$ & $(0.0099)$ & $(0.0117)$ & $(0.0061)$ & $(0.0062)$ & $(0.0061)$ & $(0.0064)$ & $(0.0073)$ \\
\hline \multirow[t]{2}{*}{ CAR0to8 } & $-0.0221^{* *}$ & $-0.0220^{* *}$ & $-0.0213^{* *}$ & $-0.0203^{* *}$ & $-0.0236^{* *}$ & -0.0161 & -0.0164 & -0.0122 & -0.0116 & -0.0213 & $-0.0202^{* * *}$ & $-0.0200^{* * *}$ & $-0.0206^{* * *}$ & $-0.0197^{* * *}$ & $-0.0172^{* *}$ \\
\hline & $(0.0090)$ & $(0.0092)$ & $(0.0092)$ & $(0.0095)$ & $(0.0117)$ & $(0.0114)$ & $(0.0115)$ & $(0.0112)$ & $(0.0114)$ & $(0.0133)$ & $(0.0069)$ & $(0.0070)$ & $(0.0070)$ & $(0.0071)$ & $(0.0083)$ \\
\hline \multirow[t]{2}{*}{ CAR0to9 } & $-0.0261^{* * *}$ & $-0.0258^{* * *}$ & $-0.0263^{* * *}$ & $-0.0223^{* *}$ & $-0.0276^{* *}$ & -0.0201 & -0.0199 & -0.0177 & -0.0122 & -0.0234 & $-0.0237^{* * *}$ & $-0.0235^{* * *}$ & $-0.0249^{* * *}$ & $-0.0232^{* * *}$ & $-0.0193^{* *}$ \\
\hline & $(0.0094)$ & $(0.0097)$ & $(0.0095)$ & $(0.0100)$ & $(0.0123)$ & $(0.0122)$ & $(0.0123)$ & $(0.0120)$ & $(0.0123)$ & $(0.0143)$ & $(0.0075)$ & $(0.0077)$ & $(0.0076)$ & $(0.0079)$ & $(0.0096)$ \\
\hline \multirow[t]{2}{*}{ CAR0to10 } & $-0.0248^{* *}$ & $-0.0239^{* *}$ & $-0.0257^{* *}$ & $-0.0216^{* *}$ & $-0.0252^{*}$ & -0.0202 & -0.0191 & -0.0192 & -0.0136 & -0.0216 & $-0.0201^{* *}$ & $-0.0195^{* *}$ & $-0.0222^{* * *}$ & $-0.0202^{* *}$ & -0.0089 \\
\hline & $(0.0097)$ & $(0.0100)$ & $(0.0099)$ & $(0.0104)$ & $(0.0128)$ & $(0.0125)$ & $(0.0128)$ & $(0.0125)$ & $(0.0127)$ & $(0.0152)$ & $(0.0079)$ & $(0.0080)$ & $(0.0080)$ & $(0.0084)$ & $(0.0100)$ \\
\hline Size and Leverage & $x$ & $\mathrm{x}$ & $x$ & $x$ & $x$ & $x$ & $x$ & $\mathrm{X}$ & $\mathrm{X}$ & $x$ & $x$ & $\mathrm{x}$ & $x$ & $x$ & $\mathrm{X}$ \\
\hline Headquarter FE & & $\mathrm{X}$ & & & & & $\mathrm{X}$ & & & & & $x$ & & & \\
\hline Year FE & & & $x$ & & & & & $x$ & & & & & $x$ & & \\
\hline Event FE & & & & $x$ & & & & & $x$ & & & & & $x$ & \\
\hline Company FE & & & & & $x$ & & & & & $x$ & & & & & $x$ \\
\hline Observations & 3877 & 3877 & 3875 & 3870 & 3799 & 2702 & 2702 & 2700 & 2697 & 2613 & 4107 & 4107 & 4105 & 4100 & 4020 \\
\hline Clusters & 142 & 142 & 140 & 135 & 140 & 112 & 112 & 110 & 107 & 111 & 153 & 153 & 151 & 147 & 152 \\
\hline
\end{tabular}

Notes: $\quad$ Robust standard errors are clustered on the event-level in parentheses: ${ }^{*} p<0.1,{ }^{* *} p<0.5,{ }^{* * *} p<0.01$. 
Table D.5: The effect of assassination events on stock price - Admin1 control sample.

\begin{tabular}{|c|c|c|c|c|c|c|c|c|c|c|}
\hline & (1) & (2) & (3) & (4) & (5) & (6) & (7) & (8) & (9) & (10) \\
\hline \multirow[t]{2}{*}{ CAR0to0 } & -0.0070 & -0.0067 & -0.0043 & -0.0057 & -0.0116 & -0.0073 & -0.0078 & -0.0046 & -0.0037 & -0.0155 \\
\hline & $(0.0046)$ & $(0.0047)$ & $(0.0039)$ & $(0.0043)$ & $(0.0076)$ & $(0.0058)$ & $(0.0067)$ & $(0.0053)$ & $(0.0055)$ & $(0.0103)$ \\
\hline \multirow[t]{2}{*}{ CAR0to1 } & -0.0115 & -0.0120 & -0.0082 & -0.0103 & $-0.0295^{*}$ & -0.0071 & -0.0092 & -0.0029 & -0.0031 & -0.0275 \\
\hline & $(0.0080)$ & $(0.0086)$ & $(0.0075)$ & $(0.0085)$ & $(0.0172)$ & $(0.0101)$ & $(0.0117)$ & $(0.0103)$ & $(0.0116)$ & $(0.0214)$ \\
\hline \multirow[t]{2}{*}{ CAR0to2 } & -0.0132 & -0.0134 & -0.0090 & -0.0099 & -0.0192 & -0.0054 & -0.0078 & 0.0006 & -0.0002 & -0.0103 \\
\hline & $(0.0098)$ & $(0.0107)$ & $(0.0096)$ & $(0.0106)$ & $(0.0179)$ & $(0.0118)$ & $(0.0138)$ & $(0.0127)$ & $(0.0132)$ & $(0.0226)$ \\
\hline \multirow[t]{2}{*}{ CAR0to3 } & -0.0105 & -0.0108 & -0.0061 & -0.0085 & -0.0202 & -0.0011 & -0.0016 & 0.0059 & 0.0055 & -0.0113 \\
\hline & $(0.0108)$ & $(0.0117)$ & $(0.0100)$ & $(0.0115)$ & $(0.0185)$ & $(0.0125)$ & $(0.0144)$ & $(0.0127)$ & $(0.0143)$ & $(0.0220)$ \\
\hline \multirow[t]{2}{*}{ CAR0to4 } & -0.0170 & -0.0160 & -0.0126 & -0.0148 & -0.0269 & -0.0096 & -0.0086 & -0.0021 & -0.0008 & -0.0198 \\
\hline & (0.0108) & $(0.0118)$ & $(0.0103)$ & $(0.0116)$ & $(0.0189)$ & $(0.0124)$ & $(0.0143)$ & $(0.0128)$ & $(0.0144)$ & $(0.0222)$ \\
\hline \multirow[t]{2}{*}{ CAR0to5 } & -0.0147 & -0.0126 & -0.0117 & -0.0120 & -0.0279 & -0.0064 & -0.0044 & -0.0001 & 0.0065 & -0.0241 \\
\hline & $(0.0111)$ & $(0.0122)$ & $(0.0114)$ & $(0.0124)$ & $(0.0216)$ & $(0.0120)$ & $(0.0138)$ & $(0.0128)$ & $(0.0140)$ & $(0.0251)$ \\
\hline \multirow[t]{2}{*}{ CAR0to6 } & -0.0163 & -0.0151 & -0.0130 & -0.0117 & -0.0180 & -0.0092 & -0.0080 & -0.0037 & 0.0037 & -0.0115 \\
\hline & (0.0117) & $(0.0128)$ & $(0.0121)$ & $(0.0126)$ & $(0.0221)$ & $(0.0132)$ & $(0.0148)$ & $(0.0138)$ & $(0.0146)$ & $(0.0246)$ \\
\hline \multirow[t]{2}{*}{ CAR0to7 } & $-0.0193^{*}$ & -0.0162 & -0.0164 & -0.0127 & -0.0233 & -0.0105 & -0.0059 & -0.0044 & 0.0056 & -0.0170 \\
\hline & $(0.0112)$ & $(0.0127)$ & (0.0119) & $(0.0126)$ & $(0.0233)$ & $(0.0131)$ & $(0.0147)$ & $(0.0137)$ & $(0.0139)$ & $(0.0253)$ \\
\hline \multirow[t]{2}{*}{ CAR0to8 } & $-0.0214^{*}$ & -0.0187 & -0.0177 & -0.0128 & -0.0302 & -0.0140 & -0.0107 & -0.0078 & 0.0044 & -0.0218 \\
\hline & $(0.0125)$ & $(0.0140)$ & $(0.0131)$ & $(0.0136)$ & $(0.0254)$ & $(0.0138)$ & $(0.0157)$ & $(0.0144)$ & $(0.0145)$ & $(0.0270)$ \\
\hline \multirow{2}{*}{ CAR0to9 } & $-0.0267^{* *}$ & -0.0207 & $-0.0235^{*}$ & -0.0129 & -0.0339 & -0.0206 & -0.0131 & -0.0156 & 0.0010 & -0.0263 \\
\hline & $(0.0131)$ & $(0.0148)$ & $(0.0136)$ & $(0.0134)$ & $(0.0273)$ & $(0.0154)$ & $(0.0171)$ & $(0.0161)$ & $(0.0152)$ & $(0.0290)$ \\
\hline \multirow[t]{2}{*}{ CAR0to10 } & $-0.0281^{* *}$ & -0.0215 & $-0.0250^{*}$ & -0.0139 & -0.0308 & -0.0195 & -0.0103 & -0.0145 & 0.0075 & -0.0227 \\
\hline & $(0.0136)$ & $(0.0152)$ & $(0.0143)$ & $(0.0139)$ & $(0.0275)$ & $(0.0159)$ & $(0.0174)$ & $(0.0164)$ & $(0.0152)$ & $(0.0301)$ \\
\hline Size and Lev & $x$ & $x$ & $X$ & $x$ & $x$ & $\mathrm{X}$ & $\mathrm{X}$ & $x$ & $\mathrm{X}$ & $x$ \\
\hline Profitability & & & & & & $X$ & $X$ & $X$ & $X$ & $x$ \\
\hline Cubic Terms & & & & & & $X$ & $X$ & $X$ & $X$ & $x$ \\
\hline Headquarter FE & & $\mathrm{X}$ & & & & & $x$ & & & \\
\hline Year FE & & & $X$ & & & & & $X$ & & \\
\hline Event FE & & & & $X$ & & & & & $X$ & \\
\hline Company FE & & & & & $x$ & & & & & $x$ \\
\hline Observati & 676 & 675 & 676 & 673 & 605 & 658 & 657 & 658 & 653 & 586 \\
\hline Clusters & 92 & 92 & 92 & 89 & 89 & 92 & 92 & 92 & 87 & 88 \\
\hline
\end{tabular}

Notes: $\quad$ Robust standard errors are clustered on the event-level in parentheses: ${ }^{*} p<0.1,{ }^{* *} p<0.5,{ }^{* * *} p<0.01$. 
Table D.6: The effect of assassination events on stock prices without company ties.

\begin{tabular}{|c|c|c|c|c|c|c|c|c|c|c|}
\hline & (1) & (2) & (3) & (4) & (5) & (6) & (7) & (8) & (9) & (10) \\
\hline \multirow[t]{2}{*}{ CAR0to0 } & -0.0050 & -0.0049 & -0.0028 & -0.0058 & -0.0034 & -0.0041 & -0.0050 & -0.0023 & -0.0059 & -0.0029 \\
\hline & $(0.0061)$ & $(0.0064)$ & $(0.0046)$ & $(0.0048)$ & $(0.0072)$ & $(0.0060)$ & $(0.0063)$ & $(0.0045)$ & $(0.0045)$ & $(0.0074)$ \\
\hline \multirow[t]{2}{*}{ CAR0to1 } & -0.0019 & -0.0025 & -0.0022 & -0.0035 & -0.0047 & -0.0018 & -0.0022 & -0.0023 & -0.0046 & -0.0052 \\
\hline & $(0.0040)$ & $(0.0042)$ & $(0.0048)$ & $(0.0075)$ & $(0.0050)$ & $(0.0040)$ & $(0.0042)$ & $(0.0045)$ & $(0.0071)$ & $(0.0051)$ \\
\hline \multirow[t]{2}{*}{ CAR0to2 } & 0.0002 & -0.0004 & -0.0005 & -0.0012 & -0.0070 & -0.0009 & -0.0026 & -0.0012 & -0.0032 & -0.0086 \\
\hline & $(0.0052)$ & $(0.0057)$ & $(0.0062)$ & $(0.0087)$ & $(0.0080)$ & $(0.0051)$ & $(0.0058)$ & $(0.0056)$ & $(0.0079)$ & $(0.0084)$ \\
\hline \multirow[t]{2}{*}{ CAR0to3 } & -0.0014 & -0.0026 & -0.0009 & -0.0016 & -0.0102 & -0.0074 & -0.0109 & -0.0061 & -0.0077 & -0.0108 \\
\hline & $(0.0074)$ & $(0.0078)$ & $(0.0072)$ & $(0.0094)$ & $(0.0102)$ & $(0.0072)$ & $(0.0077)$ & $(0.0066)$ & $(0.0086)$ & $(0.0107)$ \\
\hline \multirow[t]{2}{*}{ CAR0to4 } & -0.0008 & -0.0016 & -0.0029 & -0.0006 & -0.0136 & -0.0066 & -0.0097 & -0.0082 & -0.0055 & -0.0135 \\
\hline & $(0.0067)$ & $(0.0067)$ & $(0.0075)$ & $(0.0101)$ & $(0.0096)$ & $(0.0067)$ & $(0.0069)$ & $(0.0069)$ & $(0.0095)$ & (0.0099) \\
\hline \multirow[t]{2}{*}{ CAR0to5 } & 0.0007 & -0.0020 & -0.0031 & -0.0048 & -0.0132 & -0.0041 & -0.0094 & -0.0080 & -0.0102 & -0.0129 \\
\hline & $(0.0078)$ & $(0.0081)$ & $(0.0085)$ & $(0.0117)$ & $(0.0106)$ & $(0.0082)$ & $(0.0086)$ & $(0.0082)$ & $(0.0110)$ & $(0.0110)$ \\
\hline \multirow[t]{2}{*}{ CAR0to6 } & -0.0013 & -0.0052 & -0.0072 & -0.0148 & -0.0088 & -0.0069 & -0.0133 & -0.0127 & $-0.0223^{*}$ & -0.0093 \\
\hline & $(0.0094)$ & $(0.0095)$ & $(0.0102)$ & $(0.0134)$ & (0.0119) & $(0.0094)$ & $(0.0095)$ & $(0.0100)$ & $(0.0128)$ & $(0.0124)$ \\
\hline \multirow[t]{2}{*}{ CAR0to7 } & 0.0031 & 0.0001 & -0.0009 & -0.0096 & -0.0007 & -0.0020 & -0.0068 & -0.0065 & -0.0169 & -0.0013 \\
\hline & $(0.0119)$ & $(0.0118)$ & $(0.0111)$ & $(0.0124)$ & $(0.0156)$ & $(0.0123)$ & $(0.0121)$ & $(0.0114)$ & $(0.0118)$ & $(0.0164)$ \\
\hline \multirow[t]{2}{*}{ CAR0to8 } & -0.0019 & -0.0039 & -0.0064 & -0.0195 & -0.0066 & -0.0058 & -0.0100 & -0.0111 & $-0.0268^{* *}$ & -0.0066 \\
\hline & $(0.0120)$ & $(0.0117)$ & $(0.0111)$ & $(0.0132)$ & $(0.0166)$ & $(0.0120)$ & $(0.0116)$ & $(0.0111)$ & $(0.0122)$ & $(0.0171)$ \\
\hline \multirow[t]{2}{*}{ CAR0to9 } & -0.0003 & -0.0043 & -0.0047 & -0.0151 & -0.0100 & -0.0058 & -0.0121 & -0.0106 & $-0.0233^{*}$ & -0.0101 \\
\hline & $(0.0137)$ & $(0.0136)$ & $(0.0126)$ & $(0.0144)$ & $(0.0172)$ & $(0.0138)$ & $(0.0134)$ & $(0.0122)$ & $(0.0130)$ & $(0.0177)$ \\
\hline \multirow[t]{2}{*}{ CAR0to10 } & -0.0047 & -0.0059 & -0.0058 & -0.0134 & -0.0164 & -0.0093 & -0.0129 & -0.0110 & -0.0197 & -0.0168 \\
\hline & $(0.0174)$ & $(0.0176)$ & $(0.0151)$ & $(0.0166)$ & $(0.0193)$ & $(0.0171)$ & $(0.0170)$ & $(0.0146)$ & $(0.0153)$ & $(0.0198)$ \\
\hline Size and Leverage & $X$ & $X$ & $X$ & $X$ & $X$ & $X$ & $X$ & $X$ & $X$ & $X$ \\
\hline Profitability & & & & & & $X$ & $X$ & $X$ & $X$ & $X$ \\
\hline Cubic Terms & & & & & & $X$ & $X$ & $X$ & $X$ & $X$ \\
\hline Headquarter FE & & $X$ & & & & & $X$ & & & \\
\hline Year FE & & & $X$ & & & & & $X$ & & \\
\hline Event FE & & & & $X$ & & & & & $X$ & \\
\hline Company FE & & & & & $X$ & & & & & $X$ \\
\hline Observations & 1472 & 1470 & 1472 & 1471 & 1403 & 1434 & 1432 & 1434 & 1433 & 1368 \\
\hline Clusters & 62 & 62 & 62 & 61 & 62 & 62 & 62 & 62 & 61 & 62 \\
\hline
\end{tabular}

Notes: $\quad$ Robust standard errors are clustered on the event-level in parentheses: ${ }^{*} p<0.1,{ }^{* *} p<0.5,{ }^{* * *} p<0.01$. 
Table D.7: The Effect of Assassination Events on ESG Scores - Controlling for Total IO

\begin{tabular}{|c|c|c|c|c|c|c|}
\hline \multirow[b]{2}{*}{ Dep. Variable: } & \multicolumn{4}{|c|}{ Asset4 z-Scores } & \multicolumn{2}{|c|}{ Dyck et al. (2019) } \\
\hline & Overall ESG & Overall ESGC & Human Rights & Community & Human Rights & Community \\
\hline Assassination & $\begin{array}{l}-0.0081 \\
(0.0320)\end{array}$ & $\begin{array}{l}-0.0314 \\
(0.0418)\end{array}$ & $\begin{array}{c}-0.0328 \\
(0.0907)\end{array}$ & $\begin{array}{c}0.0861 \\
(0.0938)\end{array}$ & $\begin{array}{l}-0.0154 \\
(0.0292)\end{array}$ & $\begin{array}{l}-0.0182 \\
(0.0188)\end{array}$ \\
\hline Company Controls & $X$ & $X$ & $x$ & $x$ & $x$ & $x$ \\
\hline Total IO & $X$ & $X$ & $X$ & $X$ & $x$ & $x$ \\
\hline Company FE & $x$ & $x$ & $x$ & $x$ & $x$ & $x$ \\
\hline Year FE & $X$ & $x$ & $x$ & $X$ & $X$ & $x$ \\
\hline R-squared & 0.817 & 0.795 & 0.663 & 0.734 & 0.765 & 0.764 \\
\hline Observations & 41912 & 41912 & 17953 & 41667 & 41665 & 35843 \\
\hline
\end{tabular}

Notes: $\quad$ Rank based Asset 4 z-Scores provided by Thomson Reuter are presented in columns 1 to 4 . Columns 5 and 6 present indicator based scores following the procedure outlined in Dyck et al. (2019) and detailed in Section B.2 in the Appendix. Robust standard errors clustered on the company-level in parentheses: ${ }^{*} \mathrm{p}<0.1,{ }^{* *} \mathrm{p}<0.05,{ }^{* * *} \mathrm{p}<0.01$. 
Table D.8: The Effect of Assassination Events on ESG Scores - Lagged Dependent Variable

\begin{tabular}{|c|c|c|c|c|c|c|}
\hline \multirow[b]{2}{*}{ Dep. Variable: } & \multicolumn{4}{|c|}{ Asset4 z-Scores } & \multicolumn{2}{|c|}{ Dyck et al. (2019) } \\
\hline & Overall ESG & Overall ESGC & Human Rights & Community & Human Rights & Community \\
\hline Assassination & -0.0155 & -0.0288 & -0.0650 & 0.0347 & -0.0300 & -0.0229 \\
\hline & $(0.0235)$ & $(0.0362)$ & $(0.0611)$ & $(0.0461)$ & $(0.0223)$ & $(0.0186)$ \\
\hline Company Controls & $x$ & $x$ & $x$ & $x$ & $x$ & $x$ \\
\hline Lagged Dependent Variable & $x$ & $x$ & $x$ & $\mathrm{X}$ & $\mathrm{X}$ & $\mathrm{X}$ \\
\hline Company FE & $X$ & $x$ & $x$ & $x$ & $x$ & $x$ \\
\hline Year FE & $x$ & $x$ & $x$ & $x$ & $x$ & $x$ \\
\hline R-squared & 0.877 & 0.852 & 0.750 & 0.805 & 0.851 & 0.797 \\
\hline Observations & 47126 & 47126 & 19149 & 46744 & 46682 & 36883 \\
\hline
\end{tabular}

Notes: $\quad$ Rank based Asset 4 z-Scores provided by Thomson Reuter are presented in columns 1 to 4 . Columns 5 and 6 present indicator based scores following the procedure outlined in Dyck et al. (2019) and detailed in Section B.2 in the Appendix. Robust standard errors clustered on the company-level in parentheses: ${ }^{*} \mathrm{p}<0.1,{ }^{* *} \mathrm{p}<0.05,{ }^{* * *} \mathrm{p}<0.01$. 
Table D.9: The Effect of Assassination Events on ESG Scores - First Differences

\begin{tabular}{|c|c|c|c|c|c|c|}
\hline \multirow[b]{2}{*}{ Dep. Variable: } & \multicolumn{4}{|c|}{ Asset4 z-Scores } & \multicolumn{2}{|c|}{ Dyck et al. (2019) } \\
\hline & $\Delta$ Overall ESG & $\Delta$ Overall ESGC & $\Delta$ Human Rights & $\Delta$ Community & $\Delta$ Human Rights & $\Delta$ Community \\
\hline$\Delta$ Assassination & 0.0066 & 0.0006 & $-0.1287^{* *}$ & -0.0135 & -0.0264 & -0.0183 \\
\hline & $(0.0188)$ & $(0.0342)$ & $(0.0580)$ & $(0.0247)$ & $(0.0207)$ & $(0.0162)$ \\
\hline Company Controls & $\mathrm{X}$ & $X$ & $\mathrm{X}$ & $X$ & $\mathrm{X}$ & $X$ \\
\hline Year FE & $x$ & $x$ & $x$ & $x$ & $X$ & $X$ \\
\hline R-squared & 0.014 & 0.012 & 0.004 & 0.007 & 0.013 & 0.087 \\
\hline Observations & 46704 & 46704 & 19689 & 46329 & 46281 & 36918 \\
\hline
\end{tabular}

Notes: $\quad$ Rank based Asset4 z-Scores provided by Thomson Reuter are presented in columns 1 to 4 . Columns 5 and 6 present indicator based scores following the procedure outlined in Dyck et al. (2019) and detailed in Section B.2 in the Appendix. Robust standard errors clustered on the company-level in parentheses: ${ }^{*} \mathrm{p}<0.1,{ }^{* *} \mathrm{p}<0.05$, ${ }^{* * *} \mathrm{p}<0.01$. 
Table D.10: The Relationship between Assassinations and the Channge in Tax Revenue Shares

\begin{tabular}{lcccc}
\hline & \multicolumn{4}{c}{ Dependent Variable: $\Delta$ Tax Share } \\
\cline { 2 - 5 } & $(1)$ & $(2)$ & $(3)$ & $(4)$ \\
\hline Assassination & 0.012 & 0.011 & 0.012 & 0.013 \\
& $(0.031)$ & $(0.033)$ & $(0.032)$ & $(0.033)$ \\
\hline Country FE & & $\mathrm{X}$ & $\mathrm{X}$ & \\
Year FE & & & $\mathrm{X}$ & $\mathrm{X}$ \\
Country $\times$ Year FE & & & & 0.053 \\
\hline R-squared & 0.001 & 0.002 & 0.011 & 0.054 \\
Observations & 784 & 784 & 784 & 784 \\
\hline
\end{tabular}

Notes: $\quad$ The $\Delta$ Tax Share share is the first difference of the Tax Share defined as the taxes and royalties paid by a corporation to the host country government divided by the total tax revenue received from the mining industry. 